\title{
Recommended nuclear data for medical radioisotope production: diagnostic gamma emitters
}

\author{
F. T. Tárkányi ${ }^{1}$ A. V. Ignatyuk ${ }^{2} \cdot$ A. Hermanne ${ }^{3} \cdot$ R. Capote $^{4}$ (D) B. V. Carlson $^{5} \cdot$ J. W. Engle ${ }^{6} \cdot$

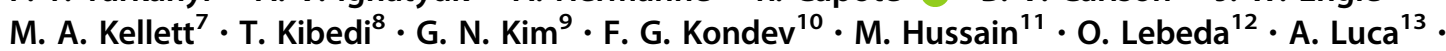 \\ Y. Nagai ${ }^{14}$ - H. Naik ${ }^{15}$ - A. L. Nichols ${ }^{16}$ - F. M. Nortier ${ }^{6}$ S. V. Suryanarayana ${ }^{15} \cdot$ S. Takács ${ }^{1}$. \\ M. Verpelli ${ }^{4}$
}

Received: 23 May 2018/Published online: 3 October 2018

(C) The Author(s) 2018

\begin{abstract}
An extensive series of evaluations have been performed as part of an IAEA coordinated research project to study a set of nuclear reactions that produce the diagnostic gamma-ray emitting radionuclides ${ }^{51} \mathrm{Cr},{ }^{99 \mathrm{~m}} \mathrm{Tc},{ }^{111} \mathrm{In},{ }^{123} \mathrm{I}$ and ${ }^{201} \mathrm{Tl}$. Recommended cross-section data in the form of excitation functions have been derived, along with quantifications of their uncertainties. These evaluations involved the compilation of all previously published values and newly measured experimental data, followed by critical assessments and selection of those experimental datasets and accompanying uncertainties judged to be fully valid and statistically consistent for model-independent least-squares fitting by means of Padé approximations. Integral yields as a function of the energy were also calculated on the basis of the recommended cross sections deduced from these various fits. All evaluated numerical results and their corresponding uncertainties are available online at www-nds.iaea.org/medical/gamma_emitters.html and also on the medical portal of the International Atomic Energy Agency/Nuclear Data Section (IAEA-NDS) www-nds.iaea.org/medportal/.
\end{abstract}

Keywords IAEA Coordinated Research Project $\cdot$ Diagnostic medical isotopes $\cdot \gamma$-ray emitters $\cdot$ Cross-section evaluation $\cdot$ Uncertainty estimation · Padé fit · Recommended $\sigma$ - and yield data

R. Capote

r.capotenoy@iaea.org

Institute of Nuclear Research, Debrecen, Hungary

2 Institute of Physics and Power Engineering (IPPE), Obninsk, Russia

3 Vrije Universiteit Brussel, Brussels, Belgium

4 NAPC-Nuclear Data Section, International Atomic Energy Agency, Vienna A-1400, Austria

5 Instituto Tecnológico de Aeronáutica, São José dos Campos, Brazil

6 Los Alamos National Laboratory (LANL), Los Alamos, USA

7 Laboratoire National Henri Becquerel (LNHB), CEA Saclay, Gif-sur-Yvette, France

8 Australian National University (ANU), Canberra, Australia

9 Kyungpook National University, Daegu, Republic of Korea

10 Argonne National Laboratory (ANL), Lemont, USA
11 Government College University, Lahore, Pakistan

12 Nuclear Physics Institute, Rez, Czech Republic

13 Horia Hulubei National Institute for R\&D in Physics and Nuclear Engineering (IFIN-HH), Măgurele, Romania

14 Japan Atomic Energy Agency (JAEA), Tokaimura Naka, Ibaraki-ken, Japan

15 Bhabha Atomic Research Centre (BARC), Trombay, Mumbai, India

16 University of Surrey, Guildford, UK 


\section{Introduction}

The production of diagnostic and therapeutic radionuclides for medical applications is a very important non-energy related application of nuclear science and technology [1]. Such radionuclides are produced in both neutron and charged-particle induced nuclear reactions, and the list of these reactions used for the generation of diagnostic radioisotopes (gamma-ray emitters for SPECT and $\beta^{+}$ emitters for PET imaging) and employed to monitor these preparative procedures is long. Dedicated compilations and evaluations of production cross-section data for such medical radionuclides were started over 20 years ago in a Coordinated Research Project (CRP) initiated and supported by the International Atomic Energy Agency (IAEA) [2]. This first concerted effort was identified with nuclear reactions used to produce widely used diagnostic radionuclides for SPECT and PET imaging (twenty-six reactions to generate ${ }^{11} \mathrm{C},{ }^{13} \mathrm{~N},{ }^{15} \mathrm{O},{ }^{18} \mathrm{~F},{ }^{67} \mathrm{Ga},{ }^{68} \mathrm{Ge} /{ }^{68} \mathrm{Ga}$, ${ }^{81} \mathrm{Rb},{ }^{82} \mathrm{Sr},{ }^{111} \mathrm{In},{ }^{123} \mathrm{I},{ }^{123} \mathrm{Cs} /{ }^{123} \mathrm{Xe} /{ }^{123} \mathrm{I}$ and $\left.{ }^{201} \mathrm{~Pb} /{ }^{201} \mathrm{Tl}\right)$, and a selection of twenty-two reactions used to monitor beam parameters during the irradiations. All results were published in IAEA-TECDOC-1211 [3], made available within the medical portal of the IAEA Nuclear Data Section [4], and were subsequently updated in 2003 and 2004 $[5,6]$. Both methods of presentation contain recommended cross-section data and the corresponding deduced yields. A second IAEA CRP was launched in 2003 to cover the production routes for established $\left({ }^{103} \mathrm{Pd},{ }^{186} \mathrm{Re}\right.$ and $\left.{ }^{192} \mathrm{Ir}\right)$ and emerging therapeutic radionuclides $\left({ }^{64} \mathrm{Cu},{ }^{67} \mathrm{Cu},{ }^{67} \mathrm{Ga}\right.$, ${ }^{86} \mathrm{Y},{ }^{111} \mathrm{In},{ }^{114 \mathrm{~m}} \mathrm{In},{ }^{124} \mathrm{I},{ }^{125} \mathrm{I},{ }^{169} \mathrm{Yb},{ }^{177} \mathrm{Lu},{ }^{211}$ At and $\left.{ }^{225} \mathrm{Ac}\right)$ totalling thirty-five reactions [7].

According to citations and the number of data downloads, the IAEA-CRP cross-section databases have been extensively used at radionuclide production facilities worldwide. Furthermore, over recent years, new emerging radioisotopes have appeared and additional experimental data have been published on the previously evaluated reactions for medical applications and beam monitoring, along with studies of new applications of various other emerging radionuclides. Therefore, a third IAEA coordinated research project was launched in 2012, with the following primary aims [8]:

(a) Re-evaluate those reactions for which important new data have been reported,

(b) Extend the list of potential radionuclides and their recommended excitation functions for medical applications,

(c) Determine uncertainties in the recommended crosssection data deduced from Padé fits on statistically consistent and critically selected datasets, and

(d) Re-evaluate unreliable relevant decay data.
Sixteen laboratories and institutions from around the world collaborated in the project for which a fair number of specific re-evaluations required additional cross-section and decay-data measurements, and these new experimental datasets were published elsewhere on a regular basis. All cross-section data were also re-assessed and evaluated with the goal of producing recommended data with quantified uncertainties.

The physical yield (instantaneous production rate), activity generated during one hour irradiation with $1 \mu \mathrm{A}$ beam current, and saturation yield defined in terms of an infinite irradiation were calculated from the recommended cross-section data. Results for direct and cumulative production routes, mono-isotopic and enriched targets, and targets of naturally-occurring isotopic compositions were considered. As agreed at subsequent research coordination meetings [8], a set of four papers are in preparation to deal individually with the production routes for $\gamma$-emitting diagnostic radionuclides [SPECT imaging, lead author F. T. Tárkányi (this report)], $\beta^{+}$emitters and generators (PET imaging, lead author F. T. Tárkányi), therapeutic radionuclides (lead author J.W. Engle), and re-evaluated decay data (lead author A.L. Nichols). One additional paper on beam monitor reactions (lead author A. Hermanne) had already been published at the time of this submission [9].

The goal of this work is to report new model-independent cross-section evaluations with uncertainties derived by least-squares fits of statistically consistent experimental data. These evaluated data can be used to derive the physical yield for radionuclide production, and also aid in constraining calculations based upon nuclear reaction models.

The excitation functions for twenty-one charged-particle induced reactions have been assessed on the basis of their compilation, evaluation and a well-recognised data fitting procedure. These studies have involved the formation of five specific SPECT radionuclides selected for study in this CRP [8]: ${ }^{51} \mathrm{Cr},{ }^{99} \mathrm{Mo}{ }^{199 m} \mathrm{Tc},{ }^{111} \mathrm{In},{ }^{123} \mathrm{I}$ and ${ }^{201} \mathrm{Tl}$. Several other reactions were also considered for the formation of ${ }^{99} \mathrm{Mo}$ induced by photon and neutron beams to assess the production of the extremely important ${ }^{99} \mathrm{Mo} /{ }^{99 \mathrm{~m}} \mathrm{Tc}$ generator. Our recent studies of various different routes for the selected radioisotopes are each discussed on an individual basis. After a short description of the decay data adopted for radionuclidic quantification and the medical applications for these radionuclides, the individual results for each production route are given, including figures that show (a) all compiled datasets, and (b) selected statistically consistent datasets (with experimental total uncertainties) along with the recommended fitted curve and uncertainty of the fit. Final figures for each dataset compare the integral physical yields for the medically relevant radionuclide that are based on the present recommended data for each route. 
All evaluated cross sections and their uncertainties are available online at the IAEA Nuclear Data Section Web site www-nds.iaea.org/medical/gamma_emitters.html and also at the IAEA medical portal www-nds.iaea.org/med portal/. These Web pages include details of the evaluations, and the numerical data considered and adopted for analyses to generate the evaluated cross sections with their uncertainties and the corresponding production yields.

\section{Evaluation, fitting and uncertainty estimates}

All available literature sources containing relevant experimental data were used in the compilation process (primary journals, reports, conference abstracts and proceedings, yield compilations, reference databases, nuclear reaction databases such as EXFOR and NSR, PhD theses, etc.). Analyses and selection of the published experimental yields were based on detailed assessments of the measurement procedures including the determination of the particle energy, composition and nature of the target material, intensity of the beam, chemical separation processes, quantifying capabilities of measurement technique, nuclear data adopted, proper definition of the yield, and finally the aims of individual measurements and particularly attempts made to obtain precise values. Whenever needed and possible, known changes were introduced to adopted calibrant values (decay data and/or experimental parameters), as well as correcting conversion and computational errors. The compiled experimental data were also compared with the results of theoretical calculations based on the TALYS code system, and taken from the TENDL2015 and TENDL-2017 libraries [10].

Corrected experimental data that exhibited large disagreements with the other datasets, unusual shapes, systematic energy shifts, and data significantly below the reaction threshold were rejected from the fitting procedure whereby a fully and statistically consistent dataset was established. Originally reported experimental uncertainties were considered when determining the variable uncertainties in the recommended consistent dataset. However, no proper quantified descriptions of the uncertainties are given in many publications, or the adopted measurements technique(s) imply that the quoted uncertainties had been significantly underestimated and merit correction to avoid excessive weight within the subsequent fitting process. This initiative has involved compilers who possess significant experience in experimental cross-section studies, which allows them to estimate the full functionality and accuracy of the experiments under consideration (i.e., sound subjective judgments can be made with respect to accelerator systems and laboratory facilities, identification of researchers with proven experience, and degree of technical application on production machines).

By and large, most contemporary evaluation procedures are based on various manifestations of the least-squares method (e.g., see review [11] and references therein). The least-squares method is the state-of-art Bayesian approach that combines all available knowledge to derive the evaluated result and corresponding uncertainties. Evaluations undertaken in this paper are in most cases model-independent evaluations free from potential model defects and deficiencies. However, such an approach implies that comprehensive and consistent experimental inputs should be available before the least-square fit is undertaken. When the status of the experimental data is appropriate, a purely statistical fit over the selected data points can be performed.

Often, least-square fits use analytical functions, the most prominent being polynomials or the ratio of two polynomials. An analytical approximation based on the ratio of two polynomials was proposed by Padé over 125 years ago [12], and has become one of the most important interpolation techniques of statistical mathematics [13, 14]. As a rational function, the Padé approximant can be expressed by a set of polynomial coefficients, or by a set of coefficients of the pole expansion

$p_{L}(z)=c+\sum_{l} \frac{a_{l}}{z-\eta_{l}}+\sum_{k} \frac{\alpha_{k}\left(z-\varepsilon_{k}\right)+\beta_{k}}{\left(z-\varepsilon_{k}\right)^{2}+\gamma_{k}^{2}}$

where $z=x+i y$ is a complex variable and $L$ is an order of the polynomial presentation of the Padé approximant [15]. This equation is also called the resonance expansion, in which $\varepsilon_{k}$ and $\gamma_{k}$ are the energy and the total half-width of the $k$-th resonance, while $\alpha_{k}$ and $\beta_{k}$ are the partial widths and interference parameters. The first sum corresponds to the real poles, while the second sum relates to the complex poles.

Effective codes for practical applications of the Padé approximation were developed by the Obninsk group [15]. The simplest version of these codes permits analyses of up to 500 experimental points with the number of parameters $L \leq 40$ and a ratio limit of analysed experimental data points $f_{j}$ up to $\max \left(f_{j}\right) / \min \left(f_{j}\right) \leq 10^{6}$. A more detailed description of the method can be found in Refs. [15, 16], and some important questions of application are discussed in Refs. [17, 18]. The Padé approximation is also very convenient for calculations of the data uncertainties and the corresponding covariance matrices because the fitting procedure involves minimisation of the least-square deviation functional

$\chi^{2}=(N-L)^{-1} \sum_{j=1}^{N}\left(p_{L}\left(x_{j}\right)-f_{j}\right)^{2} / \sigma_{j}^{2}$ 
where $f_{j}$ are the available experimental data, $\sigma_{j}$ are their uncertainties and $N$ is the number of analysed points. Such minimisation is carried out by iterations using the discrete optimisation approach. The minimal least-square deviation for a given $L$ is computed using Eq. (2) by looking through a possible choice of $L$ points from the available $N$ points and the construction of corresponding approximants given by Eq. (1). Once this process has been completed, $L$ is changed and the iteration is repeated until an overall minimum is found from all discrete possibilities available. Some additional features of this method of analysis are discussed in our recent paper on evaluated beam-monitor reactions [9].

Along with a consistent consideration of the statistical uncertainties of the experimental data, the Padé method allows (a) determination of some systematic uncertainties in the data that are usually underestimated by their authors and (b) establishment of some implicit correlations of the data. The averaged deviation of the experimental data from the approximating function is regarded as the systematic uncertainty for each reaction, while the deviations of the experimental points from the approximant are regarded as the statistical uncertainties. An optimal description of all data is achieved by the traditional iteration procedure of minimising the mean-squares deviations with respect to these statistical and systematic uncertainties. Whenever required and possible, we have attempted to correct the published experimental data and introduce realistic uncertainties, although the resulting fitting procedures still indicated that the systematic uncertainties of the experimental studies were being underestimated. Often the different experimental datasets for a given reaction show large systematic disagreements, without any obvious explanation. One reason could be that commercially-purchased target thicknesses were not always checked by independent measurement which might result in erroneous estimations of the number of target nuclei. Another explanation is that experimental data are frequently measured relative to beam-monitor reactions, but the monitoring technique is not properly applied: the incident energy is not checked, or possible deviations are not considered; and the complete excitation function of the monitor reactions is not simultaneously re-measured. Another issue is that the recommended cross-section data of the monitor reactions may change over the years, resulting in difficulties in establishing which monitor data were used in older publications. A further problem that cannot be addressed involves outdated decay data that do not linearly contribute to the cross-section dataset (i.e., half-life), because the timescales of the irradiation and the measuring process are not fully documented in the original publication.

Not all of the selected datasets are totally independent, but possess a certain degree of correlation. A significant number of the datasets were obtained by means of the stacked-foil irradiation technique in which the number of particles interacting with each foil is supposed to be constant and can be determined by application of the recommended beam-monitoring data. Several studies involved the generation of datasets obtained from different experiments in which the samples were measured with the same detectors operated at the same efficiency and sourceto-detector distances. These correlations and the various correction factors are difficult to take into account in the evaluation, such that components of the systematic uncertainties are only partially considered. Therefore, an additional $4 \%$ systematic uncertainty was added to the experimental statistical uncertainties to obtain reasonable and realistic estimates of the evaluated uncertainties on the recommended excitation functions and their production yields.

\section{Summary of the results from previous IAEA evaluations of cross sections for the production of diagnostic gamma emitters}

The nuclear reactions for production of SPECT radionuclides evaluated as part of an earlier IAEA coordinated research project are summarised in Table 1. Results of the evaluations were initially presented in Ref. [3], and updated on the IAEA-NDS Web page [4], including plots of all the relevant experimental excitation functions and derived physical yields based upon the approach adopted in Refs. [5, 6]. All recommended cross-section data were based on Padé or spline fitting, as were the integral production yields as a function of beam energy. A full list of references and reasons for their rejection/selection for the fitting procedure were also provided. However, no uncertainties were provided within this first work package of recommended excitation functions.

Decay data used in the original cross-section evaluations were updated to the latest recommended values available from NuDat [19], as listed in Table 1. 


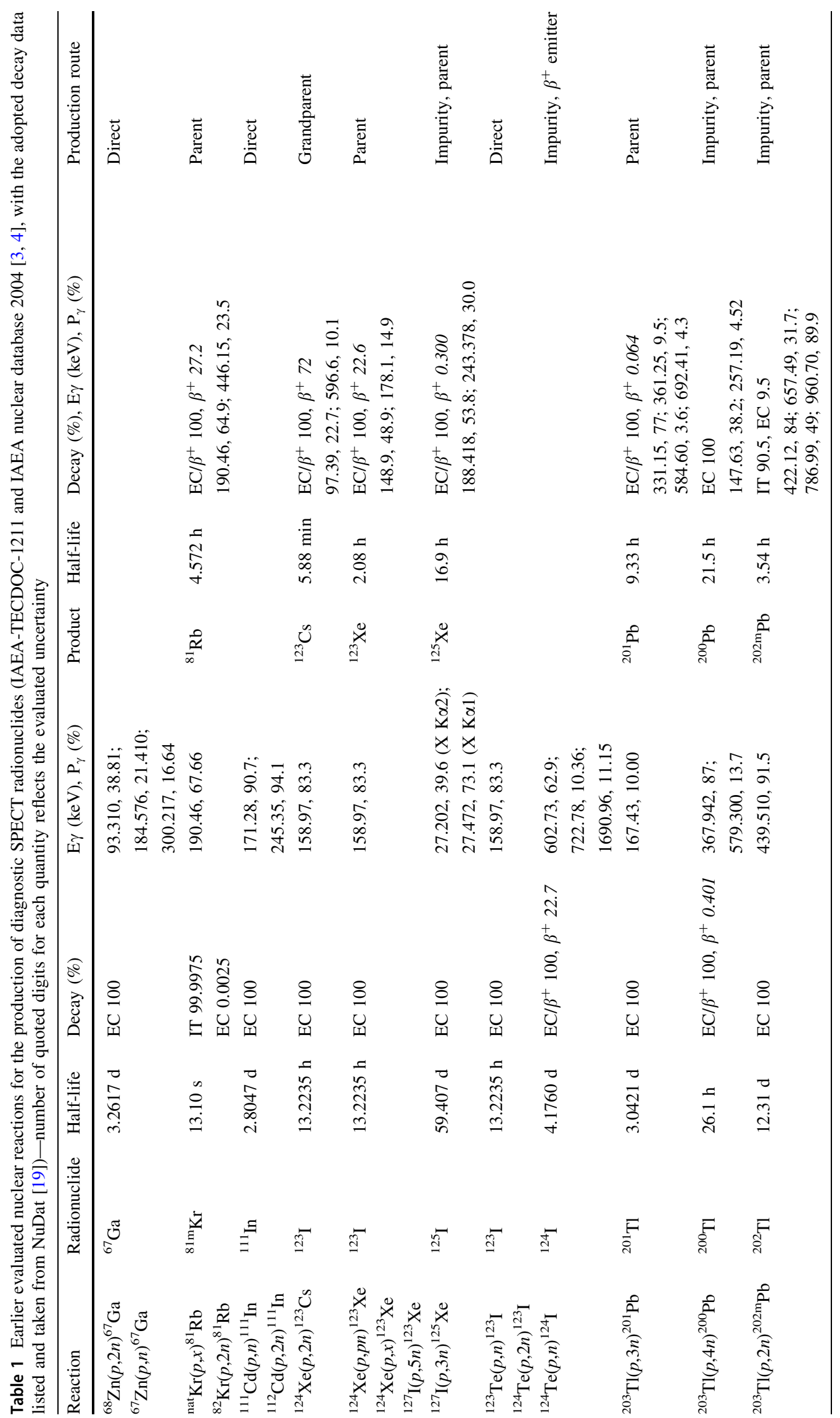




\section{Further evaluations of cross sections for the production of diagnostic gamma emitters}

\section{Overview of reactions studied}

The list of SPECT radionuclides studied in this most recent coordinated research project has been extended to consider various production routes for widely used ${ }^{99 \mathrm{~m}} \mathrm{Tc}$ and ${ }^{51} \mathrm{Cr}$. New experimental data measurements since 2004 for production of ${ }^{123} \mathrm{I},{ }^{111} \mathrm{In}$ and ${ }^{201} \mathrm{Tl}$ have been included in this current series of evaluations based upon the development of suitable lists of possible production reactions. Due to the considerable importance of ${ }^{99 \mathrm{~m}} \mathrm{Tc}$ and parent ${ }^{99} \mathrm{Mo}$ in medical applications, consideration has also been given to a number of different production routes including chargedparticle irradiations, neutron-induced reactions, and photon beams.

The various production reactions and the decay data of the medical radionuclides as taken from NuDat are listed in Table 2 [19], along with the degree of the adopted Padé polynomial fit.

\section{Presentation of results}

Every evaluation undertaken and the results for each reaction are illustrated in two figures that display the following: first figure depicts all available experimental data without their uncertainties, followed by a second figure that contains only the selected data with their experimental uncertainties and the Padé fit that defines the recommended cross sections with uncertainties expressed as percentages (uncertainty scale is on the right-hand side of the figure along the $y$-axis). Predicted cross-section values are also shown for comparison, as taken from the TENDL 2015 and TENDL 2017 libraries that are based on the TALYS code [10]. References for each reaction are reported separately in chronological order but have only been listed once in the reference list. Selection of appropriate and consistent datasets relies on many parameters for which the main reasons for rejection include the following:

- Systematic energy shift towards lower or higher energy,

- Significantly higher and lower values, or unusual shape when compared with the main body of data or theory,

- Cross-section data below the threshold, and

- Relatively high degree of scattered data.

Almost in all cases, the data points within an individual reference were considered in this manner as a fundamental part of the selection/rejection process. Only in a few cases mainly involving significant outliers close to the threshold were individual data points omitted to improve the possibility of a proper fit. Original proton data published by Levkovskij were all corrected for the erroneous values of the ${ }^{96 \mathrm{~m}} \mathrm{Tc}$ beam monitor. The factor used is described in detail with reference to new measurements and earlier discussions within Section II.K of the latest evaluation of monitor reactions [9].

Integral physical yields for the different production reactions of each radionuclide of specific or indirect medical interest are calculated from the recommended data, and are shown in separate figures at the end of each subsection. 


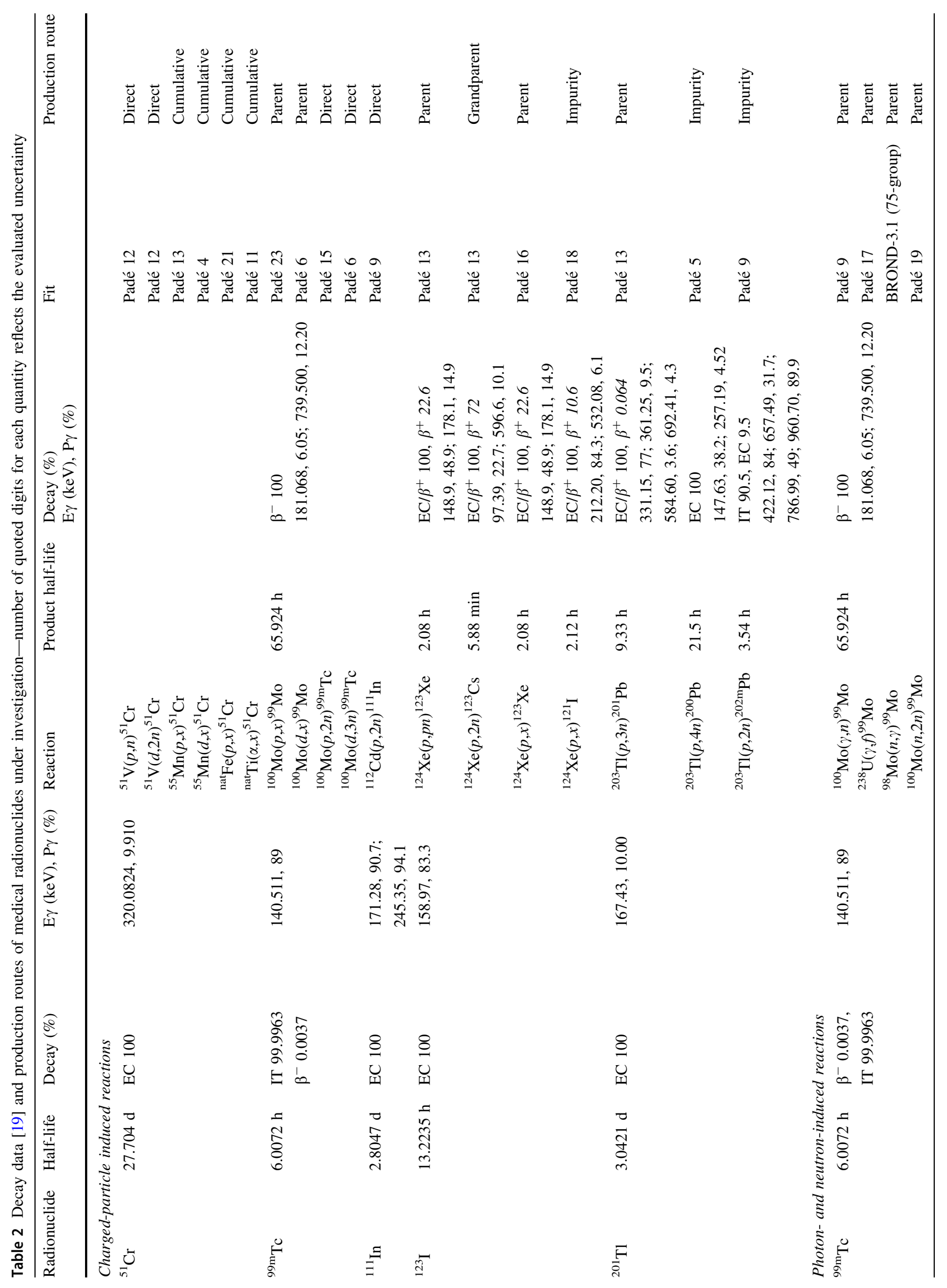




\section{Charged-particle induced reactions}

\section{Reactions for the production of ${ }^{51} \mathrm{Cr}\left(T_{1 / 2}=\right.$ 27.701 d)}

Applications rather long-lived ${ }^{51} \mathrm{Cr}$ is used to label red blood cells, and quantify gastro-intestinal protein loss and glomerular filtration rate (especially in paediatrics).

Evaluations have been made of the ${ }^{51} \mathrm{~V}(p, n)^{51} \mathrm{Cr}$, ${ }^{51} \mathrm{~V}(d, 2 n){ }^{51} \mathrm{Cr}, \quad{ }^{55} \mathrm{Mn}(p, x){ }^{51} \mathrm{Cr}, \quad{ }^{55} \mathrm{Mn}(d, x)^{51} \mathrm{Cr}$, ${ }^{\text {nat }} \mathrm{Fe}(p, x)^{51} \mathrm{Cr}$, and ${ }^{\text {nat }} \mathrm{Ti}(\alpha, x)^{51} \mathrm{Cr}$ reactions.

${ }^{51} \mathrm{~V}(p, n){ }^{51} \mathrm{Cr}$

The thirty-two experimental datasets available in the literature for the generation of ${ }^{51} \mathrm{Cr}$ from ${ }^{51} \mathrm{~V}$ targets are shown in Fig. 1 [20-49] (at 99.75\% natural abundance of ${ }^{51} \mathrm{~V}$ in ${ }^{\text {nat }} \mathrm{V}$, irradiations on natural $\mathrm{V}$ are considered to express the cross section for interactions on $\left.{ }^{51} \mathrm{~V}\right)$. Refs. $[36,41]$ contain two datasets each labelled as (a) and (b) in Fig. 1. All of the data in Fig. 1 are also compared with equivalent TENDL-2015 and TENDL-2017 calculations. Ten datasets were rejected (Tanaka and Furukawa [22] (values too low), Albouy et al. [24] (values too high), Hontzeas and Yaffe [28] (energy shift), Chodil et al. [33] (values too high), Mehta et al. (a) [36] (energy shift above $10 \mathrm{MeV}$ ), Stück [40] (data in energy range not included in fit), Kailas et al. (b) [41] (energy shift), Michel et al. [42] (data in energy range not included in fit), Bastos et al. [43] (values too high), and Musthafa et al. [47] (values too low)), and the remaining twenty-two sets were used in the statistical fitting procedure. These selected data and their experimental uncertainties are shown in Fig. 2 together with the Padé fit $\left(L=12, N=500, \chi^{2}=1.57\right)$ and estimated uncertainties as percentages, including $4 \%$ systematic uncertainty (right-hand scale).
Fig. 1 Thirty-two experimental datasets for the ${ }^{51} \mathrm{~V}(p, n){ }^{51} \mathrm{Cr}$ reaction available in the literature [20-49], and the TENDL calculations. Both Refs. [36, 41] contain two datasets labelled (a) and (b)

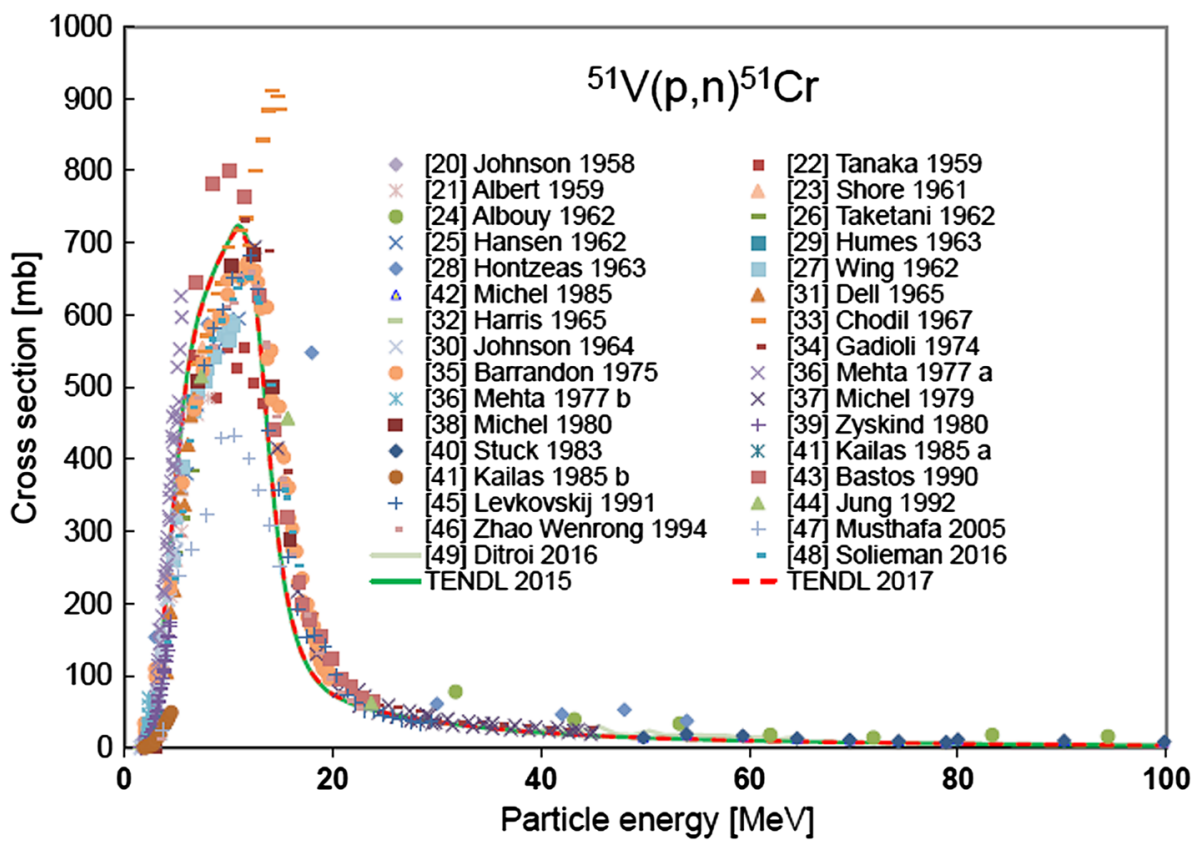




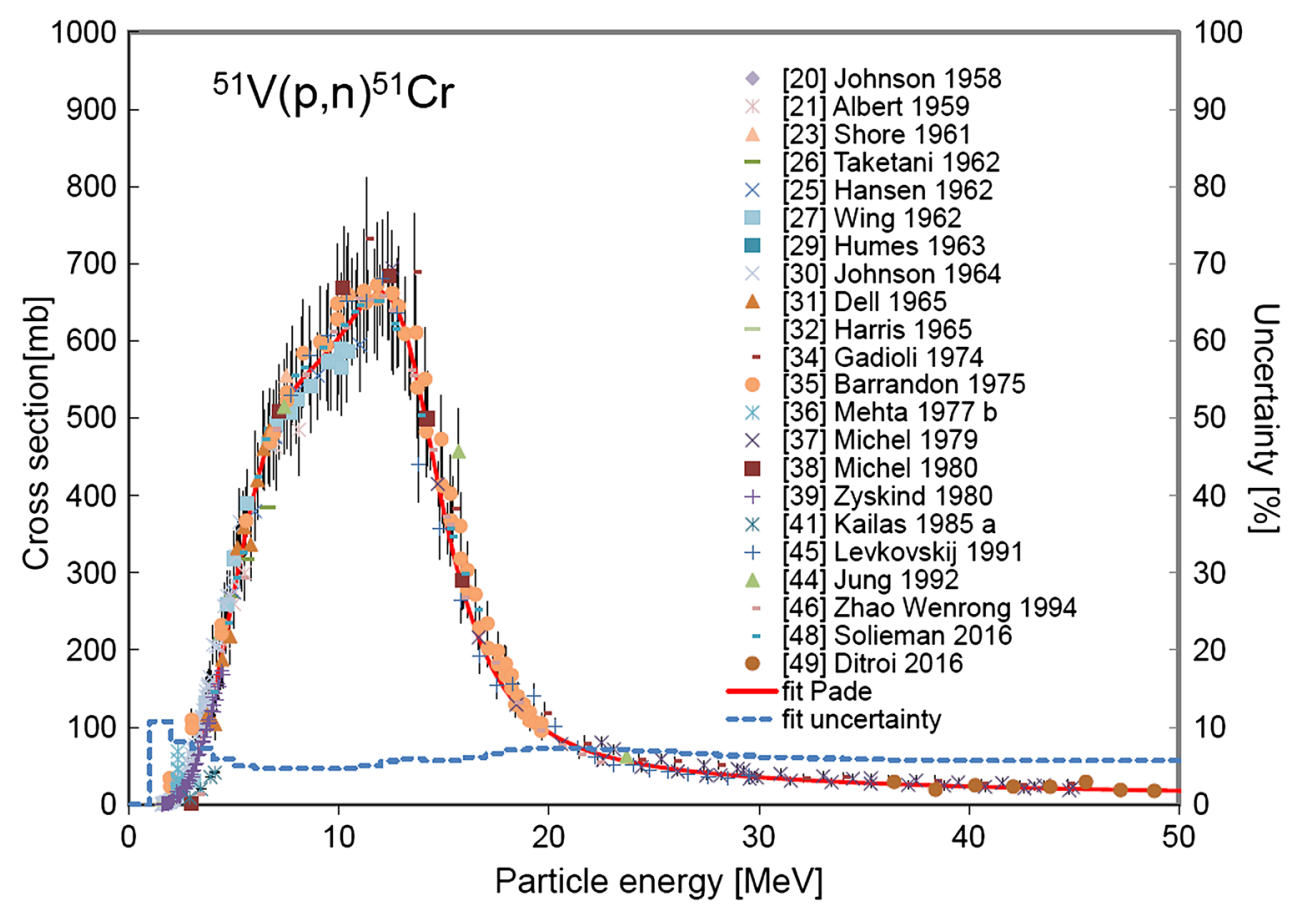

Fig. 2 Twenty-two selected experimental datasets for the ${ }^{n a t} \mathrm{~V}(p, x)^{51} \mathrm{Cr}$ reaction $[20,21,23,25-27,29-32$, 34-36(b), 37-39, 41(a), $44-46,48,49]$ with the Padé fit $\left(L=12, N=500, \chi^{2}=1.57\right)$ and estimated uncertainties as percentages (dashed line, right-hand scale) 
${ }^{51} \mathrm{~V}(d, 2 n){ }^{51} \mathrm{Cr}$

Six experimental datasets were found in the literature and all of them were judged as suitable for Padé fitting [44, 50-54]. All data are shown in Fig. 3, and are compared with the TENDL-2015 and TENDL-2017 calculations. These datasets and their experimental uncertainties are shown in Fig. 4 together with the Padé fit $\left(L=12, N=151, \chi^{2}=0.68\right)$ and estimated uncertainties as percentages, including $4 \%$ systematic uncertainty (righthand scale). datasets for the ${ }^{51} \mathrm{~V}(d, 2 n)^{51} \mathrm{Cr}$ reaction available in the literature [44, 50-54], and the TENDL calculations
Fig. 3 Six experimental

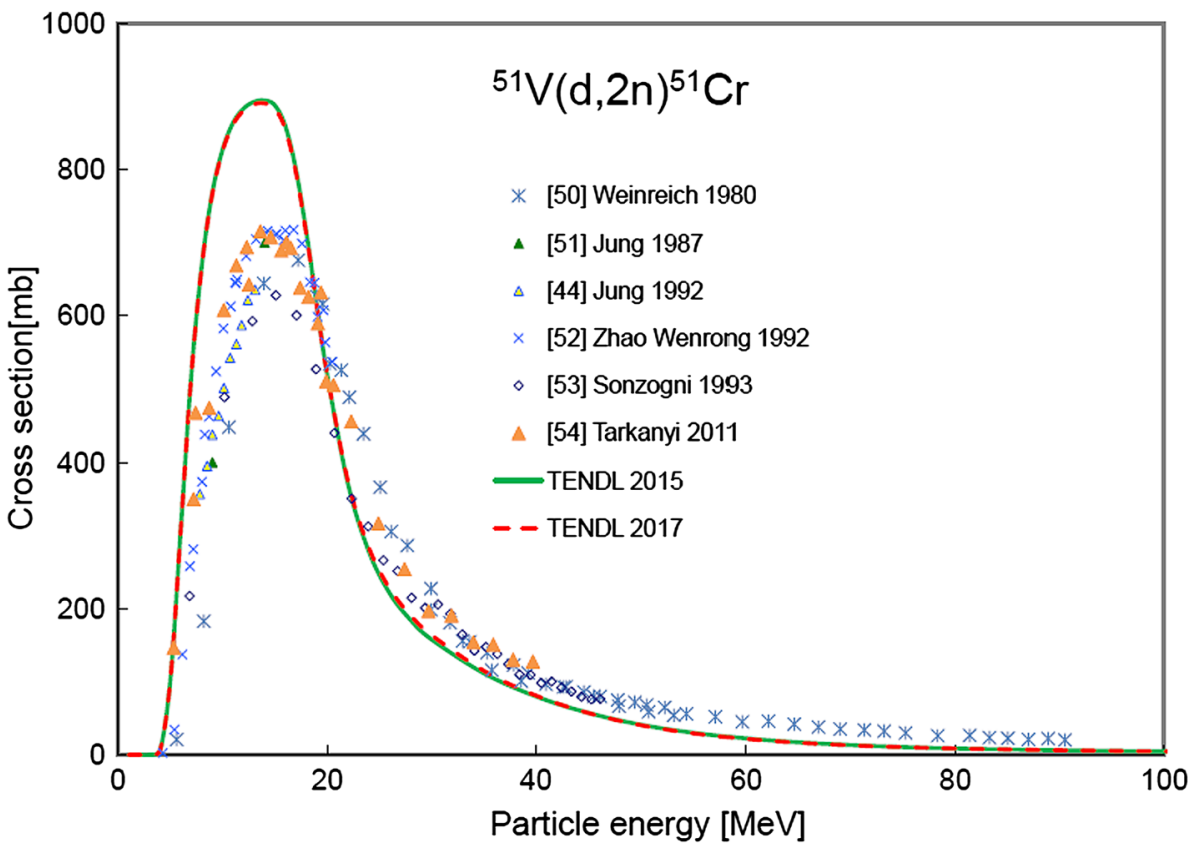

Fig. 4 Six experimental datasets for the ${ }^{51} \mathrm{~V}(d, 2 n){ }^{51} \mathrm{Cr}$ reaction $[44,50-54]$ with the Padé fit $(L=12, N=151$, $\left.\chi^{2}=0.68\right)$ and estimated uncertainties as percentages (dashed line, right-hand scale)

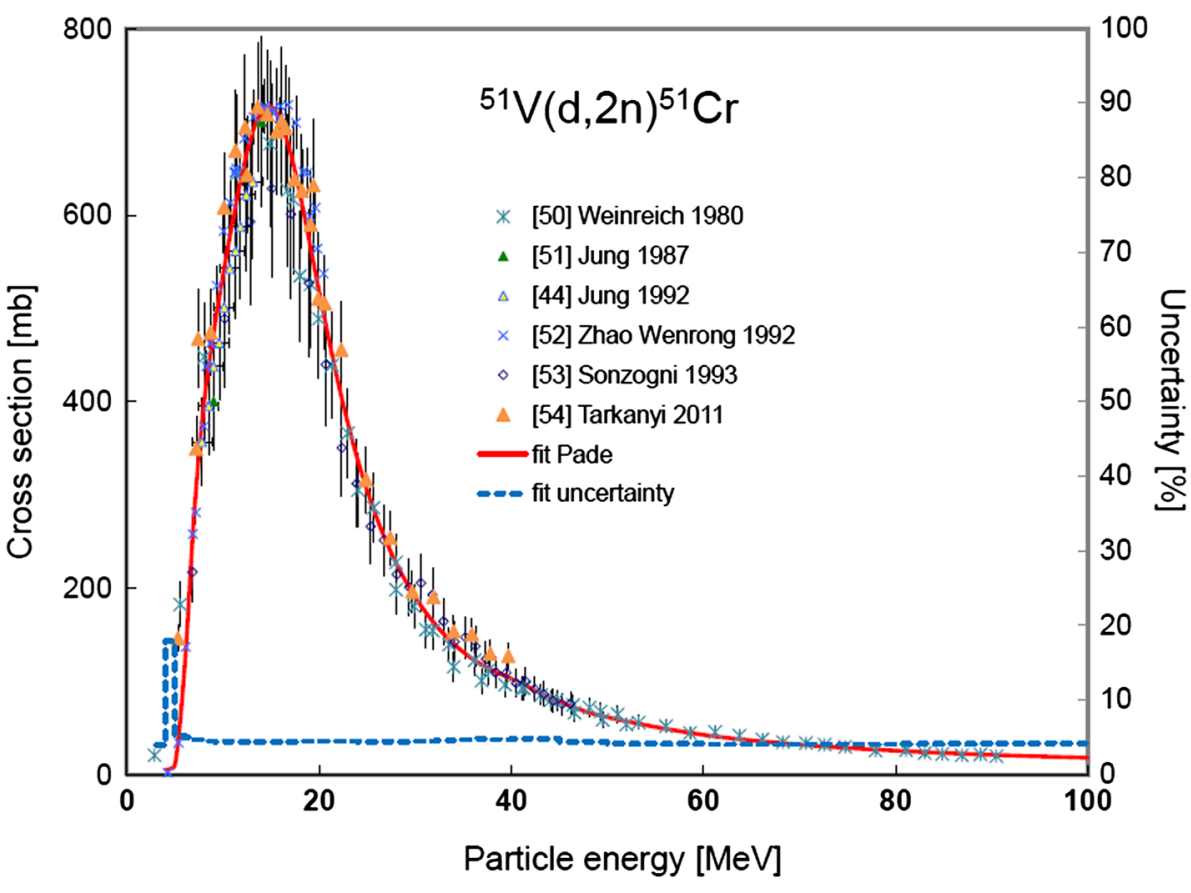


${ }^{55} \mathrm{Mn}(p, x){ }^{51} \mathrm{Cr}$

Six experimental datasets were found in the literature for the production of ${ }^{51} \mathrm{Cr}$ by means of a monoisotopic ${ }^{55} \mathrm{Mn}$ target, and all of them were judged as suitable for Padé fitting [38, 40, 45, 55-57]. All data are shown in Fig. 5, and are compared with the TENDL-2015 and TENDL-2017 calculations. Direct production occurs by means of the $(p, 2 p 3 n)$ reaction (or clustered emission) and decay contributions of simultaneously formed ${ }^{51} \mathrm{Fe}$ and ${ }^{51} \mathrm{Mn}$ shortlived parents. These datasets and their experimental uncertainties are shown in Fig. 6 together with the Padé fit ( $\left.L=13, N=94, \chi^{2}=1.75\right)$ and estimated uncertainties as percentages, including $4 \%$ systematic uncertainty (righthand scale).
Fig. 5 Six experimental datasets for the ${ }^{55} \mathrm{Mn}(p, x)^{51} \mathrm{Cr}$ reaction available in the literature [38, 40, 45, 55-57], and the TENDL calculations

Fig. 6 Six experimental datasets for the ${ }^{55} \mathrm{Mn}(p, x)^{51} \mathrm{Cr}$ reaction [38, 40, 45, 55-57] with the Pade fit $(L=13$, $\left.N=94, \chi^{2}=1.75\right)$ and estimated uncertainties as percentages (dashed line, righthand scale)
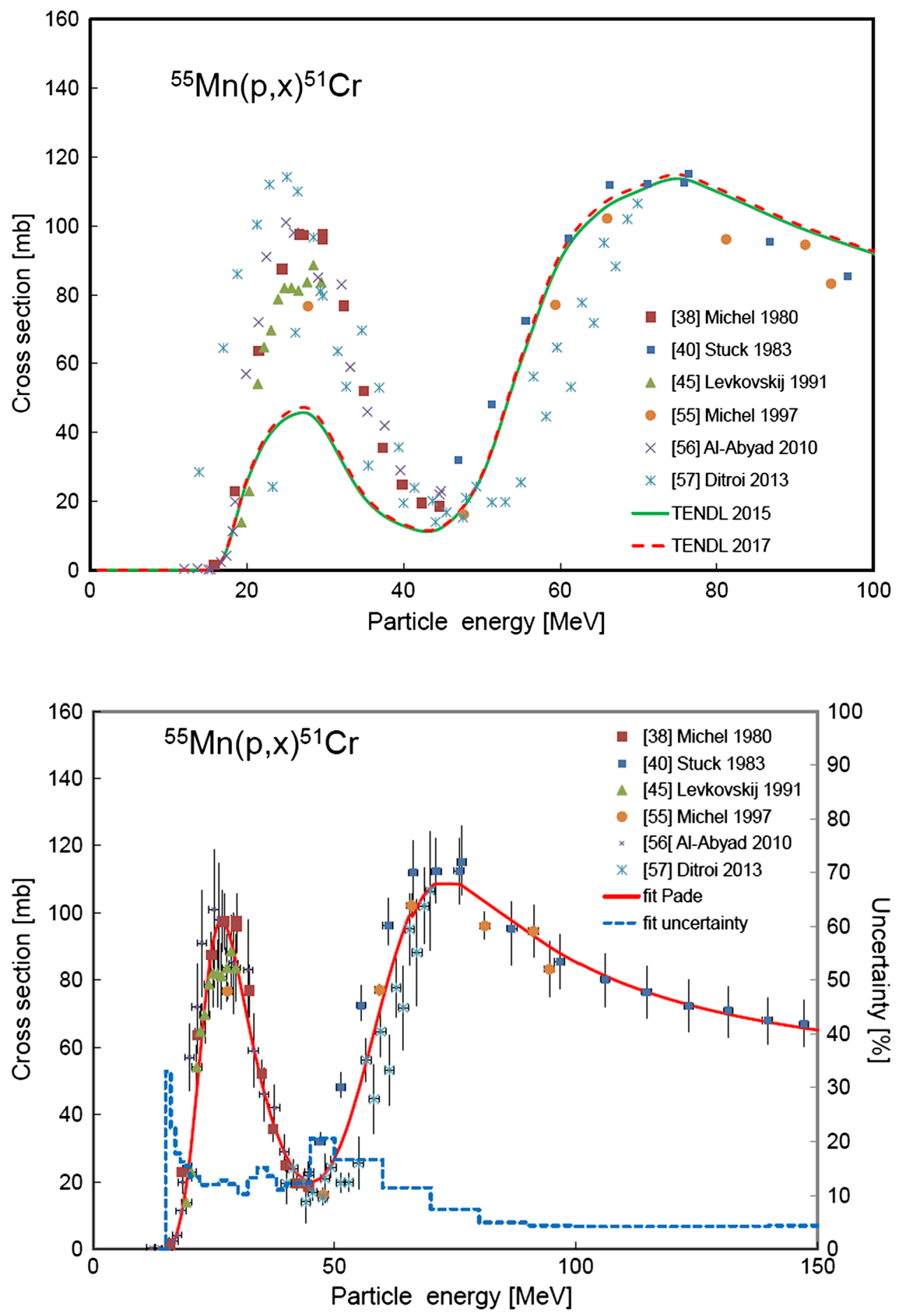
${ }^{55} \mathrm{Mn}(d, x){ }^{51} \mathrm{Cr}$

Only one experimental study was found for the cumulative deuteron-induced formation of ${ }^{51} \mathrm{Cr}$ via a ${ }^{55} \mathrm{Mn}$ target [58] (direct and decay of short-lived parents). This single dataset and experimental uncertainties are shown in Fig. 7 together with TENDL calculations, along with the Padé fit ( $\left.L=4, N=5, \chi^{2}=0.54\right)$ with estimated uncertainties as percentages, including $4 \%$ systematic uncertainty (righthand scale).
Fig. 7 Single experimental dataset for the ${ }^{55} \mathrm{Mn}(d, x)^{51} \mathrm{Cr}$ reaction [58] with TENDL calculations, and the Padé fit $\left(L=4, N=5, \chi^{2}=0.54\right)$ with estimated uncertainties as percentages (dashed line, righthand scale)

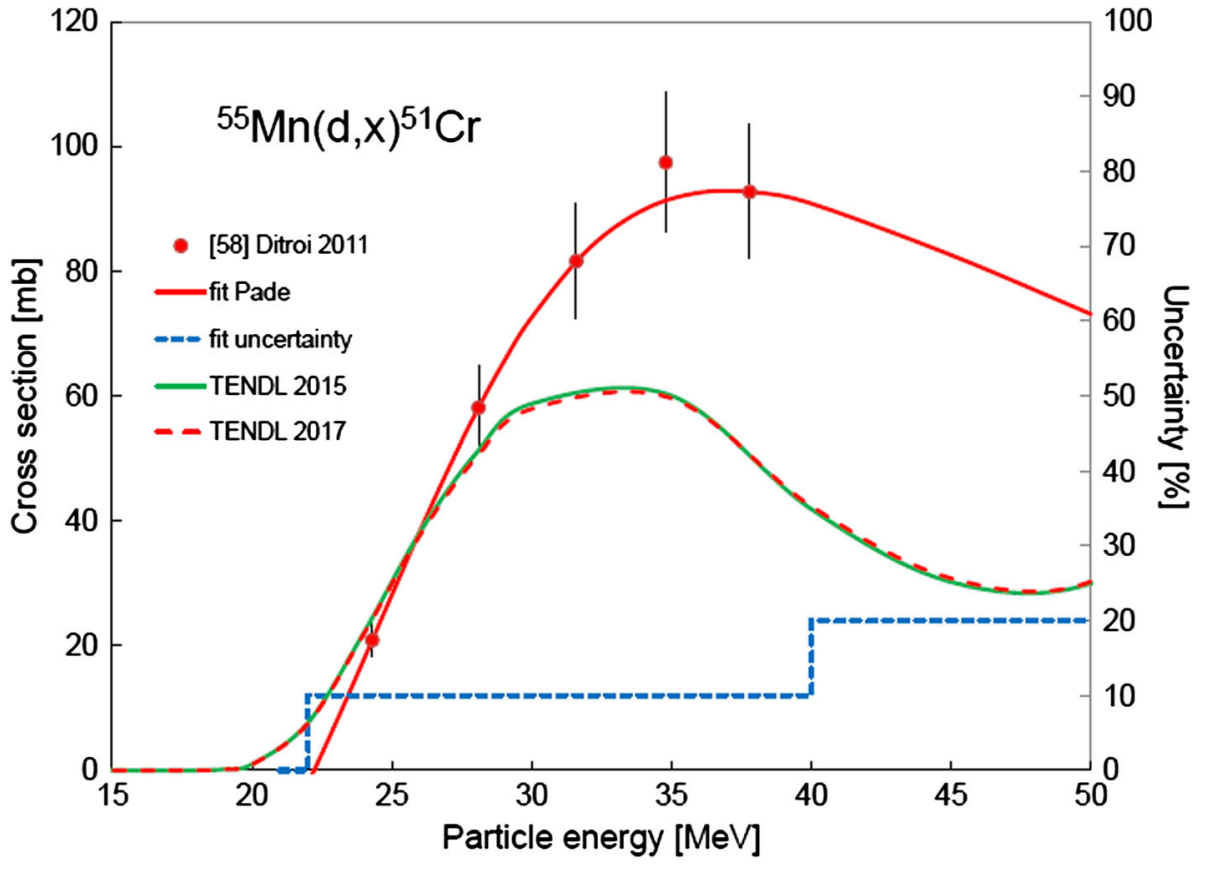


${ }^{\text {nat }} \mathrm{Fe}(p, x)^{51} \mathrm{Cr}$

Sixteen experimental datasets were found in the literature for the cumulative formation of ${ }^{51} \mathrm{Cr}$ on natural $\mathrm{Fe}$ targets [37, 38, 40, 55, 59-70]. All data are shown in Fig. 8, and are compared with the TENDL-2015 and TENDL-2017 calculations. Six datasets were rejected [Rayudu [59] (single data point too low), Williams and Fulmer [60] (values too low), Brodzinski et al. [61] (single data point too low), Walton et al. [62] (values too high), Schoen et al. [63] (values too low), and Barchuk et al. [64] (discrepant at low energy)], and the remaining ten sets were used in the statistical fitting procedure. These selected data and their experimental uncertainties are shown in Fig. 9 together with the Padé fit $\left(L=21, N=100, \chi^{2}=0.85\right)$ and estimated uncertainties as percentages, including $4 \%$ systematic uncertainty (right-hand scale).
Fig. 8 Sixteen experimental datasets for the ${ }^{\text {nat }} \mathrm{Fe}(p, x)^{51} \mathrm{Cr}$ reaction available in the literature

$[37,38,40,55,59-70]$, and the TENDL calculations

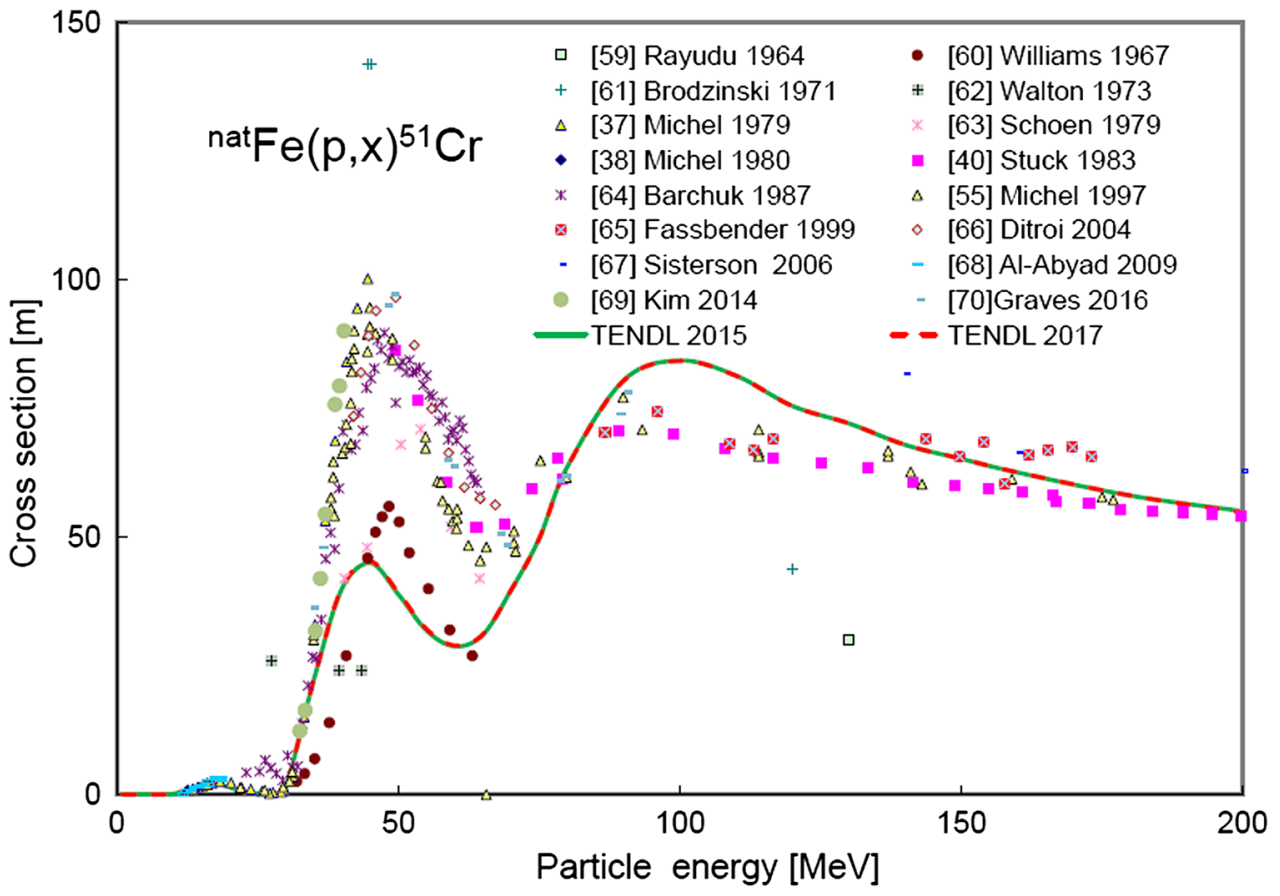

Fig. 9 Ten selected experimental datasets for the ${ }^{\text {nat }} \mathrm{Fe}(p, x){ }^{51} \mathrm{Cr}$ reaction $[37,38,40,55,65-70]$ with the Padé fit $(L=21, N=100$, $\left.\chi^{2}=0.85\right)$ and estimated uncertainties as percentages (dashed line, right-hand scale)

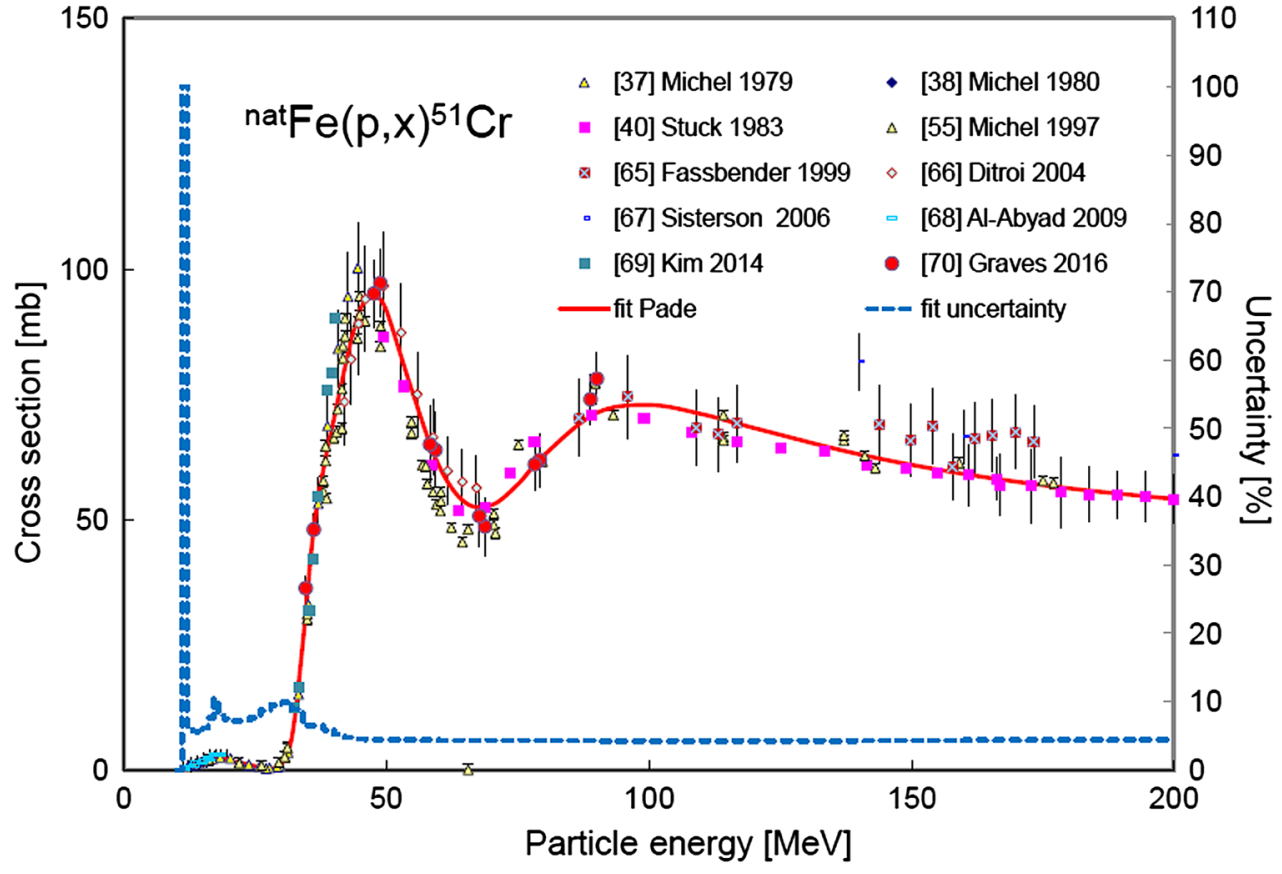


${ }^{\text {nat }} \operatorname{Ti}(\alpha, x){ }^{51} \mathrm{Cr}$

Sixteen experimental datasets were found in the literature [45, 50, 71-83]. Hermanne et al. [78] contained two datasets that have been labelled (a) and (b). All data are shown in Fig. 10, and are compared with the TENDL-2015 and TENDL-2017 calculations. Eight datasets were rejected [Levkovskij [45] (energy shift), Weinreich et al. [50] (energy shift), Iguchi et al. [71] (energy shift), Chang et al. [73] (values too low, and strange shape), Michel et al. [74] (energy shift), Tárkányi et al. [76] (energy shift), Xiufeng Peng et al. [77] (values too low), and Hermanne et al. (b) [78] (values too low)], and the remaining eight sets were used in the statistical fitting procedure. These selected data and their experimental uncertainties are shown in Fig. 11 together with the Padé fit $(L=11, N=242$, $\left.\chi^{2}=1.50\right)$ and estimated uncertainties as percentages, including $4 \%$ systematic uncertainty (right scale). This reaction is also used as a monitor reaction for $\alpha$-beams, and is discussed further in Section V.C. of Hermanne et al. [9].
Fig. 10 Sixteen experimental data datasets for the

${ }^{\text {nat }} \operatorname{Ti}(\alpha, x){ }^{51} \mathrm{Cr}$ reaction available in the literature [45, 50, 71-83], and the TENDL calculations
Fig. 11 Eight selected experimental data for the ${ }^{\text {nat }} \mathrm{Ti}(\alpha, x)^{51} \mathrm{Cr}$ reaction [72, 75, 78(a), 79-83] with the Padé fit $(L=11, N=242$, $\left.\chi^{2}=1.50\right)$ and estimated uncertainties as percentages (dashed line, right-hand scale)
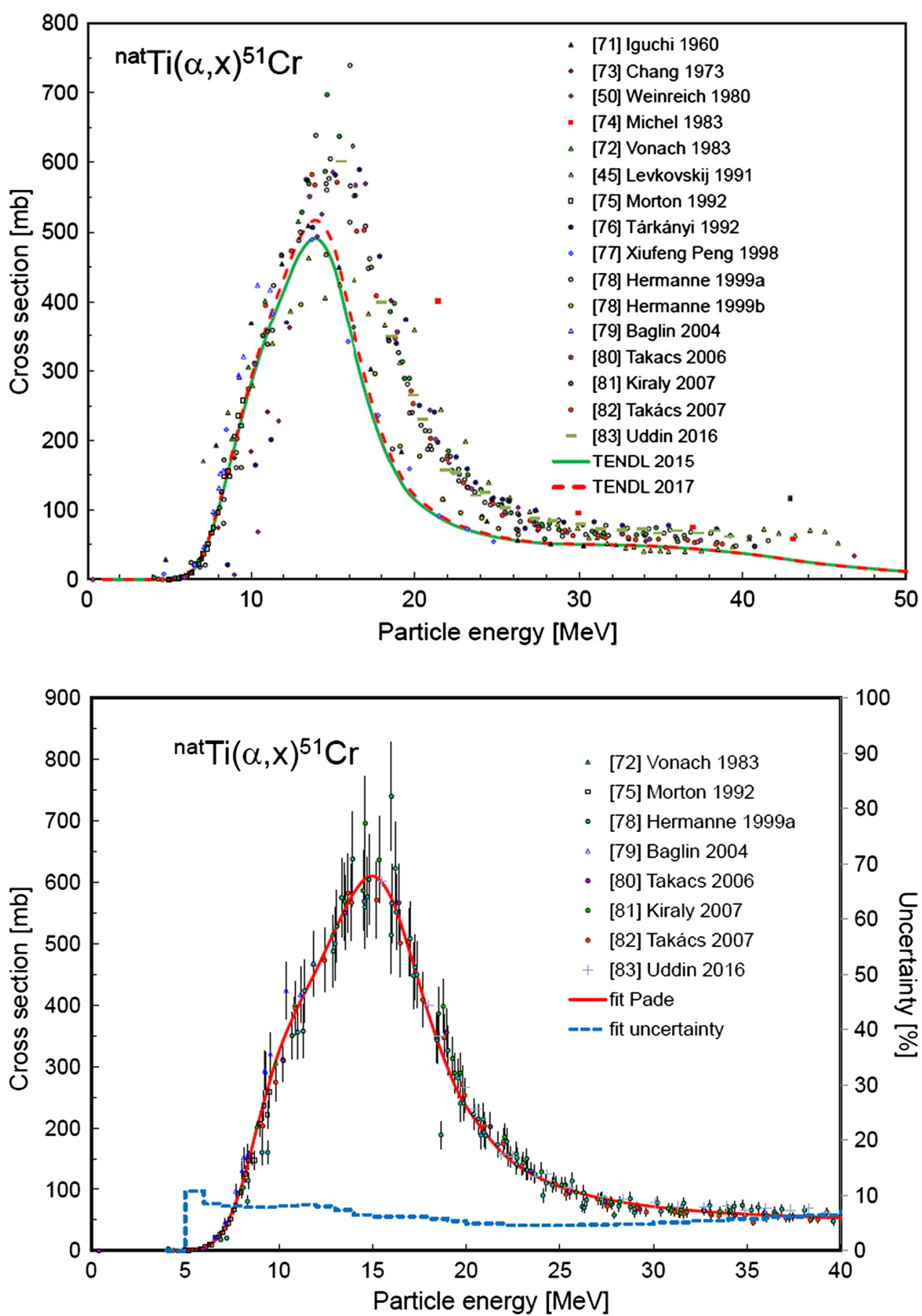


\section{Integral yields for ${ }^{51} \mathrm{Cr}$ formation}

Integral yields for the six production routes of ${ }^{51} \mathrm{Cr}$ were calculated on the basis of the fits in Figs. 2, 4, 6, 7, 9 and 11, as presented in Fig. 12. Commercially available production accelerators $(30-\mathrm{MeV}$ protons) define the $(p, n)$ reaction on natural vanadium targets (containing $99.75 \%$ ${ }^{51} \mathrm{~V}$ ) as the method of choice. The advantages of higher yield through adoption of the $(d, 2 n)$ reaction above $25-\mathrm{MeV}$ incident particle energy can only be exploited by a limited number of research centres.

\section{Reactions for the production of ${ }^{99 \mathrm{~m}} \mathrm{Tc}\left(\mathrm{T}_{1 / 2}=\right.$ 6.0072 h)}

Applications ${ }^{99 \mathrm{~m}} \mathrm{Tc}$ is most commonly used to image the skeleton and heart muscle. Also has been applied to the brain, thyroid, lungs (perfusion and ventilation), liver, spleen, kidney (structure and filtration rate), gall bladder, bone marrow, salivary and lachrymal glands, heart blood pool, infection and many other specialised medical studies.

${ }^{99 \mathrm{~m}} \mathrm{Tc}$ is the $\gamma$-emitting workhorse of diagnostic nuclear medicine (constitutes more than $70 \%$ of imaging procedures performed worldwide). Commercially distributed in the form of ${ }^{99} \mathrm{Mo} /{ }^{99 \mathrm{~m}} \mathrm{Tc}$ generators whereby all ${ }^{99} \mathrm{Mo}$ is obtained from the fission of ${ }^{235} \mathrm{U}$ within thermal research reactors $\left({ }^{99} \mathrm{Mo}_{1 / 2}=65.924 \mathrm{~h}\right)$. Uncertainty in the sustainability of the supply chain caused by unexpected or progressive shutdown of aged research reactors has triggered a search for alternative reactions to be performed in accelerator systems. Significant attention has been devoted to both charged-particle induced reactions by means of particle accelerators and photon-induced reactions by means of electron linear accelerators (linac).

\section{Production routes under investigation}

Various production routes have been fully assessed and evaluated:

- Indirect production via the ${ }^{99} \mathrm{Mo} /{ }^{99 \mathrm{~m}} \mathrm{Tc}$ generator based on the ${ }^{100} \operatorname{Mo}(p, x){ }^{99} \mathrm{Mo}$ and ${ }^{100} \mathrm{Mo}(d, x){ }^{99}$ Mo chargedparticle reactions (see below); ${ }^{100} \mathrm{Mo}(n, 2 n){ }^{99} \mathrm{Mo}$ and ${ }^{98} \mathrm{Mo}(n, \gamma){ }^{99} \mathrm{Mo}$ radiative neutron capture in reactors, and photon-induced reactions by means of linacs ${ }^{100} \mathrm{Mo}(\gamma, n){ }^{99} \mathrm{Mo}$ and ${ }^{238} \mathrm{U}(\gamma, f){ }^{99}$ Mo (all four of these routes are analysed and discussed in the subsection entitled “99m $\mathrm{Tc}$ and parent ${ }^{99} \mathrm{Mo}$ : photon-induced and neutron-induced reactions").

- Direct production by means of the ${ }^{100} \mathrm{Mo}(p, 2 n)^{99 \mathrm{~m}} \mathrm{Tc}$ and ${ }^{100} \mathrm{Mo}(d, 3 n){ }^{99 \mathrm{~m}} \mathrm{Tc}$ reactions (see below).
Fig. 12 Yields calculated from the recommended cross sections for the ${ }^{51} \mathrm{~V}(p, n),{ }^{51} \mathrm{~V}(d, 2 n){ }^{51} \mathrm{Cr}$, ${ }^{55} \mathrm{Mn}(p, x){ }^{51} \mathrm{Cr},{ }^{55} \mathrm{Mn}(d, x){ }^{51} \mathrm{Cr}$, ${ }^{\text {nat }} \mathrm{Fe}(p, x)^{51} \mathrm{Cr}$ and ${ }^{\text {nat }} \mathrm{Ti}(\alpha, x)^{51} \mathrm{Cr}$ reactions

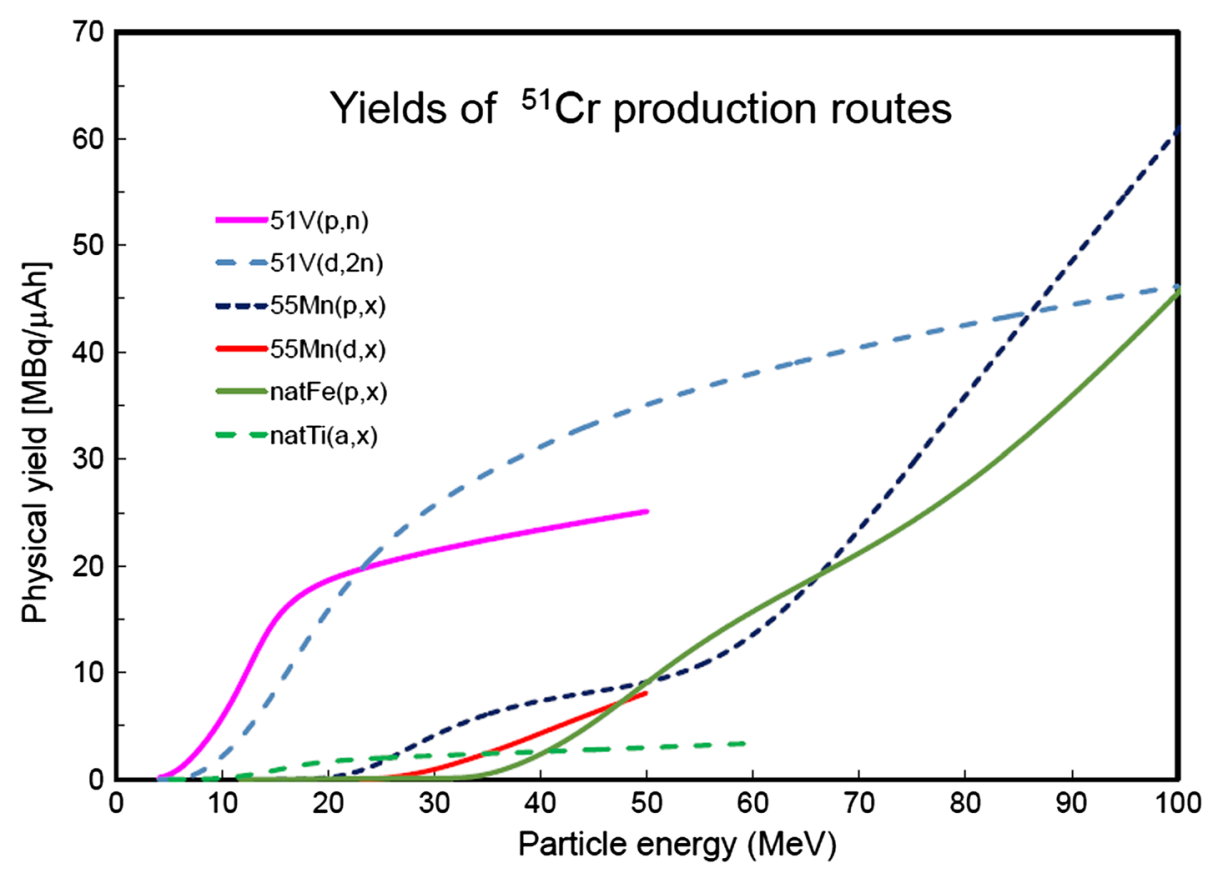


${ }^{100} \operatorname{Mo}(p, x){ }^{99} \mathrm{Mo}$

Fourteen experimental datasets were found in the literature [45, 84-96]. All data are shown in Fig. 13, and are compared with the TENDL-2015 and TENDL-2017 calculations. Five datasets were rejected [Lagunas-Solar et al. [84] (values too low), Scholten et al. [85] (values too low), Uddin et al. [87] (values too low), Khandaker et al. [88] (values too low at higher energy), and Alharbi et al. [90] (slight energy shift)], and the remaining nine sets were used in the statistical fitting procedure. These selected data and their experimental uncertainties are shown in Fig. 14 together with the Padé fit $\left(L=23, N=153, \chi^{2}=1.73\right)$ and estimated uncertainties as percentages, including $4 \%$ systematic uncertainty (right-hand scale).
Fig. 13 Fourteen experimental datasets for the ${ }^{100} \mathrm{Mo}(p, x)^{99} \mathrm{Mo}$ reaction available in the literature [45, 84-96], and the TENDL calculations

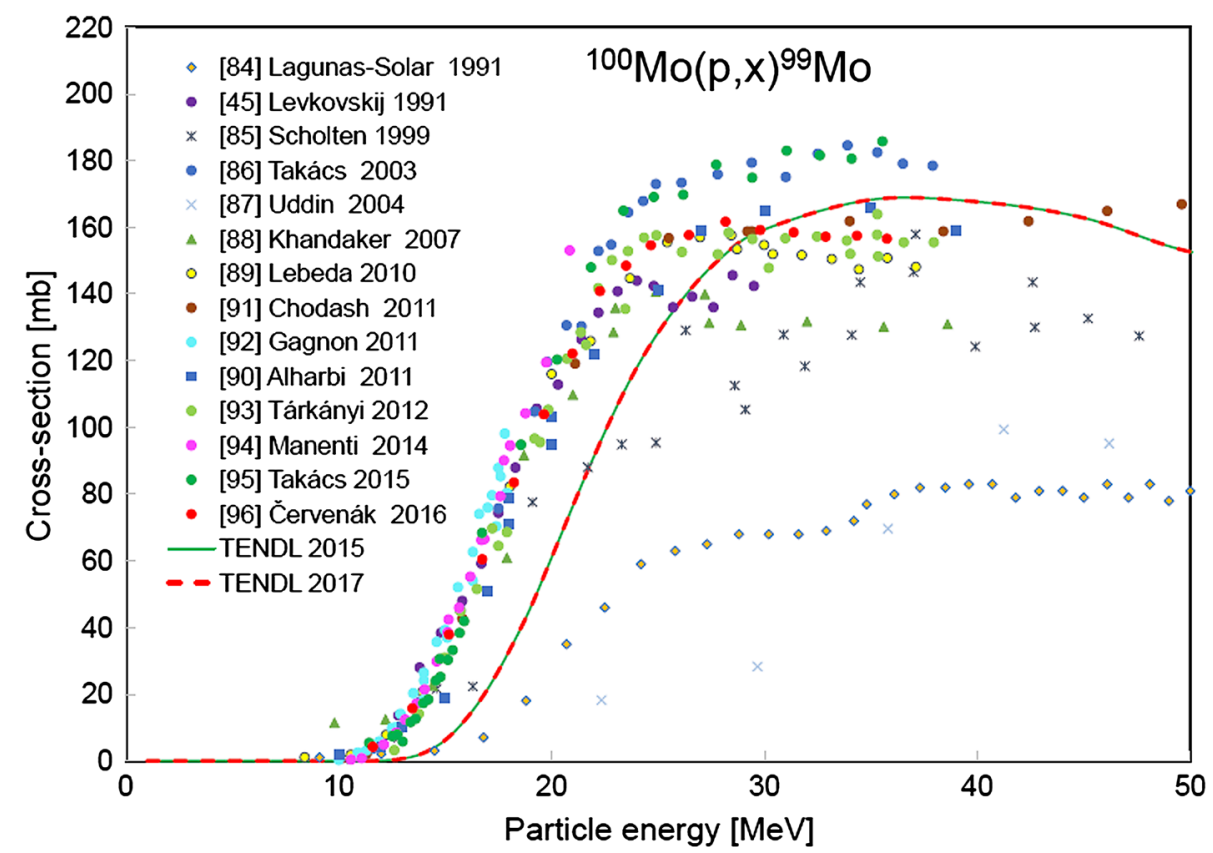

Fig. 14 Nine selected experimental datasets for the ${ }^{100} \mathrm{Mo}(p, x){ }^{99}$ Mo reaction $[45,86,89,91-96]$ with the Padé fit $(L=23, N=153$, $\left.\chi^{2}=1.73\right)$ and estimated uncertainties as percentages (dashed line, right-hand scale)

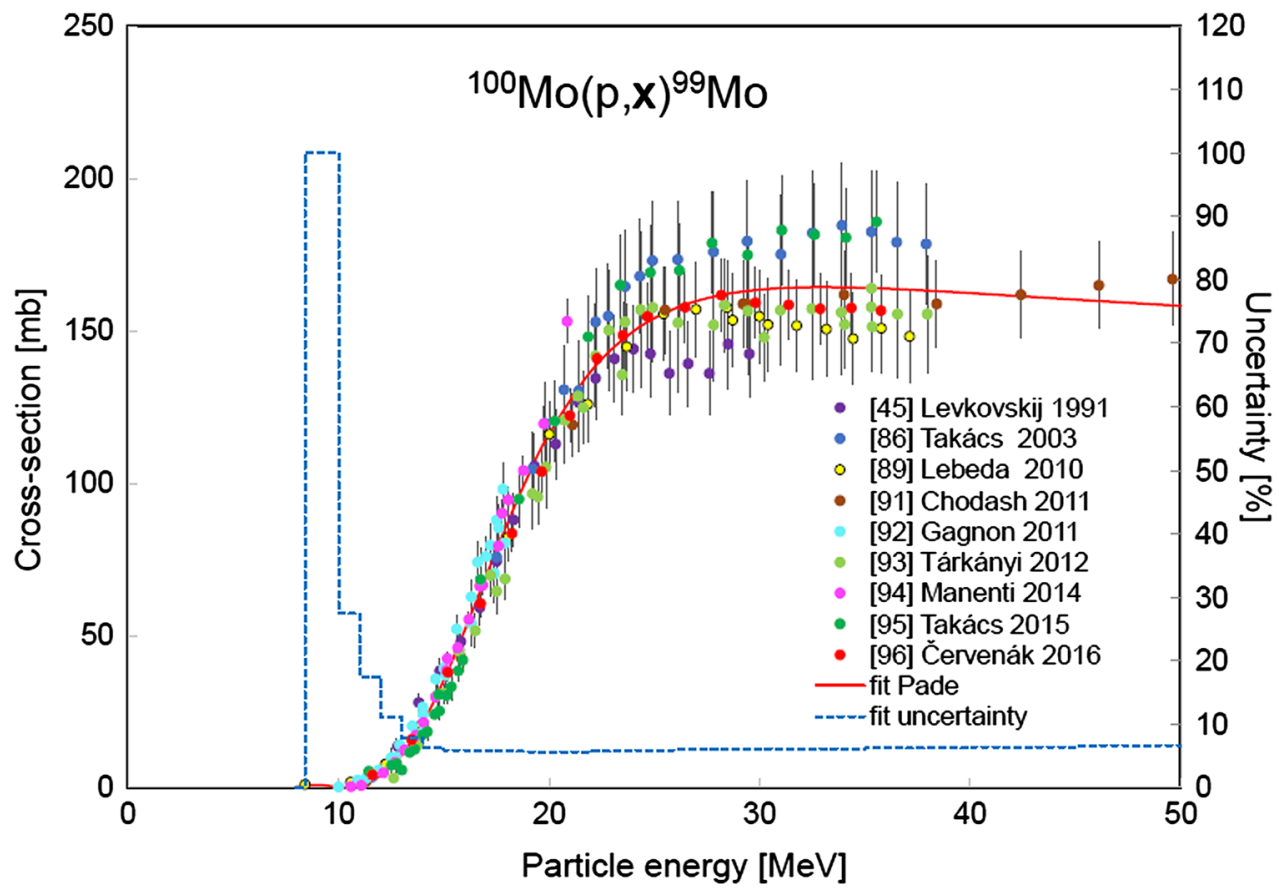




\section{${ }^{100} \mathrm{Mo}(d, x){ }^{99} \mathrm{Mo}$}

Relevant experimental data for the ${ }^{100} \operatorname{Mo}(d, x)^{99}$ Mo reaction are shown in Fig. 15 [91, 97-100], and are compared with the corresponding TENDL calculations. Only two highly specific datasets exist [97, 99] and under such limited circumstances, three other sets of experimental data measured on ${ }^{\text {nat }} \mathrm{Mo}$ and normalised to the abundance of ${ }^{100}$ Mo are also included in Fig. 15 [91, 98, 100]. All normalised data obtained with ${ }^{\text {nat }}$ Mo targets include a significant contribution from the ${ }^{98} \operatorname{Mo}(d, p){ }^{99}$ Mo reaction at a lower threshold, and therefore the excitation function for these three references are seen to exhibit abnormal behaviour at lower beam energies. Nevertheless, the data measured on ${ }^{\text {nat }}$ Mo support the ${ }^{100} \operatorname{Mo}(d, x){ }^{99}$ Mo data at energies above $30 \mathrm{MeV}$ whereby the contribution of the ${ }^{98} \mathrm{Mo}(d, p){ }^{99} \mathrm{Mo}$ reaction is small.

The two datasets obtained with ${ }^{100}$ Mo targets and their experimental uncertainties are shown in Fig. 16 [97, 99] together with the Padé fit $\left(L=6, N=70, \chi^{2}=1.23\right)$ and estimated uncertainties as percentages, including $4 \%$ systematic uncertainty (right-hand scale).
Fig. 15 Five experimental datasets for the ${ }^{100} \operatorname{Mo}(d, x){ }^{99} \mathrm{Mo}$ reaction available in the literature [91, 97-100], and the TENDL calculations
Fig. 16 Two selected experimental datasets for the ${ }^{100} \operatorname{Mo}(d, x){ }^{99}$ Mo reaction [97, 99] with the Padé fit $(L=6$, $N=70, \chi^{2}=1.23$ ) and estimated uncertainties as percentages (dashed line, righthand scale)
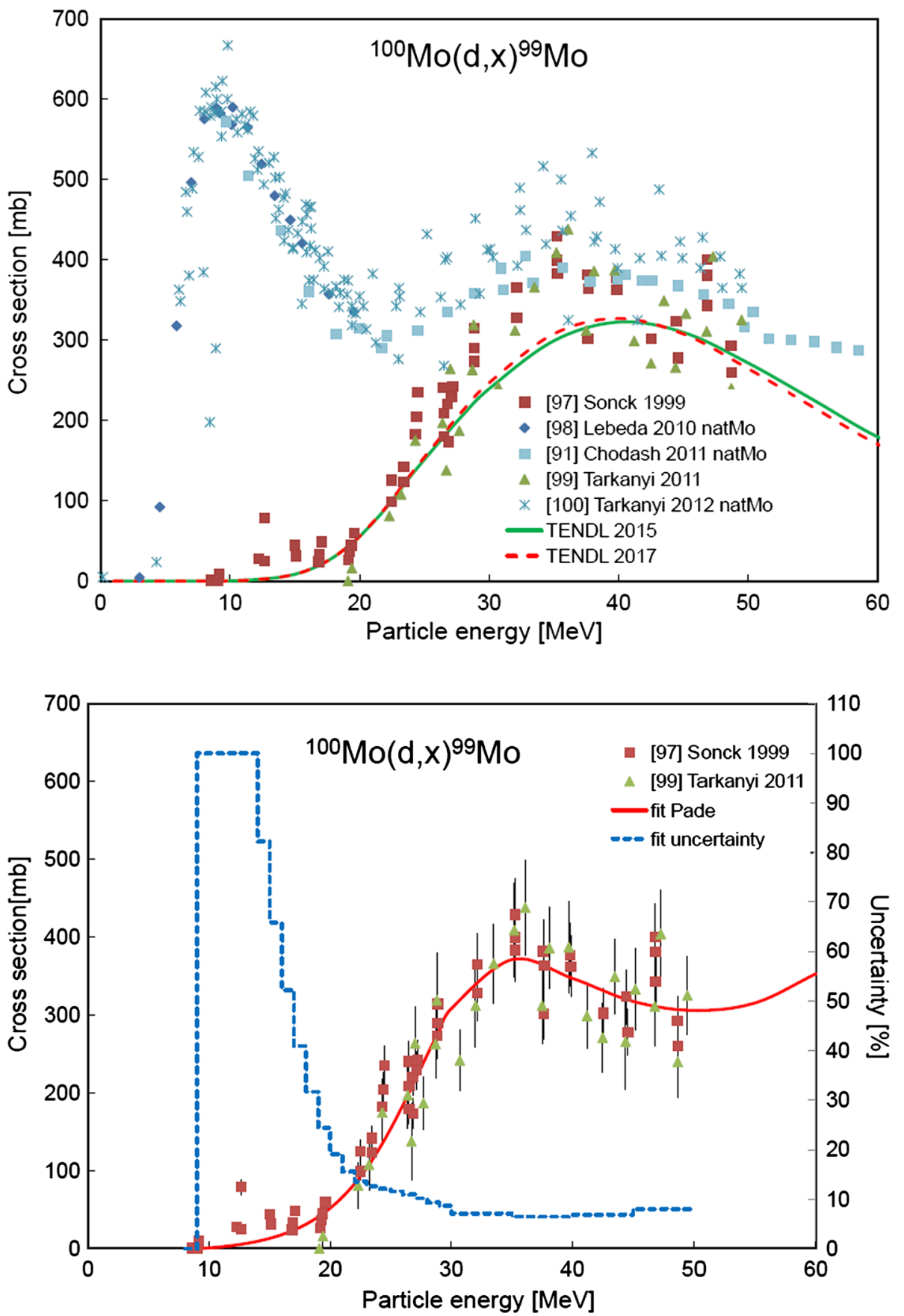
${ }^{100} \mathrm{Mo}(p, 2 n){ }^{99 \mathrm{~m}} \mathrm{Tc}$

Sixteen experimental datasets were found in the literature [45, 84-86, 88-90, 92-96, 101, 102]. Ref. [92] contains three sets of data labelled (a), (b) and (c). All data are shown in Fig. 17, and are compared with the TENDL-2015 and TENDL-2017 calculations. Ten datasets were rejected [Lagunas-Solar et al. [84] (energy shift, and values too high), Lagunas-Solar et al. [101] (values too high), Scholten et al. [85] (scattered, and values too low),
Khandaker et al. [102] (values too low), Khandaker et al. [88] (energy shift, and values too low), Alharbi et al. [90] (values too low), Gagnon et al. (a, b, c) [92] (values too high in all three sets of data), and Manenti et al. [94] (values too high)], while the remaining six sets were used in the statistical fitting procedure. The selected data and their experimental uncertainties are shown in Fig. 18 together with the Padé fit $\left(L=15, N=197, \chi^{2}=2.11\right)$ and estimated uncertainties as percentages, including $4 \%$ systematic uncertainty (right-hand scale).

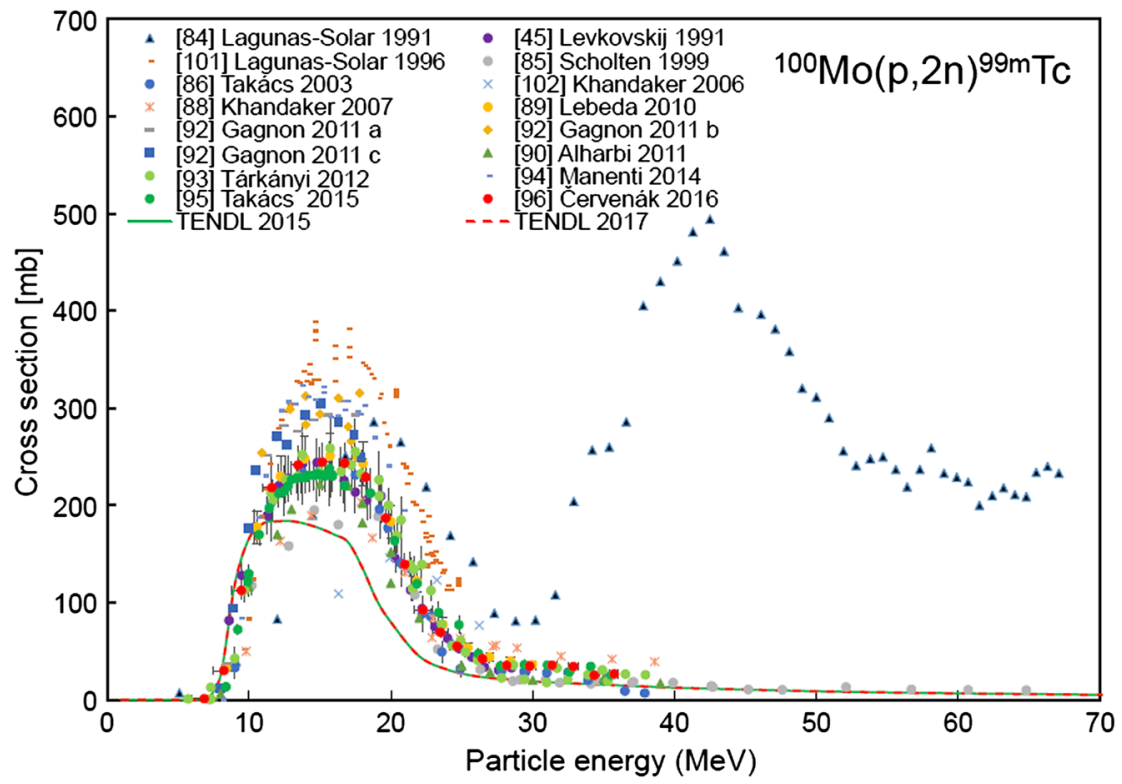

Fig. 17 Sixteen experimental datasets for the ${ }^{100} \mathrm{Mo}(p, 2 n){ }^{99 \mathrm{~m}} \mathrm{Tc}$ reaction available in the literature [45, 84-86, 88-90, 92-96, 101, 102], and the TENDL calculations. Ref. [92] contains three datasets labelled (a), (b) and (c)

Fig. 18 Six selected experimental datasets for the ${ }^{100} \mathrm{Mo}(p, 2 n){ }^{99 \mathrm{~m}} \mathrm{Tc}$ reaction $[45,86,89,93,95,96]$ with the Padé fit $(L=15, N=197$, $\left.\chi^{2}=2.11\right)$ and estimated uncertainties as percentages (dashed line, right-hand scale)

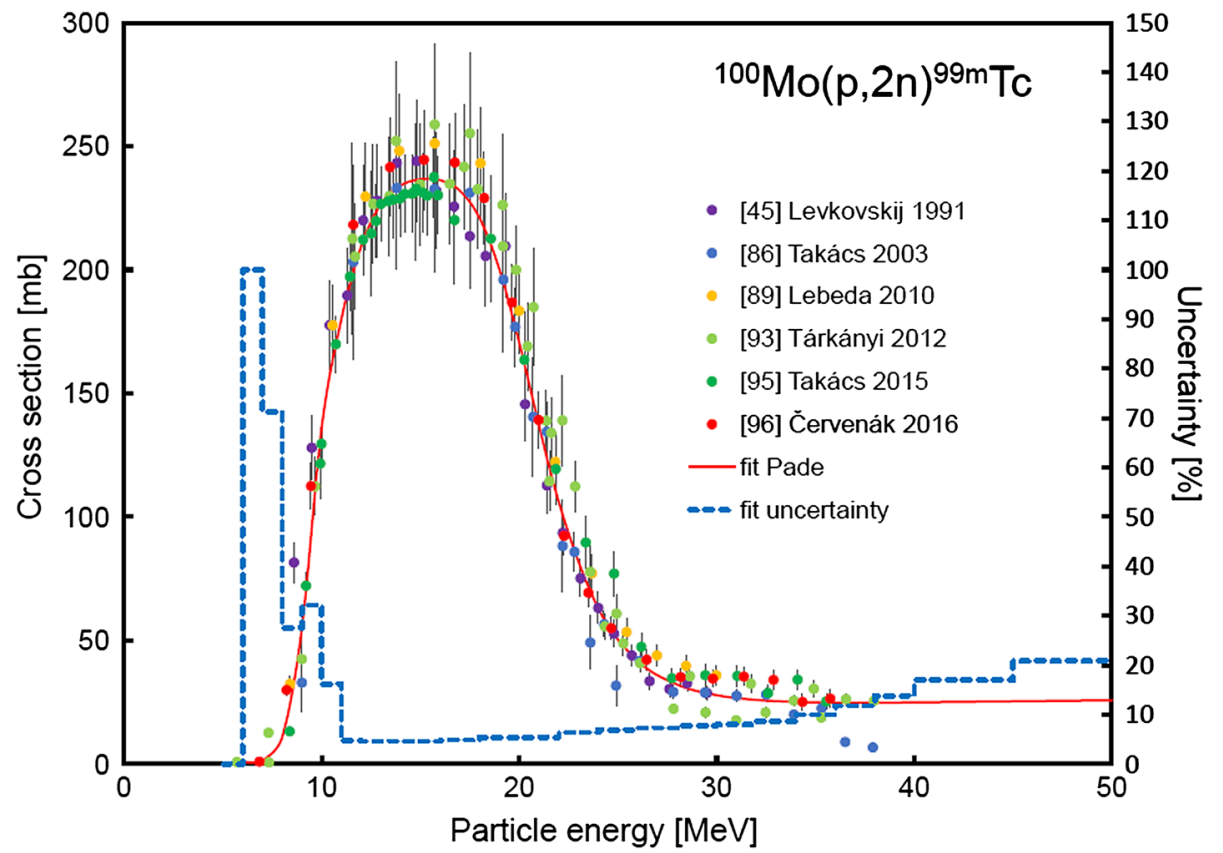


${ }^{100} \mathrm{Mo}(d, 3 n){ }^{99 \mathrm{~m}} \mathrm{Tc}$

Only one experimental dataset has been determined with highly-enriched ${ }^{100}$ Mo target material [99], and therefore three other sets of normalised data measured on ${ }^{\text {nat }}$ Mo have also been included in Fig. 19 as a guide [98-100, 103]. All data are also compared with the equivalent TENDL calculations. While these three additional datasets contain a significant contribution from the ${ }^{98} \mathrm{Mo}(d, n)^{99 \mathrm{~m}} \mathrm{Tc}$ reaction at low particle-beam energies, such impact is close to being negligible around the maximum of the ${ }^{100} \mathrm{Mo}(d, 3 n){ }^{99 \mathrm{~m}} \mathrm{Tc}$ reaction. All three datasets determined with ${ }^{\text {nat }}$ Mo targets support the single set of data measured with highly-enriched ${ }^{100}$ Mo. The Padé fit shown in Fig. 20 is based only on the data of Ref. [99] and associated experimental uncertainties $\left(L=6, N=33, \chi^{2}=0.88\right)$ with estimated uncertainties as percentages, including $4 \%$ systematic uncertainty (right-hand scale).
Fig. 19 Four experimental datasets for the

${ }^{100} \mathrm{Mo}(d, 3 n){ }^{99 \mathrm{~m}} \mathrm{Tc}$ reaction available in the literature [98-100, 103], and the TENDL calculations

Fig. 20 Single experimental dataset for the

${ }^{100} \operatorname{Mo}(d, 3 n){ }^{99 \mathrm{~m}} \mathrm{Tc}$ reaction [99] with the Padé fit ( $L=6, N=33$, $\left.\chi^{2}=0.88\right)$ and estimated uncertainties as percentages (dashed line, right-hand scale)
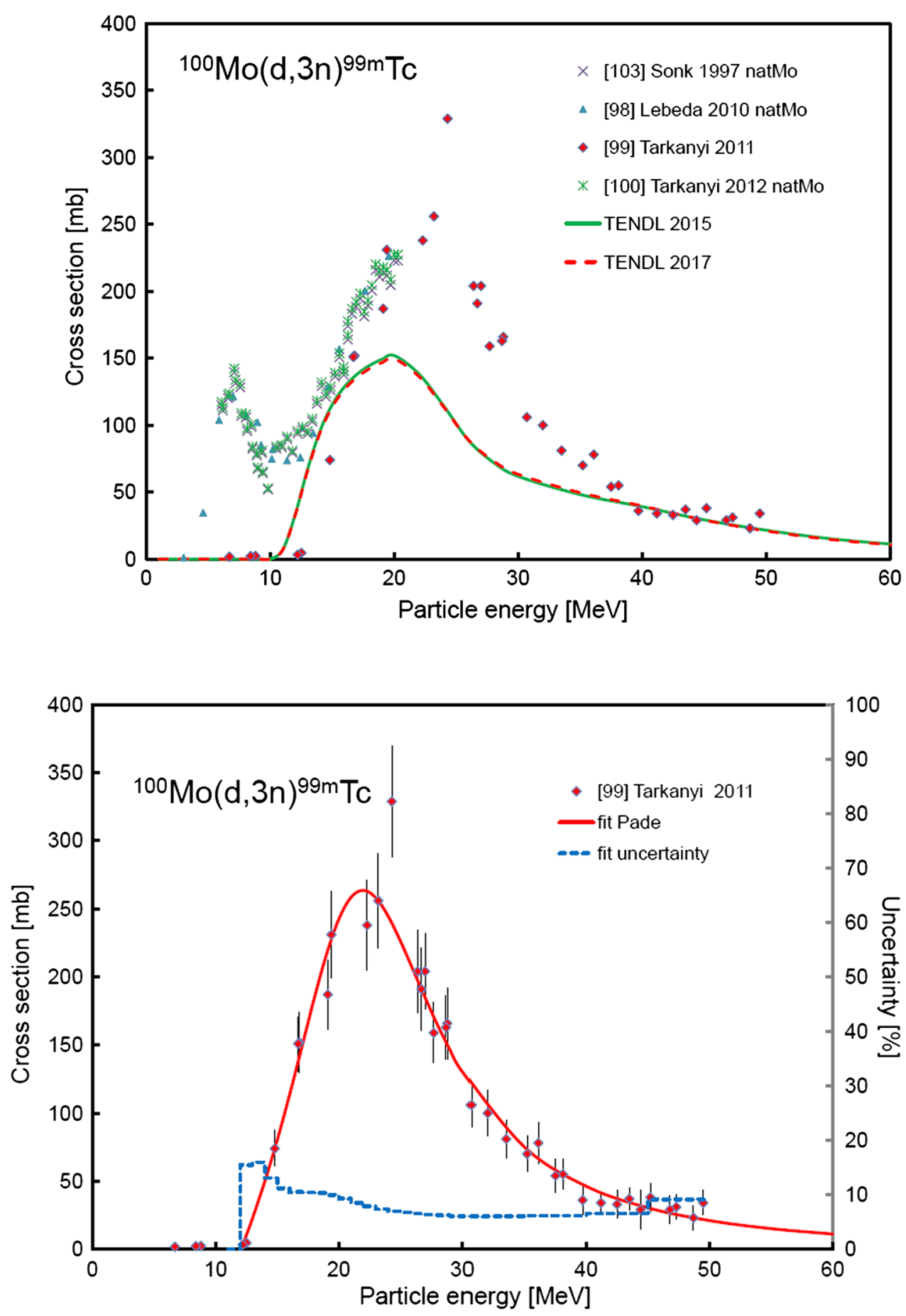


\section{Integral yields for ${ }^{99} \mathrm{Mo}$ and ${ }^{99 \mathrm{~m}} \mathrm{Tc}$ formation using proton/deuteron accelerators}

Integral yields for the production routes of ${ }^{99} \mathrm{Mo}$ and ${ }^{99 \mathrm{~m}} \mathrm{Tc}$ are shown in Figs. 21 and 22, respectively, as calculated on the basis of the fits in Figs. 14, 16, 18 and 20. Only the direct ${ }^{100} \mathrm{Mo}(p, 2 n){ }^{99 \mathrm{~m}} \mathrm{Tc}$ reaction on highly-enriched ${ }^{100}$ Mo targets could be an alternative route of production for dedicated and commercially available accelerators (30-MeV protons). Indirect production by means of higher-energy deuteron reactions could increase the yield by a factor of three through adoption of the ${ }^{100} \operatorname{Mo}(d, x){ }^{99} \mathrm{Mo}$ route, and allow the continued use of parent-based generator systems. However, both direct and indirect charge-particle routes cannot compete economically with fission based ${ }^{99} \mathrm{Mo}$ production as long as heavily subsidised research reactors are available. ${ }^{1}$
Fig. 21 Yields calculated from the recommended cross sections for the ${ }^{100} \mathrm{Mo}(p, x)^{99} \mathrm{Mo}$ and

${ }^{100} \operatorname{Mo}(d, x){ }^{99}$ Mo reactions

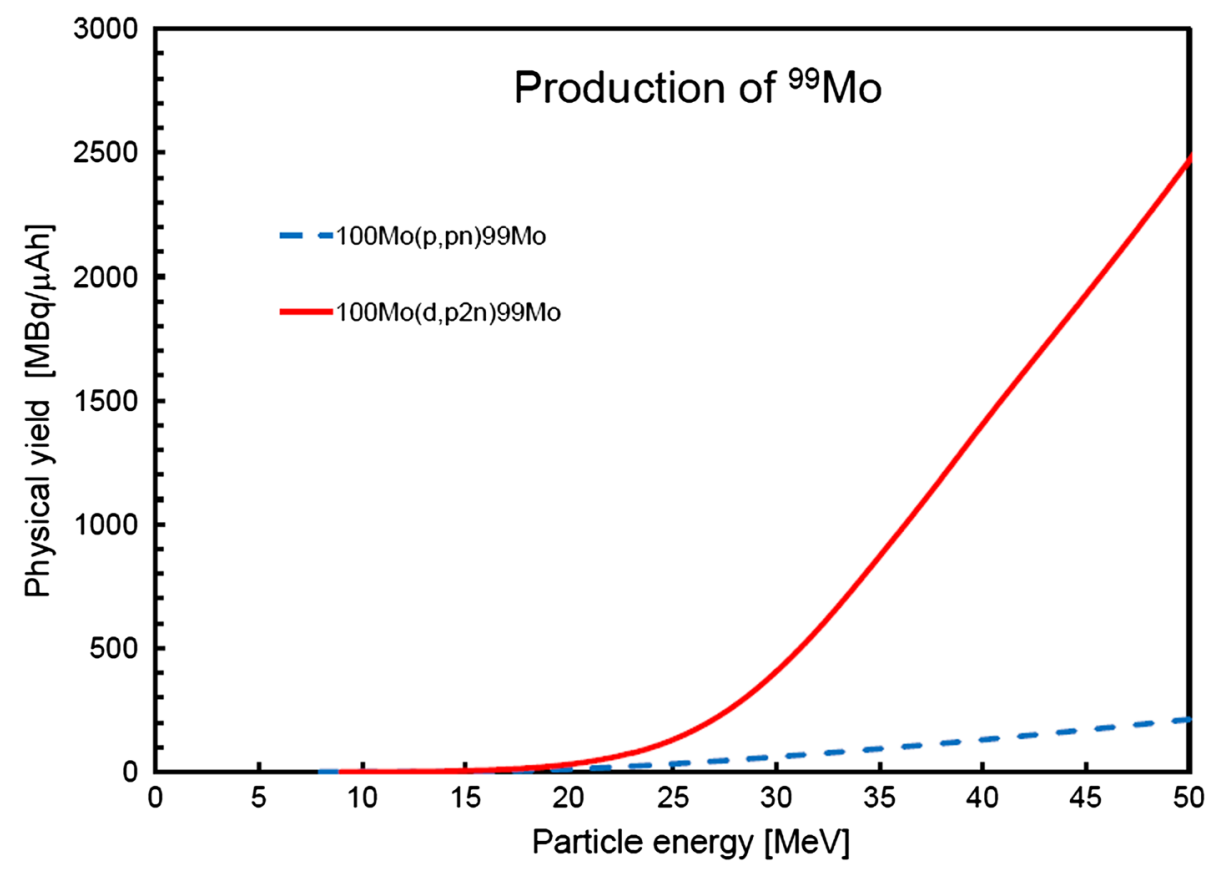

Fig. 22 Yields calculated from the recommended cross sections for the ${ }^{100} \operatorname{Mo}(p, 2 n){ }^{99 \mathrm{~m}} \mathrm{Tc}$ and ${ }^{100} \mathrm{Mo}(d, 3 n){ }^{99 \mathrm{~m}} \mathrm{Tc}$ reactions

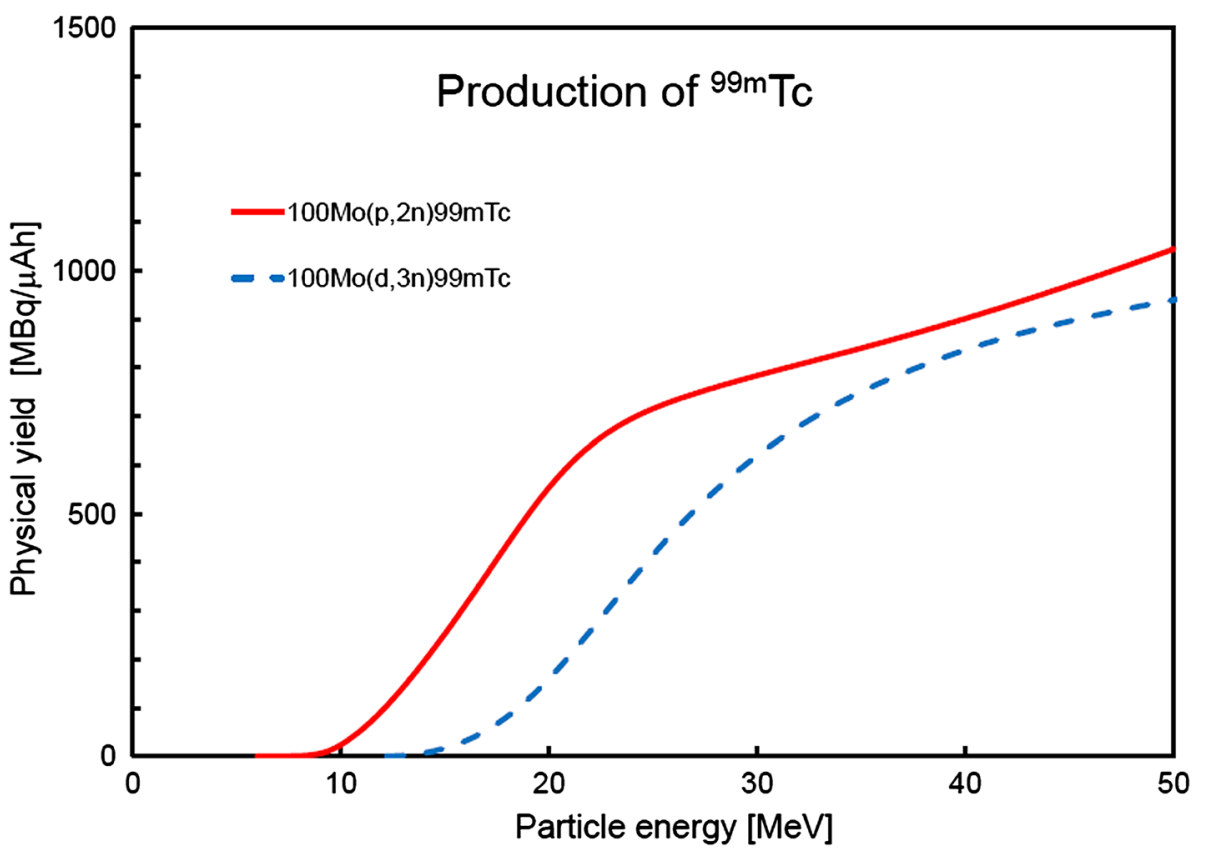

${ }^{1}$ E.g., see p.14 in A. Paterson et al (2015) J Radioanal Nucl Chem 305:13-22. 


\section{Reaction for the production of ${ }^{111} \ln \left(T_{1 / 2}=\right.$ 2.8047 d)}

Applications ${ }^{111}$ In is used for specialist diagnostic studies, such as the brain, colon transit, and infection. Also has been identified as a suitable candidate for radiotherapy.

\section{${ }^{112} \mathrm{Cd}(p, 2 n){ }^{111} \mathrm{In}$}

Nine experimental datasets were found in the literature for the ${ }^{112} \mathrm{Cd}(p, 2 n){ }^{111} \mathrm{In}$ reaction [104-112]. All data are shown in Fig. 23, and are compared with the TENDL-2015 and TENDL-2017 calculations. Only one dataset was rejected (Nieckarz and Caretto [105] (single data point above the chosen energy range of the fit)), and the remaining eight sets were used in the statistical fitting procedure. These selected datasets and their experimental uncertainties are shown in Fig. 24 together with the Padé fit $\left(L=9, N=100, \chi^{2}=1.46\right)$ and estimated uncertainties as percentages, including $4 \%$ systematic uncertainty (righthand scale).
Fig. 23 Nine experimental datasets for the ${ }^{112} \mathrm{Cd}(p, 2 n)^{111} \mathrm{In}$ reaction available in the literature [104-112], and the TENDL calculations

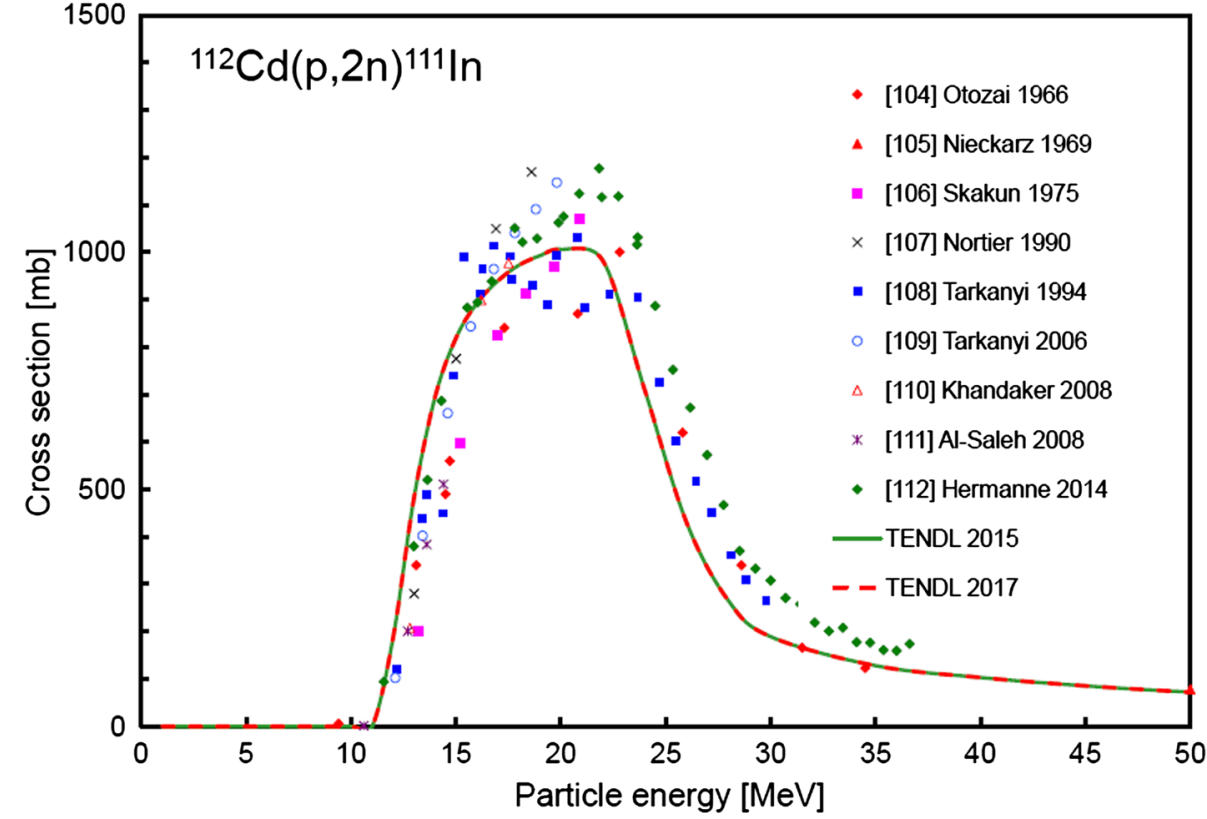

Fig. 24 Eight selected experimental datasets for the ${ }^{112} \mathrm{Cd}(p, 2 n)^{111}$ In reaction [104, 106-112] with the Padé fit $\left(L=9, N=100, \chi^{2}=1.46\right)$ and estimated uncertainties as percentages (dashed line, righthand scale)

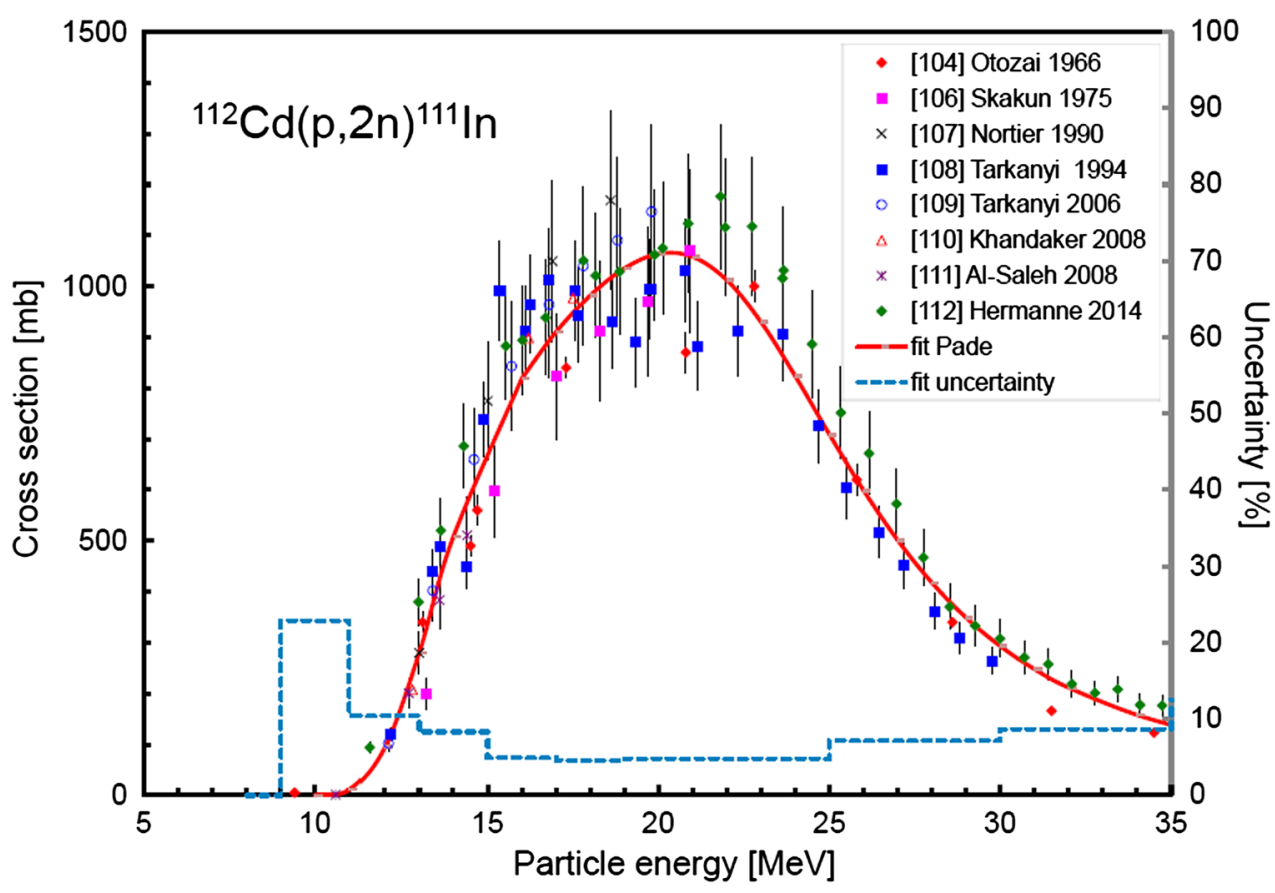




\section{Integral yield for ${ }^{111}$ In formation}

Integral yield for the ${ }^{112} \mathrm{Cd}(p, 2 n){ }^{111} \mathrm{In}$ reaction is shown in Fig. 25-used at present as a standard production route for commercially available $30-\mathrm{MeV}$ cyclotrons.

\section{Reactions for the production of ${ }^{123} I\left(T_{1 / 2}=\right.$ $13.2235 \mathrm{~h})$}

Applications ${ }^{123} \mathrm{I}$ is a standard radionuclide in the diagnosis of thyroid function and studies of the cardiac and nervous system. Complementary imaging has also been performed in conjunction with the emerging ${ }^{124} \mathrm{I} \beta^{+}$emitter, and for radiotherapy in conjunction with ${ }^{131} \mathrm{I} \beta^{-}$emitter.

Production routes for ${ }^{123} \mathrm{I}$ that employ tellurium and ${ }^{124} \mathrm{Xe}$ targets were evaluated as part of an earlier CRP $[2,3]$. Following on from these studies, re-evaluations have been made of a selection of nuclear reactions related to the production of ${ }^{123} \mathrm{I}$ precursors by proton-induced reactions on ${ }^{124} \mathrm{Xe}$ targets: ${ }^{124} \mathrm{Xe}(p, 2 n){ }^{123} \mathrm{Cs},{ }^{124} \mathrm{Xe}(p, p n){ }^{123} \mathrm{Xe}$, and ${ }^{124} \mathrm{Xe}(p, x){ }^{123} \mathrm{Xe}$. Furthermore, an assessment has also been made of the formation of ${ }^{121} \mathrm{I}$ impurity by means of the ${ }^{124} \mathrm{Xe}(p, x){ }^{121} \mathrm{I}$ reaction which limits the shelf-life of ${ }^{123} \mathrm{I}$.
Fig. 25 Yields calculated from the recommended cross sections for the ${ }^{112} \mathrm{Cd}(p, 2 n){ }^{111}$ In reaction

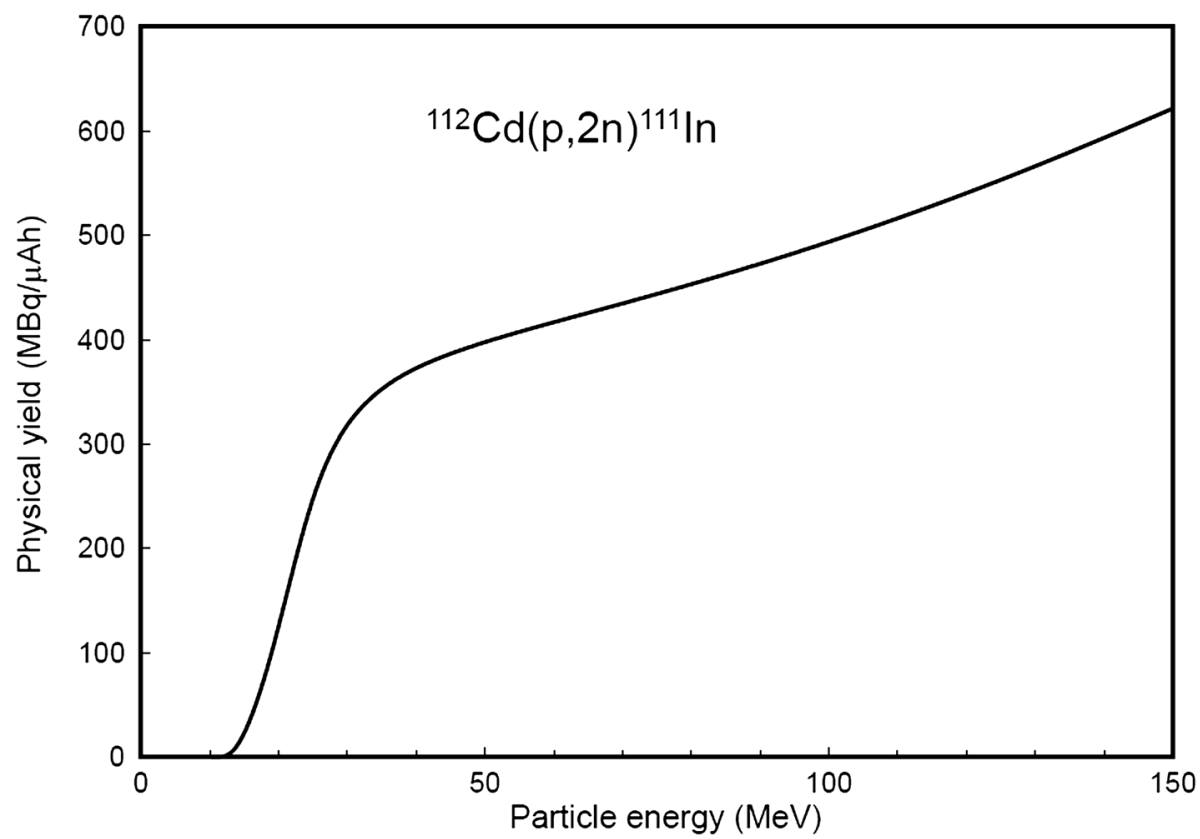




\section{${ }^{124} \mathrm{Xe}(p, 2 n){ }^{123} \mathrm{Cs}$}

Three experimental datasets were found in the literature for the ${ }^{124} \mathrm{Xe}(p, 2 n){ }^{123} \mathrm{Cs}$ reaction [113-115] that were all used in the statistical fitting procedure. All data are shown in Fig. 26, and are compared with the TENDL-2015 and TENDL-2017 calculations. These data and their experimental uncertainties are shown in Fig. 27 together with the Padé fit $\left(L=13, N=71, \chi^{2}=0.67\right)$ and estimated uncertainties as percentages, including $4 \%$ systematic uncertainty (right-hand scale).
Fig. 26 Three experimental datasets for the

${ }^{124} \mathrm{Xe}(p, 2 n){ }^{123} \mathrm{Cs}$ reaction available in the literature [113-115], and the TENDL calculations

Fig. 27 Three experimental datasets for the

${ }^{124} \mathrm{Xe}(p, 2 n){ }^{123} \mathrm{Cs}$ reaction [113-115] with the Padé fit $\left(L=13, N=71, \chi^{2}=0.67\right)$ and estimated uncertainties as percentages (dashed line, righthand scale)
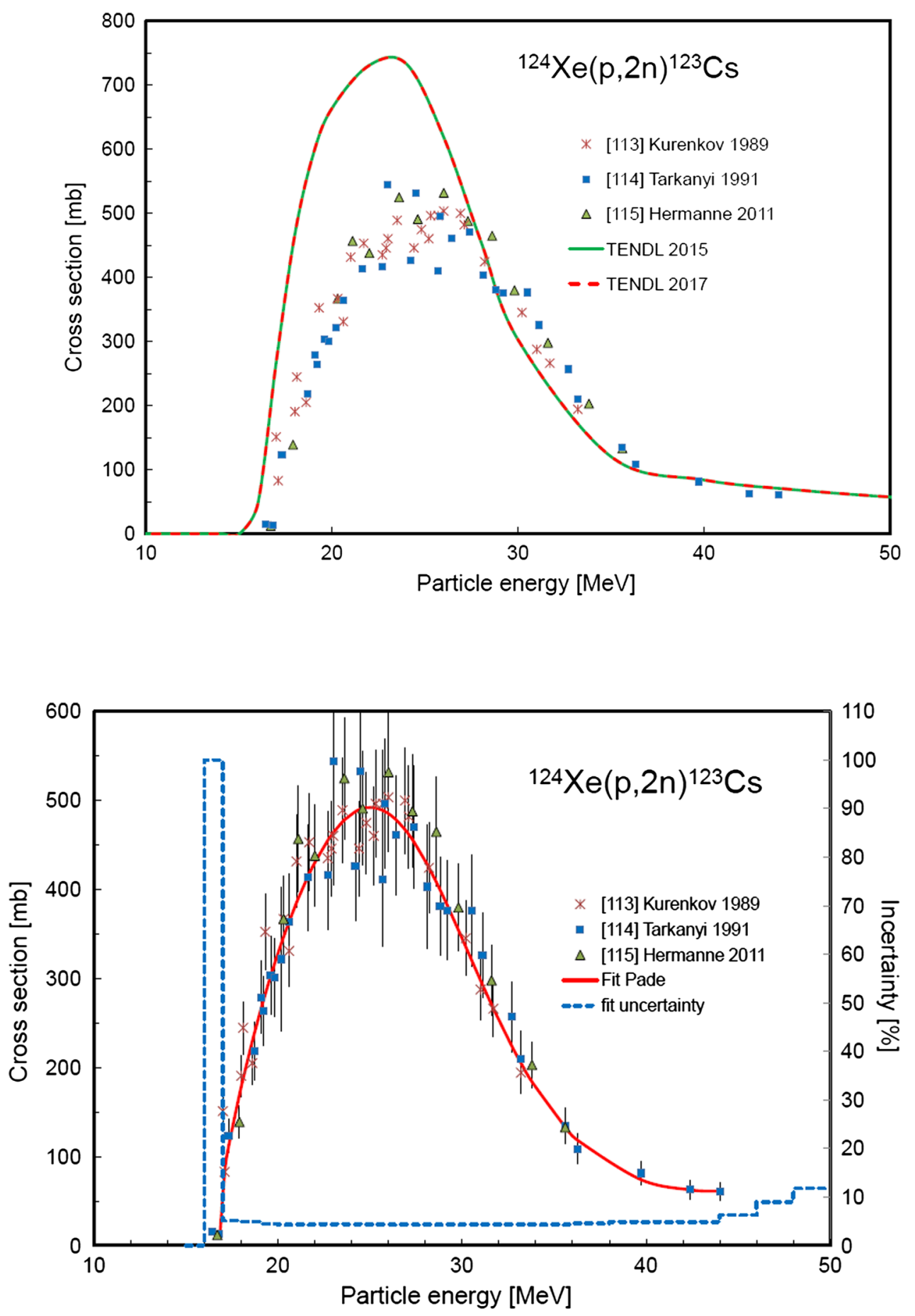


\section{${ }^{124} \mathrm{Xe}(p, p n){ }^{123} \mathrm{Xe}$}

Three experimental datasets were found in the literature for the direct ${ }^{124} \mathrm{Xe}(p, p n){ }^{123} \mathrm{Xe}$ reaction (Fig. 28) [113-115]. All data are shown in Fig. 28, and are compared with TENDL-2015 and TENDL $=2017$ calculations. The dataset of Tárkányi et al. [114] was rejected (values too low), and the remaining two sets were used in the statistical fitting procedure. These selected data and their experimental uncertainties are shown in Fig. 29 together with the Padé fit $\left(L=13, N=43, \chi^{2}=1.16\right)$ and estimated uncertainties as percentages, including $4 \%$ systematic uncertainty (right-hand scale).
Fig. 28 Three experimental datasets for the

${ }^{124} \mathrm{Xe}(p, p n){ }^{123} \mathrm{Xe}$ reaction available in the literature [113-115], and the TENDL calculations

Fig. 29 Two selected experimental datasets for the ${ }^{124} \mathrm{Xe}(p, p n){ }^{123} \mathrm{Xe}$ reaction $[113,115]$ with the Padé fit $\left(L=13, N=43, \chi^{2}=1.16\right)$ and estimated uncertainties as percentages (dashed line, righthand scale)
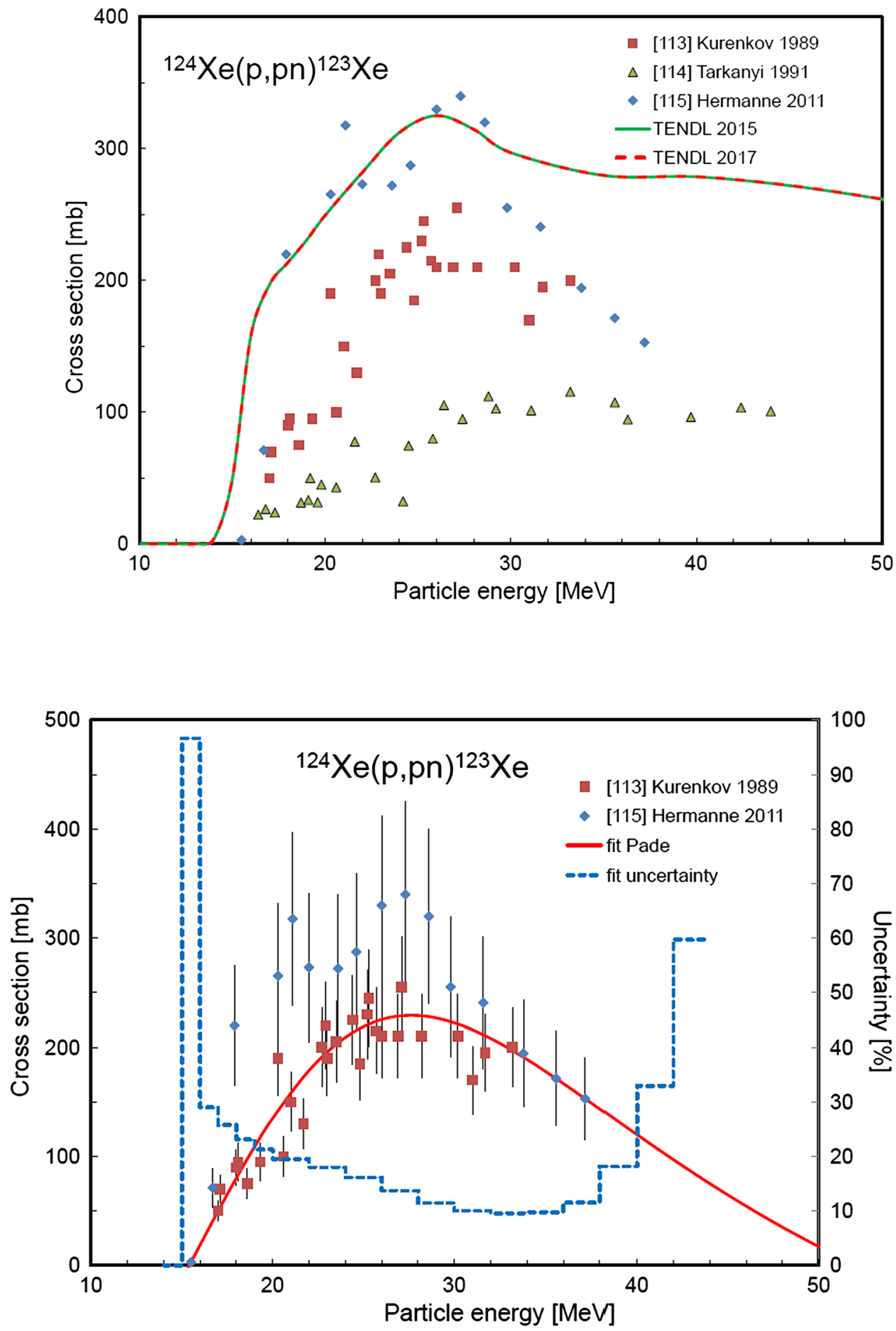


\section{${ }^{124} \mathrm{Xe}(p, x){ }^{123} \mathrm{Xe}$}

Three experimental datasets were found in the literature for this means of cumulative formation, including the decay of short-lived ${ }^{123} \mathrm{Xe}$ parent [113-115]. All data are shown in Fig. 30, and are compared with the TENDL-2015 and TENDL-2017 calculations. The dataset of Tárkányi et al. [114] was rejected (values too low), and the remaining two sets were used in the statistical fitting procedure. These selected data and their experimental uncertainties are shown in Fig. 31 together with the Padé fit $(L=16$, $\left.N=44, \chi^{2}=1.00\right)$ and estimated uncertainties as percentages, including $4 \%$ systematic uncertainty (right-hand scale).
Fig. 30 Three experimental datasets for the ${ }^{124} \mathrm{Xe}(p, x)^{123} \mathrm{Xe}$ reaction available in the literature [113-115], and the TENDL calculations

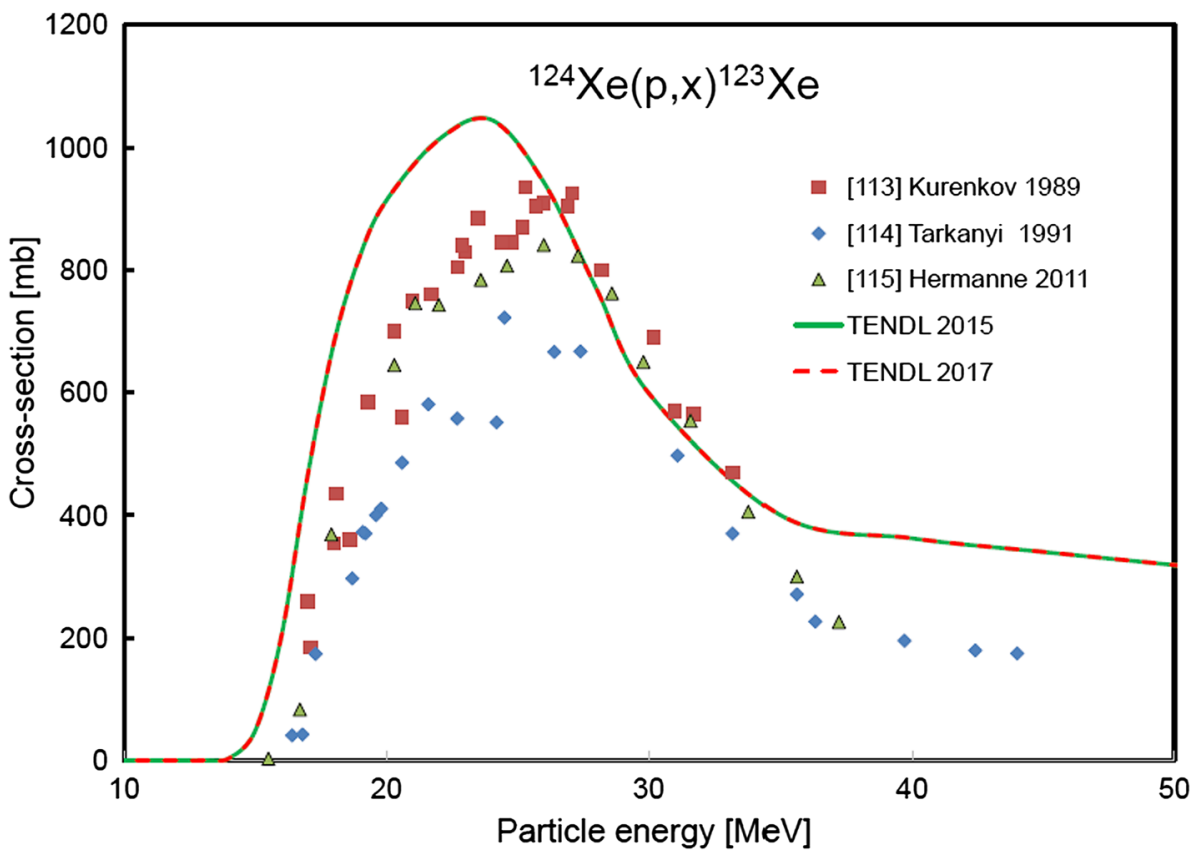

Fig. 31 Two selected experimental datasets for the ${ }^{124} \mathrm{Xe}(p, x){ }^{123} \mathrm{Xe}$ reaction $[113,115]$ with the Padé fit $\left(L=16, N=44, \chi^{2}=1.00\right)$ and estimated uncertainties as percentages (dashed line, righthand scale)

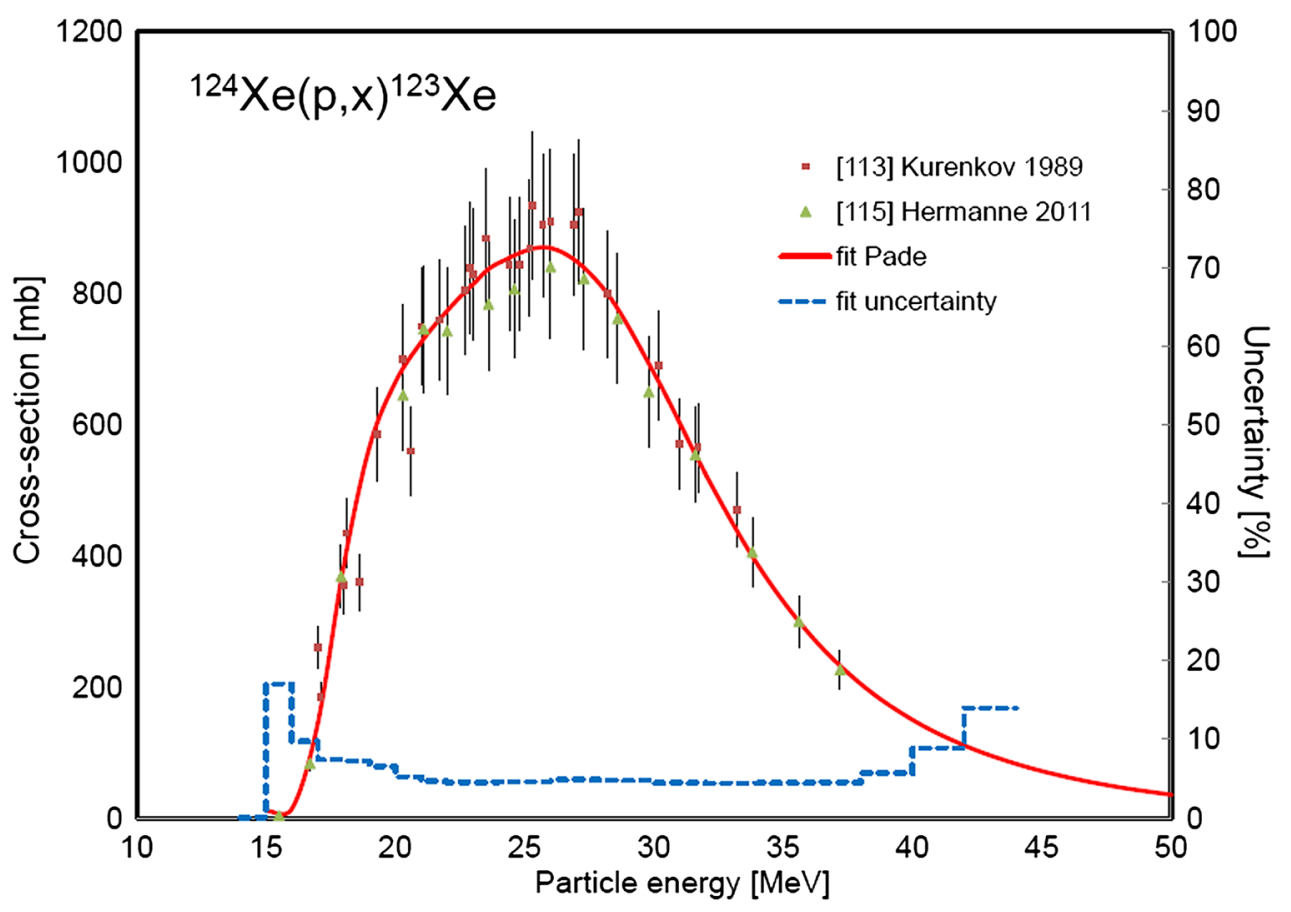




\section{${ }^{124} \mathrm{Xe}(p, x){ }^{121}$ I (reaction for generation of ${ }^{121} \mid$ impurity)}

Unavoidable contamination of ${ }^{123} \mathrm{I}$ by ${ }^{121} \mathrm{I}\left(\mathrm{T}_{1 / 2}=2.12 \mathrm{~h}\right.$, daughter product of co-produced ${ }^{121} \mathrm{Cs}^{-121} \mathrm{Xe}$ that decays to long-lived ${ }^{121} \mathrm{Te}$ ) by means of the reaction processes discussed above limits the shelf-life of batches of ${ }^{123} \mathrm{I}$ [115].

Fig. 32 Two experimental datasets for the ${ }^{124} \mathrm{Xe}(p, x)^{121} \mathrm{I}$ reaction available in the literature $[114,115]$, and the TENDL calculations

Fig. 33 Two experimental datasets for the ${ }^{124} \mathrm{Xe}(p, x)^{121} \mathrm{I}$ reaction $[114,115]$ with the Padé fit $(L=18, N=24$, $\left.\chi^{2}=1.21\right)$ and estimated uncertainties as percentages (dashed line, right-hand scale)
Two datasets were found in the literature [114, 115]. All data are shown in Fig. 32, and are compared with TENDL2015 and TENDL-2017 calculations. Both sets of data and their experimental uncertainties were used in the statistical fitting procedure as shown in Fig. 33 together with the Padé fit $\left(L=18, N=24, \chi^{2}=1.21\right)$ and estimated uncertainties as percentages, including $4 \%$ systematic uncertainty (right-hand scale).
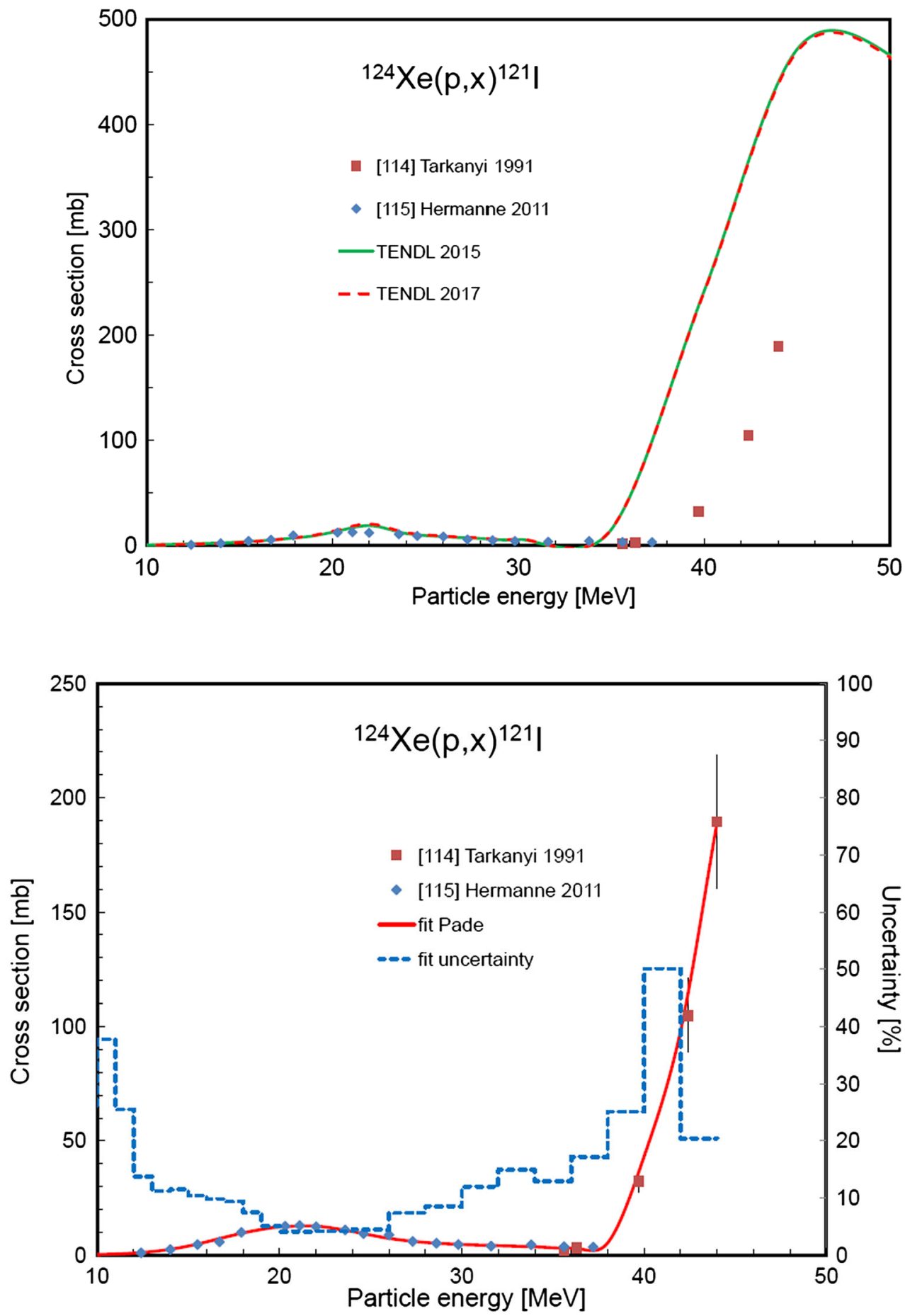
Integral yields for ${ }^{123} \mathrm{Cs}-{ }^{123} \mathrm{Xe}$ (grandparent and parent of ${ }^{123} \mathrm{I}$ ) and ${ }^{121} \mathrm{I}$ impurity formation

Integral yields related to the production of ${ }^{123} \mathrm{I}$ deduced from the fits in Figs. 27, 29, 31 and 33 are shown in

Figs. 34, 35 and 36.

Fig. 34 Yields calculated from the recommended cross sections for the ${ }^{124} \mathrm{Xe}(p, 2 n){ }^{123} \mathrm{Cs}$ reaction

Fig. 35 Yields calculated from the recommended cross sections for the ${ }^{124} \mathrm{Xe}(p, p n){ }^{123} \mathrm{Xe}$ and ${ }^{124} \mathrm{Xe}(p, x){ }^{123} \mathrm{Xe}$ reactions
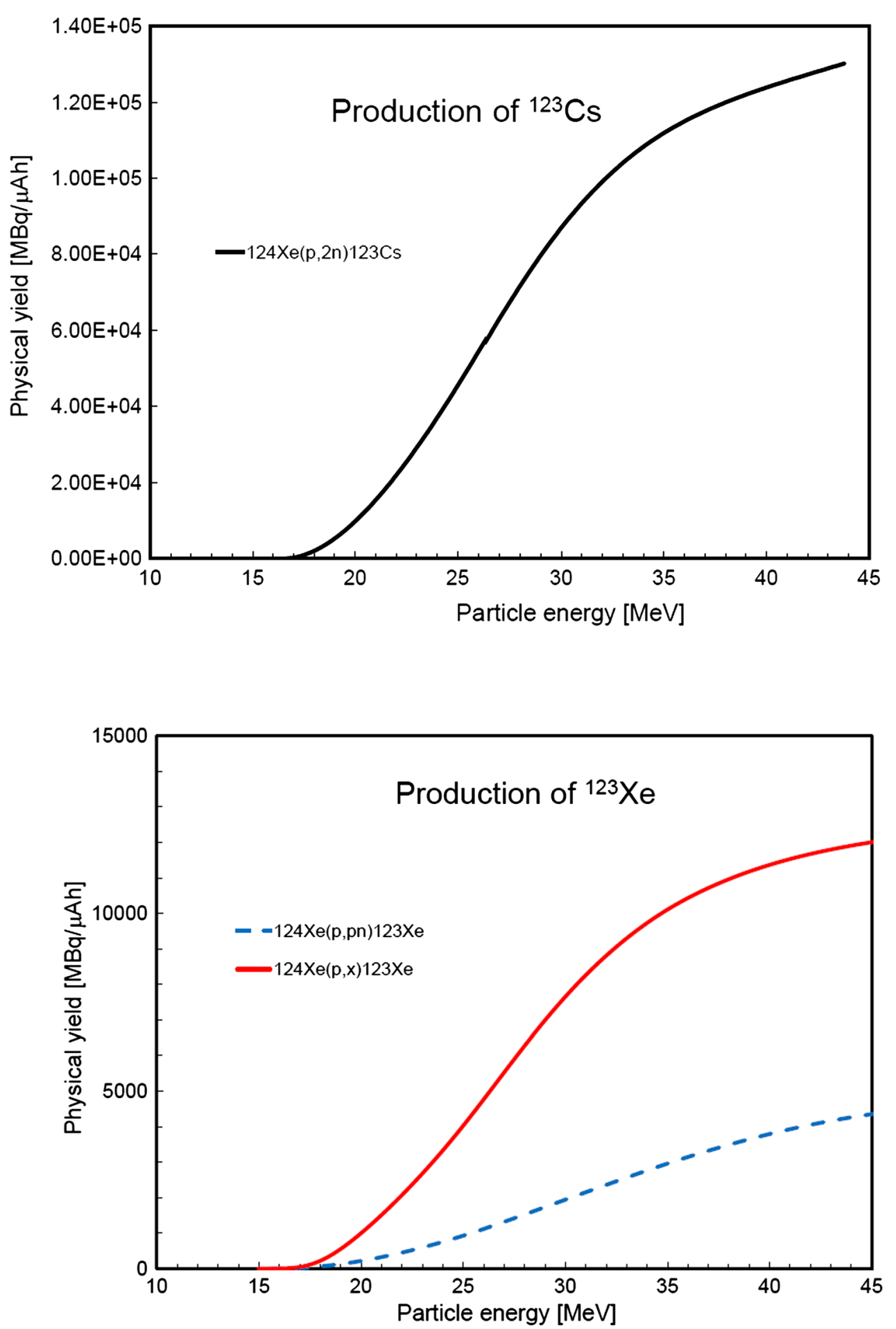
Fig. 36 Yields calculated from the recommended cross sections for the ${ }^{124} \mathrm{Xe}(p, x){ }^{121} \mathrm{I}$ reaction

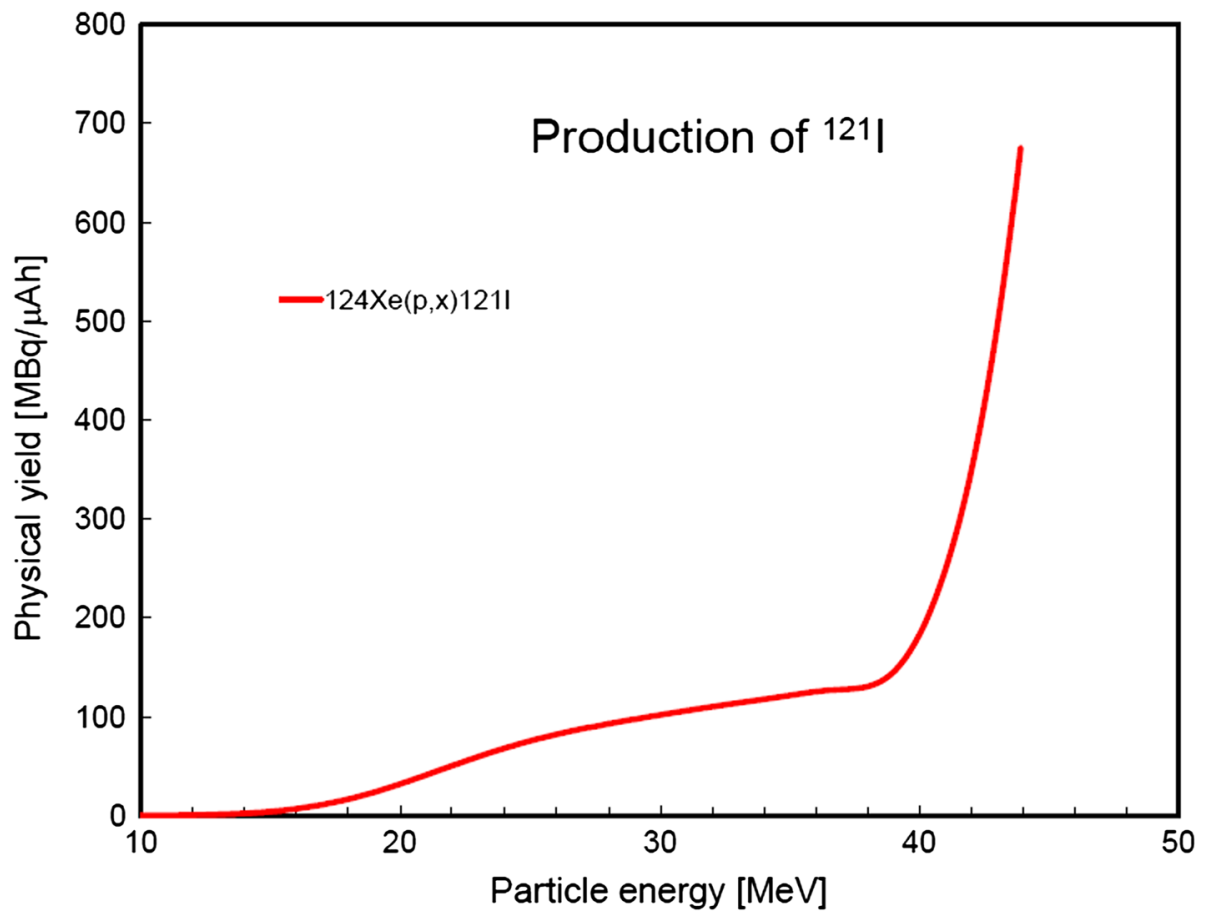

\section{Reactions for the production of ${ }^{201} \mathrm{TI}\left(\mathrm{T}_{1 / 2}=\right.$ $3.0421 \mathrm{~d})$}

Applications ${ }^{201} \mathrm{Tl}$ has been used for the diagnosis of coronary artery disease, myocardial infarct and heart muscle death, and to locate low-grade lymphomas.

Present commercial production is through the $\mathrm{EC} / \beta^{+}$ decay of parent ${ }^{201} \mathrm{~Pb}$ obtained by means of the
${ }^{203} \mathrm{Tl}(p, 3 n){ }^{201} \mathrm{~Pb}$ reaction (adoption of $95 \%$ enriched ${ }^{203} \mathrm{Tl}$ targets) and double $\mathrm{Tl}-\mathrm{Pb}$ separation chemistry. Quantitative knowledge of the unavoidable and simultaneous production of ${ }^{200} \mathrm{~Pb}$ and ${ }^{202 \mathrm{~m}} \mathrm{~Pb}$ via the ${ }^{203} \mathrm{Tl}(p, 4 n)^{200} \mathrm{~Pb}$ and ${ }^{203} \mathrm{Tl}(p, 2 n){ }^{202 \mathrm{~m}} \mathrm{~Pb}$ reactions is important from the point of view of radionuclidic purity (limits defined in pharmacopoeia). 


\section{${ }^{203} \mathrm{TI}(p, 3 n){ }^{201} \mathrm{~Pb}$}

Eleven experimental datasets were found in the literature that exhibit contradictory results [116-124]. Both Refs. $[121,124]$ contain two datasets labelled as (a) and (b). All data are shown in Fig. 37, and are compared with the TENDL-2015 and TENDL-2017 calculations. Five datasets were rejected [Sakai et al. [116] (energy shift), Lebowitz et al. [117] (values too low), Blue et al. [119] (values too low), Qaim et al. [120] (values too low), and Bonardi et al. (b) [121] (values too low)], while the remaining six datasets were used in the statistical fitting procedure. These selected data and their experimental uncertainties are shown in Fig. 38 together with the Padé fit $(L=13$, $\left.N=178, \chi^{2}=1.67\right)$ and estimated uncertainties as percentages, including $4 \%$ systematic uncertainty (right-hand scale).
Fig. 37 Eleven experimental datasets for the ${ }^{203} \mathrm{Tl}(p, 3 n)^{201} \mathrm{~Pb}$ reaction available in the literature [116-124], and the TENDL calculations. Both Refs. [121, 124] contain two datasets denoted as (a) and (b)

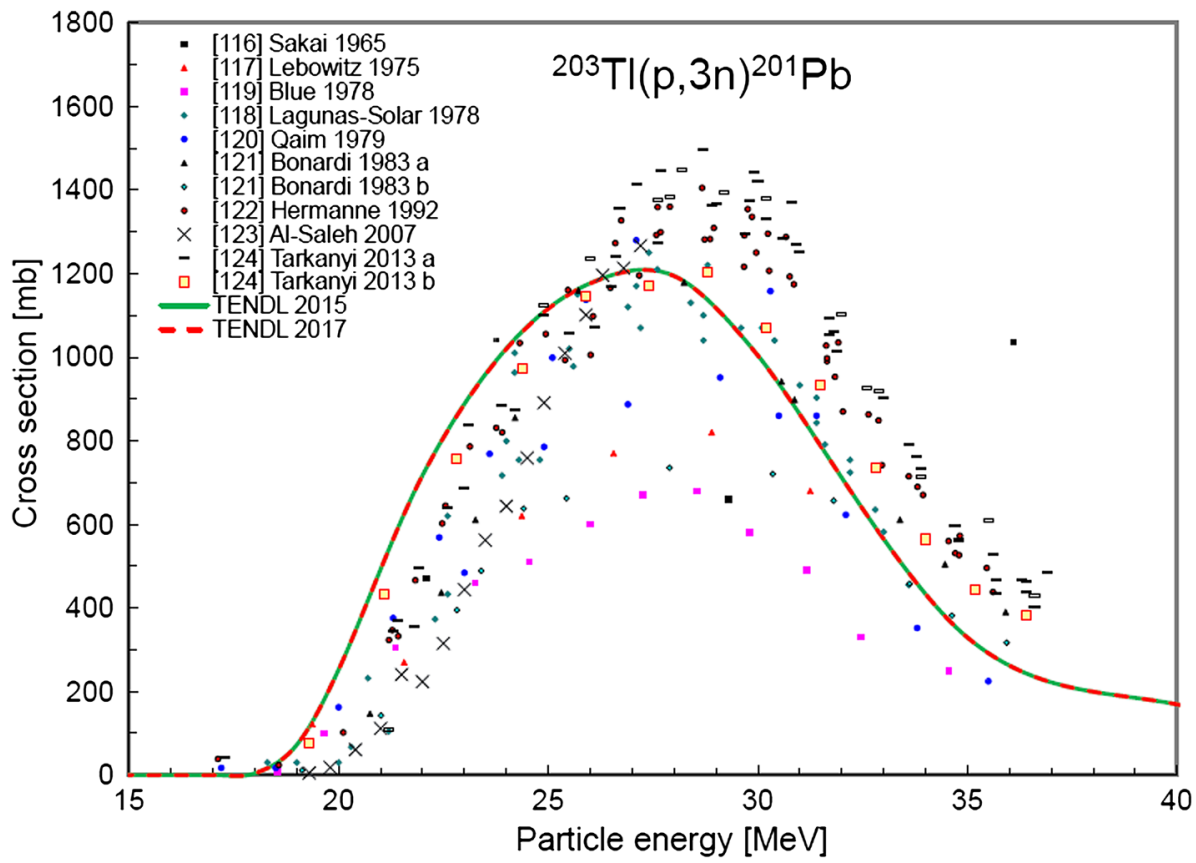

Fig. 38 Six selected experimental datasets for the ${ }^{203} \mathrm{Tl}(p, 3 n){ }^{201} \mathrm{~Pb}$ reaction $[118,121(\mathrm{a})$, $122,123,124(\mathrm{a})$ and (b)] with the Padé fit $(L=13, N=178$, $\left.\chi^{2}=1.67\right)$ and estimated uncertainties as percentages (dashed line, right-hand scale)

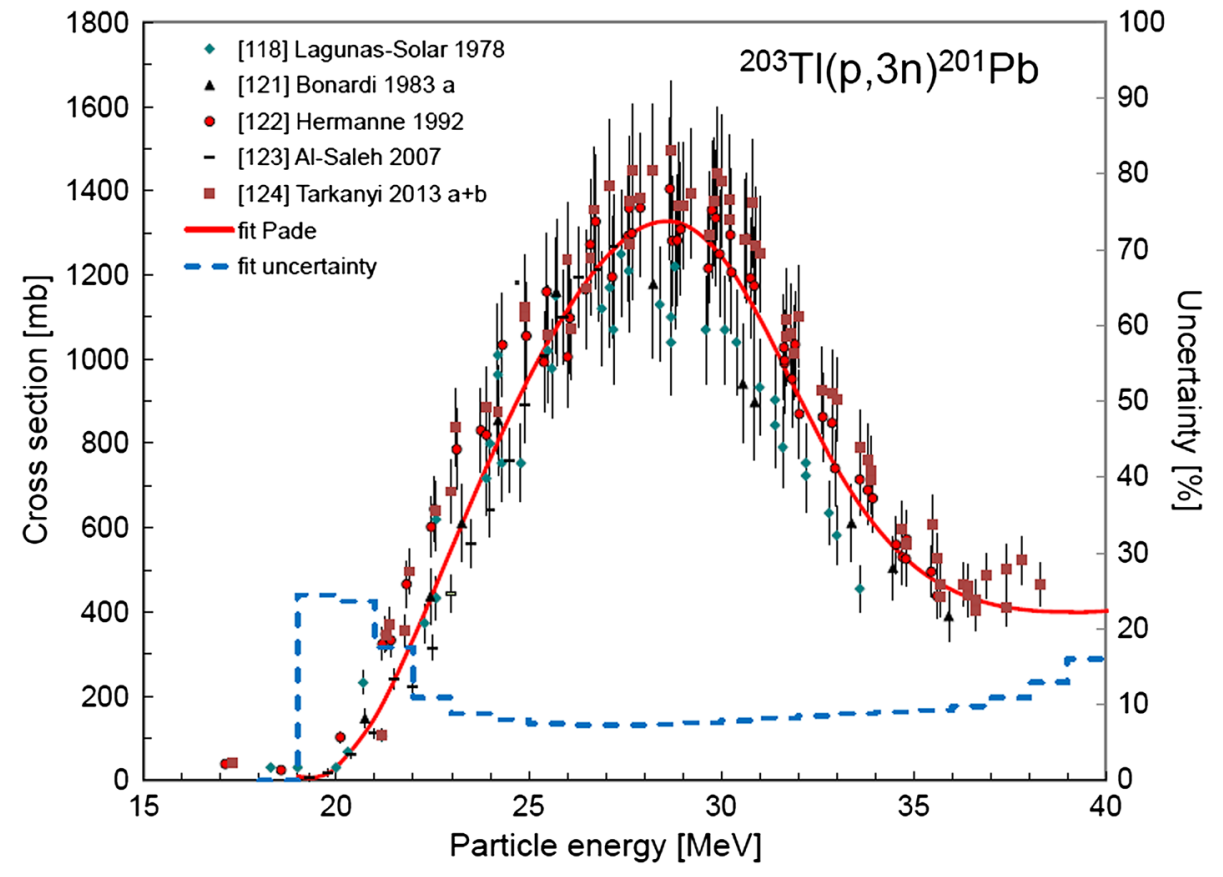




\section{${ }^{203} \mathrm{TI}(p, 4 n){ }^{200} \mathrm{~Pb}$ (impurity reaction)}

Seven experimental datasets were found in the literature [116, 118-122, 124]. All data are shown in Fig. 39, and are compared with the TENDL-2015 and TENDL-2017 calculations. Only one dataset was rejected [Sakai et al. [116] (discrepant values)], while the remaining six datasets were used in the statistical fitting procedure. These selected data and their experimental uncertainties are shown in Fig. 40 together with the Padé fit $\left(L=5, N=124, \chi^{2}=2.01\right)$ and estimated uncertainties as percentages, including $4 \%$ systematic uncertainty (right-hand scale).
Fig. 39 Seven experimental datasets for the ${ }^{203} \mathrm{Tl}(p, 4 n)^{200} \mathrm{~Pb}$ reaction available in the literature [116, 118-122, 124], and the TENDL calculations
Fig. 40 Six selected experimental datasets for the ${ }^{203} \mathrm{Tl}(p, 4 n){ }^{200} \mathrm{~Pb}$ reaction $[118-122,124]$ with the Padé fit $\left(L=5, N=124, \chi^{2}=2.01\right)$ and estimated uncertainties as percentages (dashed line, righthand scale)
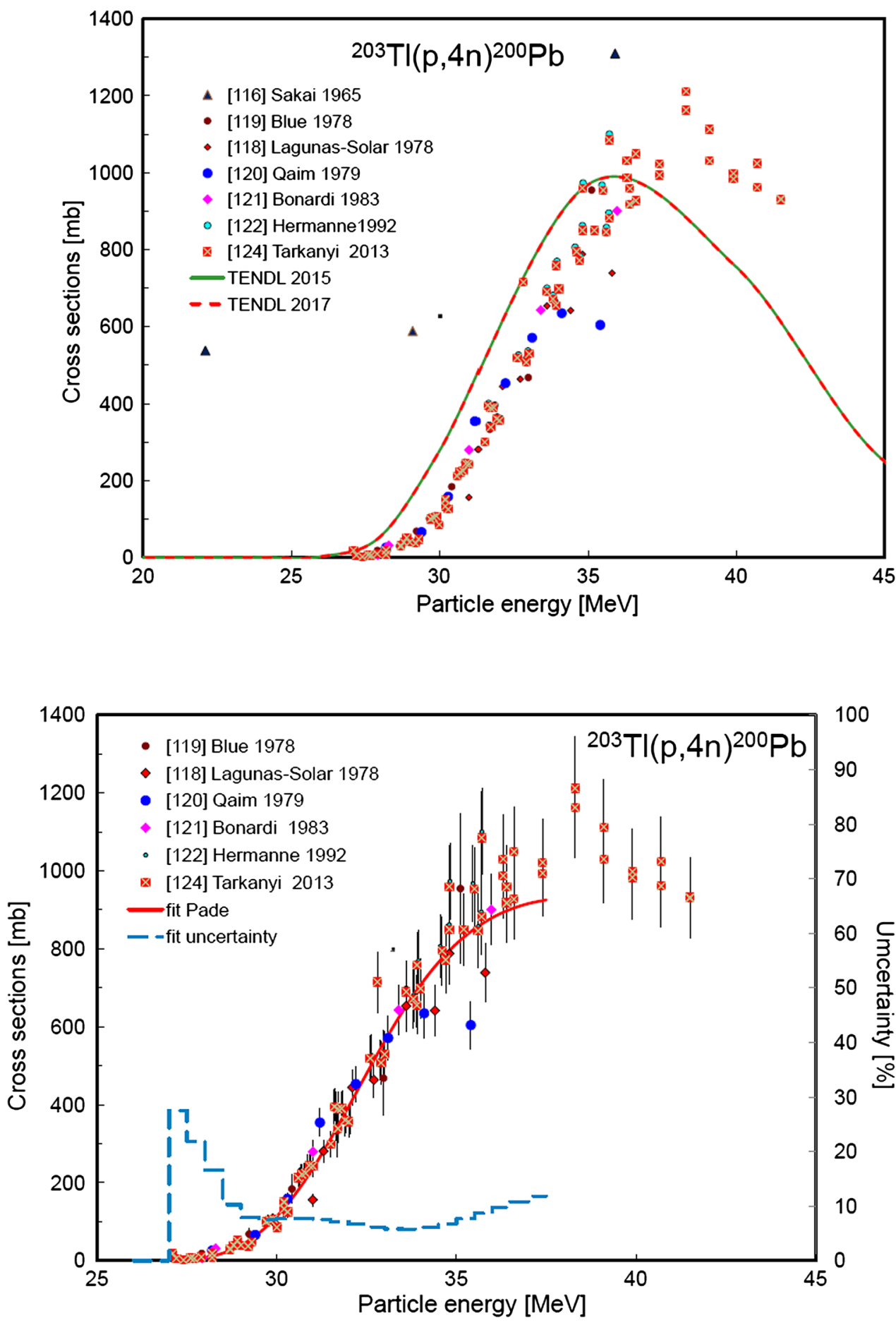


\section{${ }^{203} \mathrm{TI}(p, 2 n){ }^{202 \mathrm{~m}} \mathrm{~Pb}$ (impurity reaction)}

Six experimental datasets were found in the literature [118, 120-124]. All data are shown in Fig. 41, and are compared with the TENDL-2015 and TENDL-2017 calculations. Three datasets were rejected [Lagunas-Solar et al. [118], Bonardi et al. [121], and Al-Saleh et al. [123] (all values too low)], and the remaining three datasets were used in the statistical fitting procedure. These selected data and their experimental uncertainties are shown in Fig. 42 together with the Padé fit $\left(L=9, N=18, \chi^{2}=1.87\right)$ and estimated uncertainties as percentages, including $4 \%$ systematic uncertainty (right-hand scale).
Fig. 41 Six experimental datasets for the ${ }^{203} \mathrm{Tl}(p, 2 n){ }^{202 \mathrm{~m}} \mathrm{~Pb}$ reaction available in the literature [118, 120-124], and the TENDL calculations

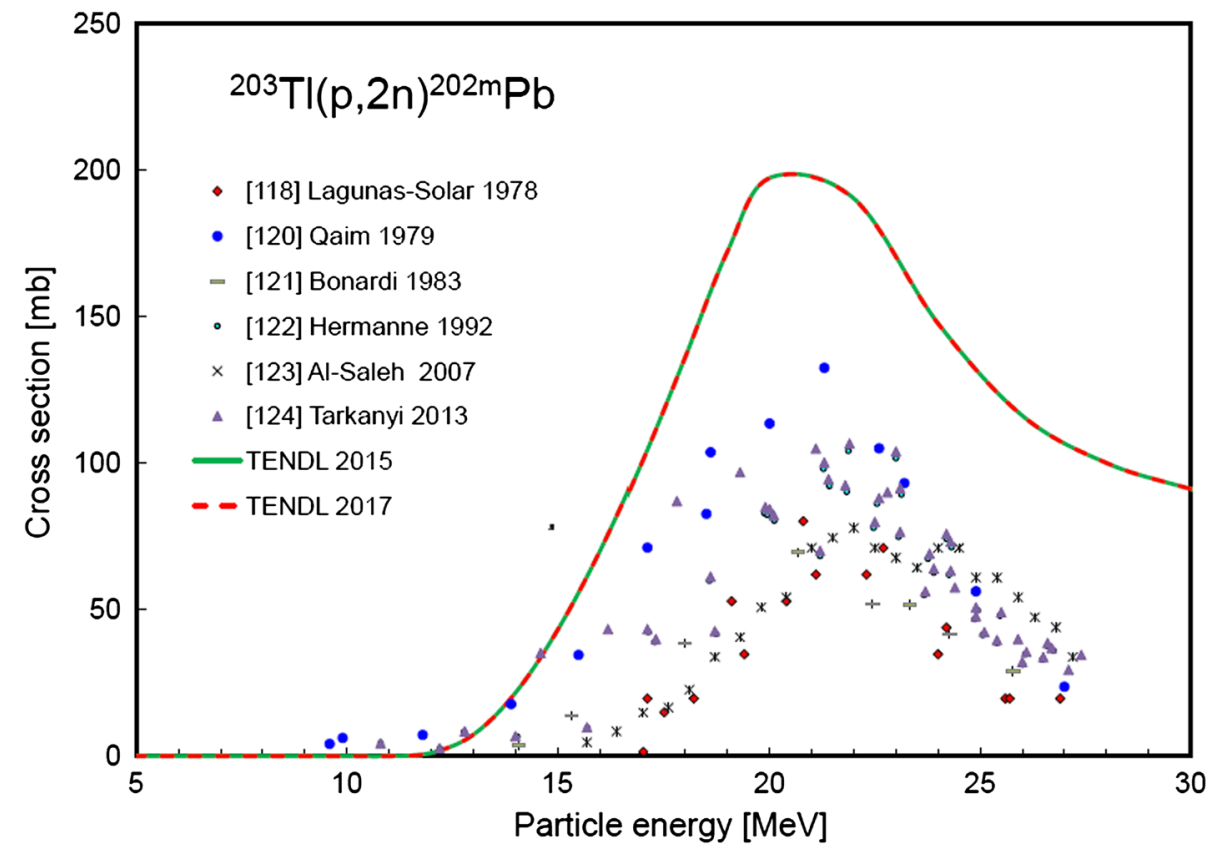

Fig. 42 Three selected experimental datasets for the ${ }^{203} \mathrm{Tl}(p, 2 n)^{202 \mathrm{~m}} \mathrm{~Pb}$ reaction $[120,122,124]$ with the Padé fit $\left(L=9, N=18, \chi^{2}=1.87\right)$ and estimated uncertainties as percentages (dashed line, righthand scale)

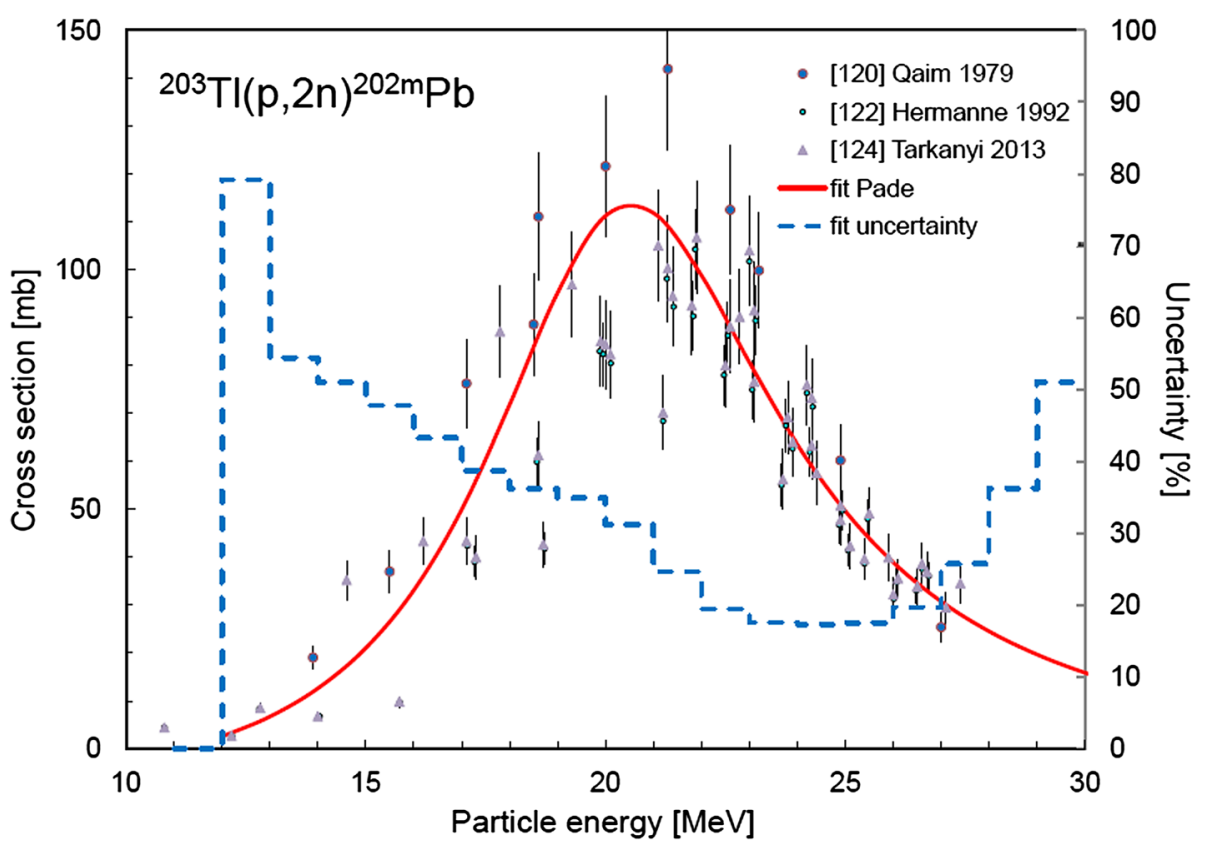




\section{Integral yields for ${ }^{201} \mathrm{Tl}$ formation}

Integral yields of reactions related to the production of ${ }^{201} \mathrm{Tl}$ and deduced from the data fittings in Figs. 38, 40 and 42 are shown in Fig. 43.

\section{${ }^{99 m}$ Tc and parent ${ }^{99}$ Mo: photon-induced and neutron-induced reactions}

Consideration was given to various non-charged-particle reactions for the production of parent ${ }^{99} \mathrm{Mo}$ to generate ${ }^{99 \mathrm{~m}} \mathrm{Tc}$, which involved the irradiation of particular molybdenum targets with photons or neutrons as well as the ${ }^{238} \mathrm{U}(\gamma, f)$ reaction.

${ }^{100} \mathrm{Mo}(\gamma, n){ }^{99} \mathrm{Mo}$

Only three experimental datasets were found in the literature, and are shown in Fig. 44 [125-127]. These datasets have also been compared with recent evaluations contained within the TENDL-2017 [10] and ENDF/B-VII.1 [128] libraries. Measurements by Ejiri et al. [126] at a gammaray energy of approximately $14.5 \mathrm{MeV}$ were performed with bremsstrahlung spectrum, and such conditions differ significantly from the other two studies carried out with
Fig. 43 Yields calculated from the recommended cross sections

${ }^{203} \mathrm{Tl}(p, 4 n){ }^{200} \mathrm{~Pb}$ and

${ }^{203} \mathrm{Tl}(p, 2 n){ }^{202 \mathrm{~m}} \mathrm{~Pb}$ reactions for the ${ }^{203} \mathrm{Tl}(p, 3 n){ }^{201} \mathrm{~Pb}$,

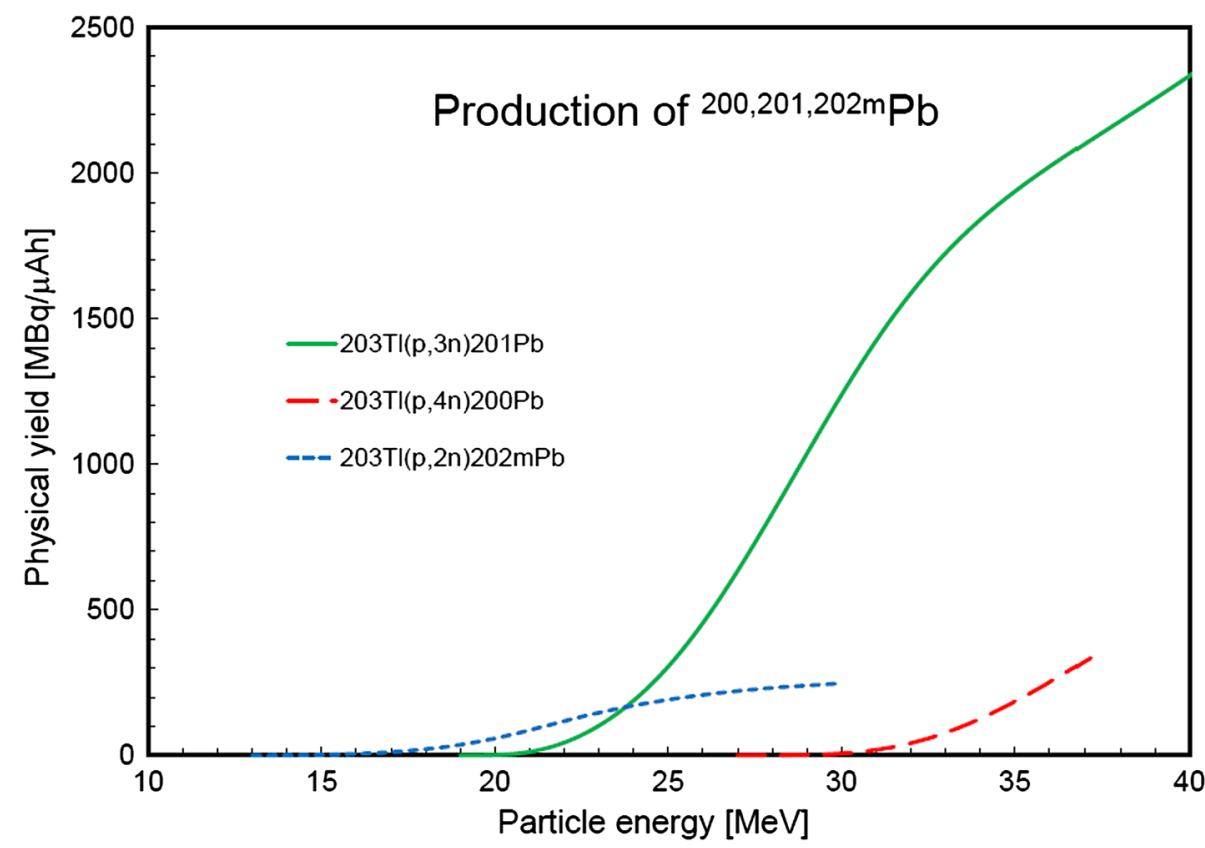

Fig. 44 Three experimental datasets for the ${ }^{100} \mathrm{Mo}(\gamma, n){ }^{99} \mathrm{Mo}$ reaction available in the literature [125-127], compared with evaluations in the TENDL2017 and ENDF/B-VII.1 libraries

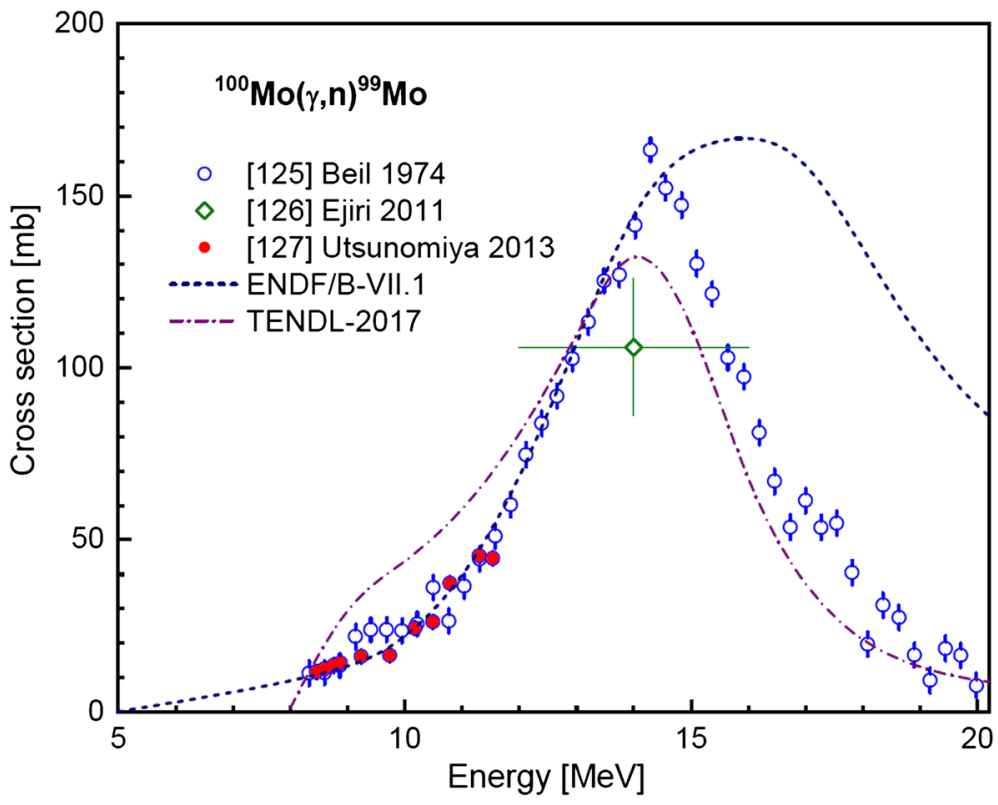


monoenergetic gamma rays $[125,127]$. Both sets of selected data and their experimental uncertainties are shown in Fig. 45 [125, 127] together with the Padé fit ( $\left.L=9, N=55, \chi^{2}=1.84\right)$ and estimated uncertainties as percentages, including $4 \%$ systematic uncertainty (righthand scale).

\section{${ }^{98} \mathrm{Mo}(n, \gamma){ }^{99} \mathrm{Mo}$}

Twenty-seven experimental datasets were found in the literature [129-155], and are shown in Fig. 46 together with the TENDL-2017 evaluation. Seven sets of these data relate to cross-section measurements for thermal neutrons [129-135], and individual data points coincide within their ranges of uncertainties (assigned the same symbol in Fig. 46 because of their overlap). Another group of nine
Fig. 45 Two selected experimental datasets for the ${ }^{100} \mathrm{Mo}(\gamma, n){ }^{99}$ Mo reaction $[125,127]$ with the Padé fit $\left(L=9, N=55, \chi^{2}=1.84\right)$ and estimated uncertainties as percentages (dashed line, righthand scale)
Fig. 46 Experimental datasets for the ${ }^{98} \operatorname{Mo}(n, \gamma){ }^{99}$ Mo reaction available in the literature [129-155], and the 75-group evaluation of TENDL-2017 [10]
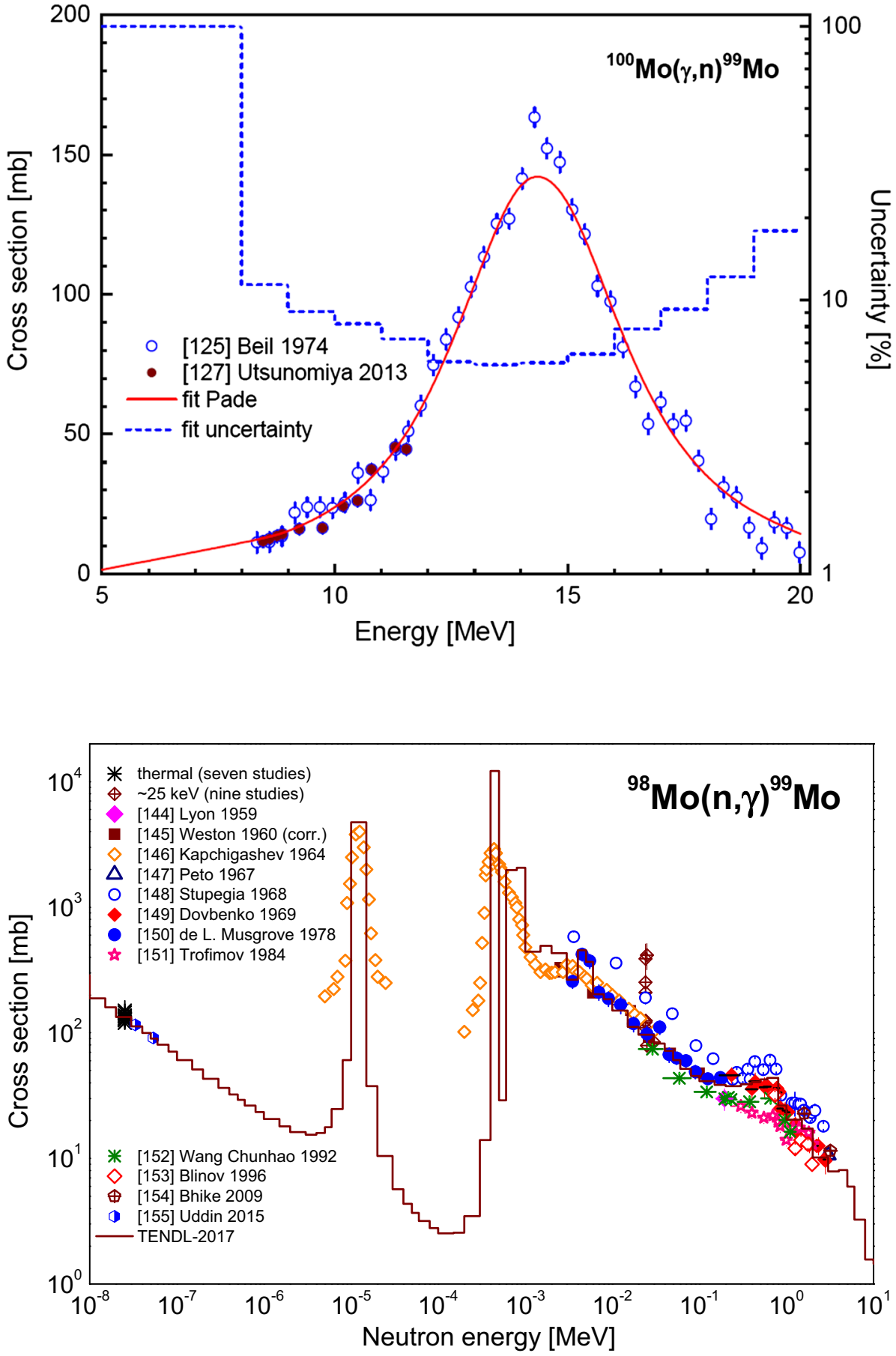
data points at a beam energy of approximately $25 \mathrm{keV}$ relates to measurements in which Po-Be neutron sources were used [132, 136-143], and they are also denoted by a common symbol because of their significant overlap. A set of seven data points measured by Weston et al. [145] over neutron energies from 2 to $100 \mathrm{keV}$ were corrected (corr.) in accord with changes in the monitor reaction cross sections, although only some of them are visible within Fig. 46 owing to the surrounding high density of data.

Neutron cross sections at low energies possess resonance structure, an example of which is shown in Fig. 46 at an energy of $\sim 12 \mathrm{eV}$ as observed in a neutron capture experiment [146]. The number of resonances increases significantly with increasing energy, particularly over the neutron energy interval up to $10 \mathrm{keV}$ as measured by Musgrove et al. [150]. Group representations of overlapping resonances in the form of averaged cross sections are usually adopted in such circumstances, and the TENDL2017 definition of this particular neutron-capture cross section is shown in Fig. 46 as a 75-group assembly [10]. This TENDL-2017 evaluation below $100 \mathrm{keV}$ coincides closely with the ENDF/B-VII.1 [128], JEFF-3.2 [156], JENDL-4.0 [157], and BROND-3.1 [158] national and international neutron data libraries, whereby the same resonance parameters have often been used [159].

Reference [146] data were only adopted for neutron energies above $3 \mathrm{keV}$ on the basis of their reasonable agreement with the high-resolution data. Eight datasets were rejected because they contradict the main trends of all other data [136-138, 140-143, 148]. A thermal neutron cross section of $(130 \pm 6) \mathrm{mb}$ was adopted, as recommended by Mughabghab [159] on the basis of a consistent analysis of the experimental data and the resonance parameters. This value is also well supported by epithermal neutron data [155].

All selected datasets are shown in Fig. 47 together with the BROND-3.1 evaluation [158]: BROND-3.1 and TENDL-2017 differ only in the energy region above $100 \mathrm{keV}$. Both sets of statistical model calculations are important for a consistent description of the abrupt decrease of the capture cross section immediately above the threshold for neutron inelastic scattering $(\sim 787 \mathrm{keV}$ for ${ }^{98} \mathrm{Mo}$ ).

Complete consideration of the complex resonance structure of the evaluated data is not required to estimate the uncertainties of the recommended cross sections. Sufficient information can normally be gleaned from the uncertainties of the multi-group cross sections to achieve this objective. Such an approach is described in detail in Ref. [158], and these estimated uncertainties for the ${ }^{98} \mathrm{Mo}(n, \gamma){ }^{99} \mathrm{Mo}$ reaction are shown in Fig. 47 (right-hand scale).
Fig. 47 Selected experimental datasets for the ${ }^{98} \mathrm{Mo}(n, \gamma){ }^{99} \mathrm{Mo}$ reaction compared with BROND-3.1 calculations and evaluation, and estimated uncertainties as percentages (dashed line, right-hand scale)

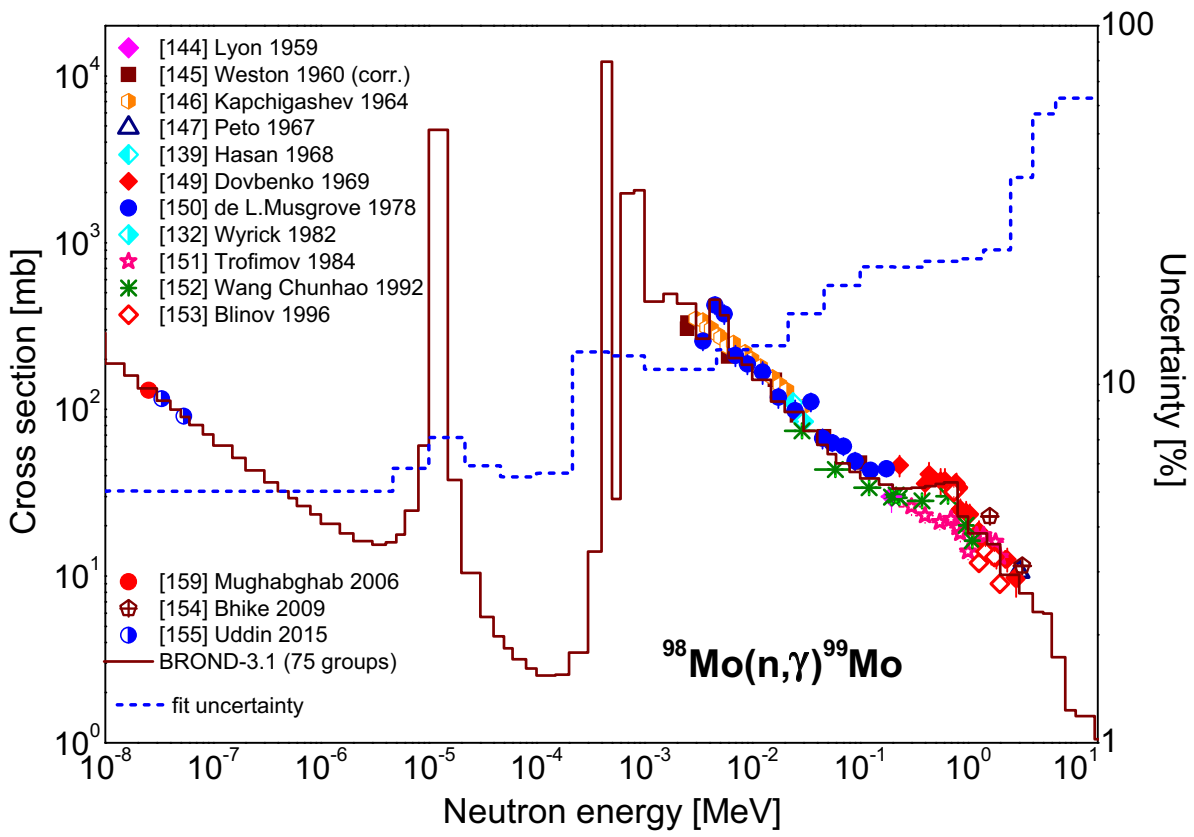




\section{${ }^{100} \mathrm{Mo}(n, 2 n){ }^{99} \mathrm{Mo}$}

Twenty-five experimental datasets were found in the literature [160-182]. Ikeda et al. [177] contains three versions of the data measured on the basis of different beam-monitor reactions, and these are labelled (a), (b) and (c). All of these data are shown in Fig. 48 together with TENDL-2017 evaluation except for the two 14-MeV data points of Refs. [160, 161] which exceed essentially all other equivalent data. Results of Ref. [174] have been corrected (corr.) in accord with the current changes in the monitor reaction cross sections, while Ref. [182] constitutes similar adjustments of previous publications performed by the original author. Eight further datasets were rejected [162-164, 167, 168, 170, 176, 179] as contradictory to the mean value of all other data around $14 \mathrm{MeV}$. The remaining fifteen sets were used in the fitting procedurethese selected data and their experimental uncertainties are shown in Fig. 49 together with the Padé fit $(L=19, N=69$, $\chi^{2}=0.84$ ) and estimated percentage uncertainties, including $4 \%$ of the systematic uncertainty (right-hand scale).
Fig. 48 Twenty-three experimental datasets for the ${ }^{100} \mathrm{Mo}(n, 2 n){ }^{99}$ Mo reaction available in the literature [162-182], and the TENDL2017 evaluation. Ikeda et al. [177] contains three versions of the data measured on the basis of different beam-monitor reactions, and these are labelled (a), (b) and (c)
Fig. 49 Fifteen selected experimental datasets for the ${ }^{100} \operatorname{Mo}(n, 2 n){ }^{99}$ Mo reaction with the Padé fit $(L=19, N=69$, $\left.\chi^{2}=0.84\right)$ and estimated uncertainties as percentages (dashed line, right-hand scale)
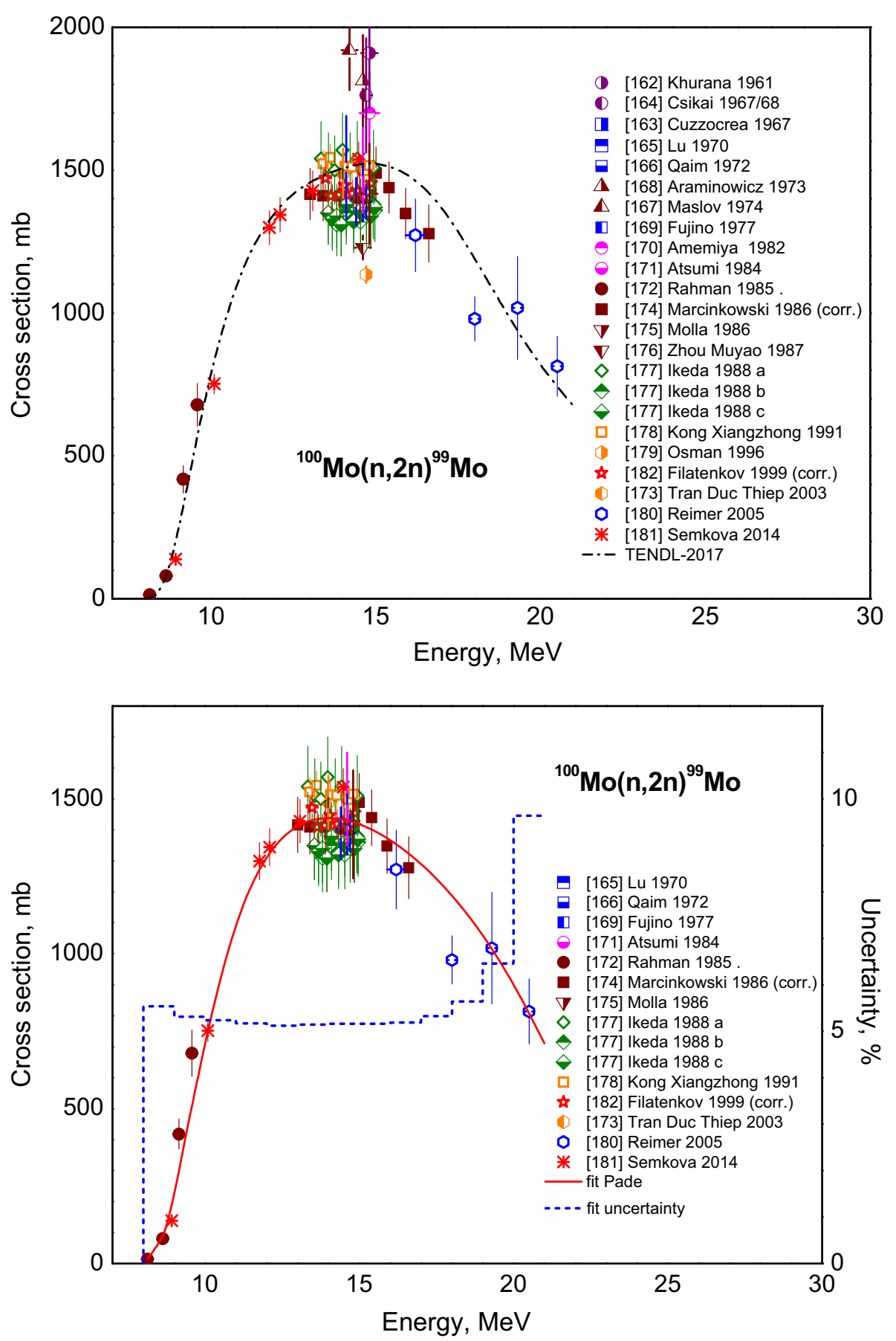


\section{${ }^{238} \mathbf{U}(\gamma, f){ }^{99}$ Mo}

While there are no directly measured experimental data for the ${ }^{238} \mathrm{U}(\gamma, f){ }^{99}$ Mo reaction, thirteen experimental datasets were found in the literature for the total photofission cross section [183-195], as shown in Fig. 50. Symbols below a gamma-ray energy of $8 \mathrm{MeV}$ overlap so severely that some data points are rather difficult to resolve. Data were only compiled and assessed for gamma-ray energies below
$30 \mathrm{MeV}$ that are important for medical applications. These data are also compared in Fig. 50 with the VarlamovPeskov (2007) evaluation which is widely considered as optimal for the photofission cross section of ${ }^{238} U$ [196].

Three datasets were rejected $[183,184,186]$ because of their disagreement with all other equivalent data. Data points from both Ref. [191] above $10 \mathrm{MeV}$ and Ref. [192] below $14 \mathrm{MeV}$ were also omitted for the same reason. The Padé fit of all remaining data is shown in Fig. $51(L=17$,
Fig. 50 Experimental datasets for the ${ }^{238} \mathrm{U}(\gamma, f)$ reaction available in the literature [183-195], and the VarlamovPeskov (2007) evaluation [196]

Fig. 51 Selected experimental datasets for the

${ }^{238} \mathrm{U}(\gamma, f)$ reaction with the Padé fit $\left(L=17, N=283, \chi^{2}=3.36\right)$ and estimated uncertainties as percentages (dashed line, righthand scale)
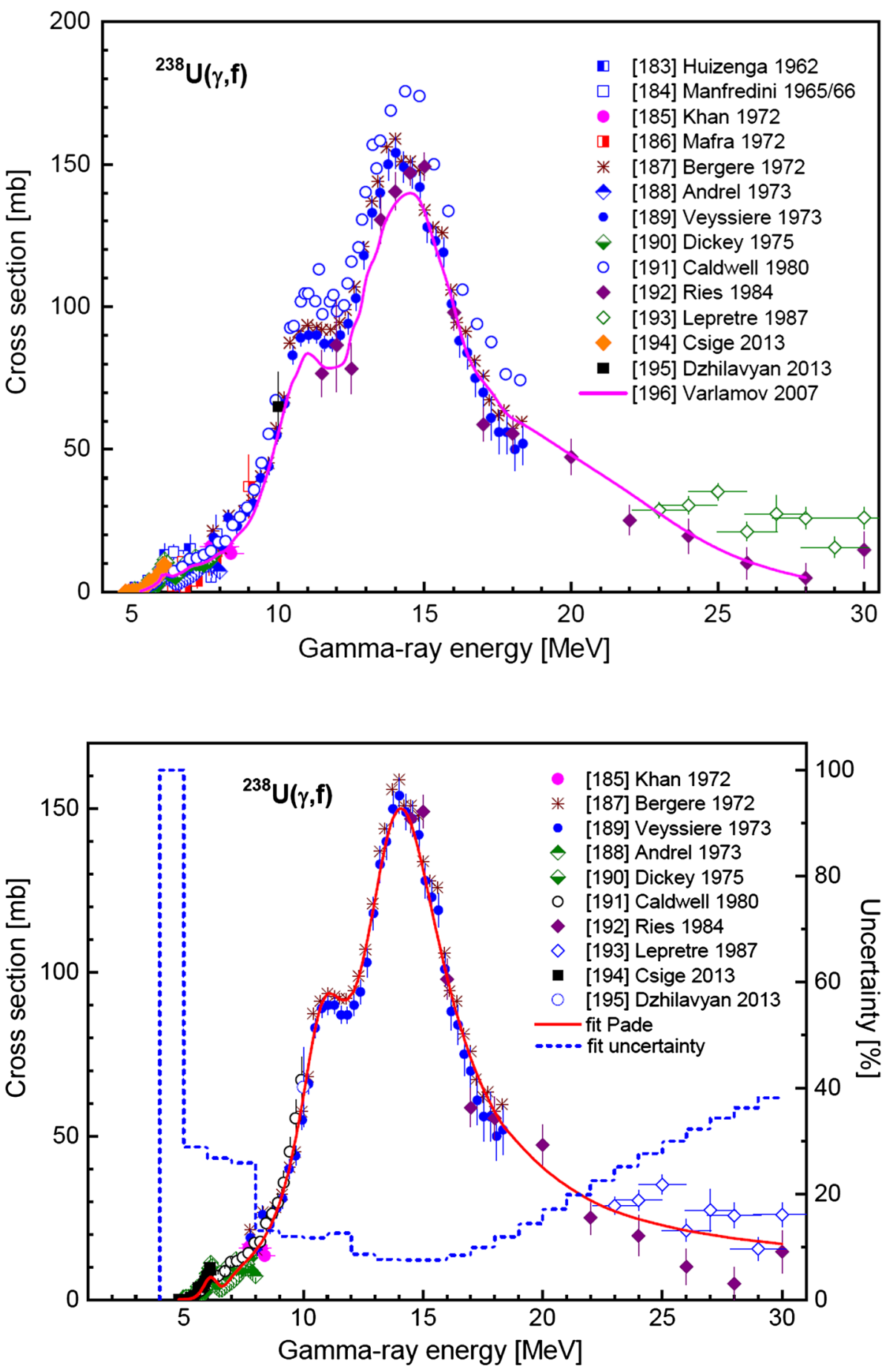
Fig. 52 Evaluated cross section for the ${ }^{238} \mathrm{U}(\gamma, f){ }^{99}$ Mo reaction based on the Padé fit of the

${ }^{238} \mathrm{U}(\gamma, f)$ reaction and the cumulative yield of ${ }^{99} \mathrm{Mo}$ [128]. Estimated uncertainties are shown as percentages (dashed line, right-hand scale)

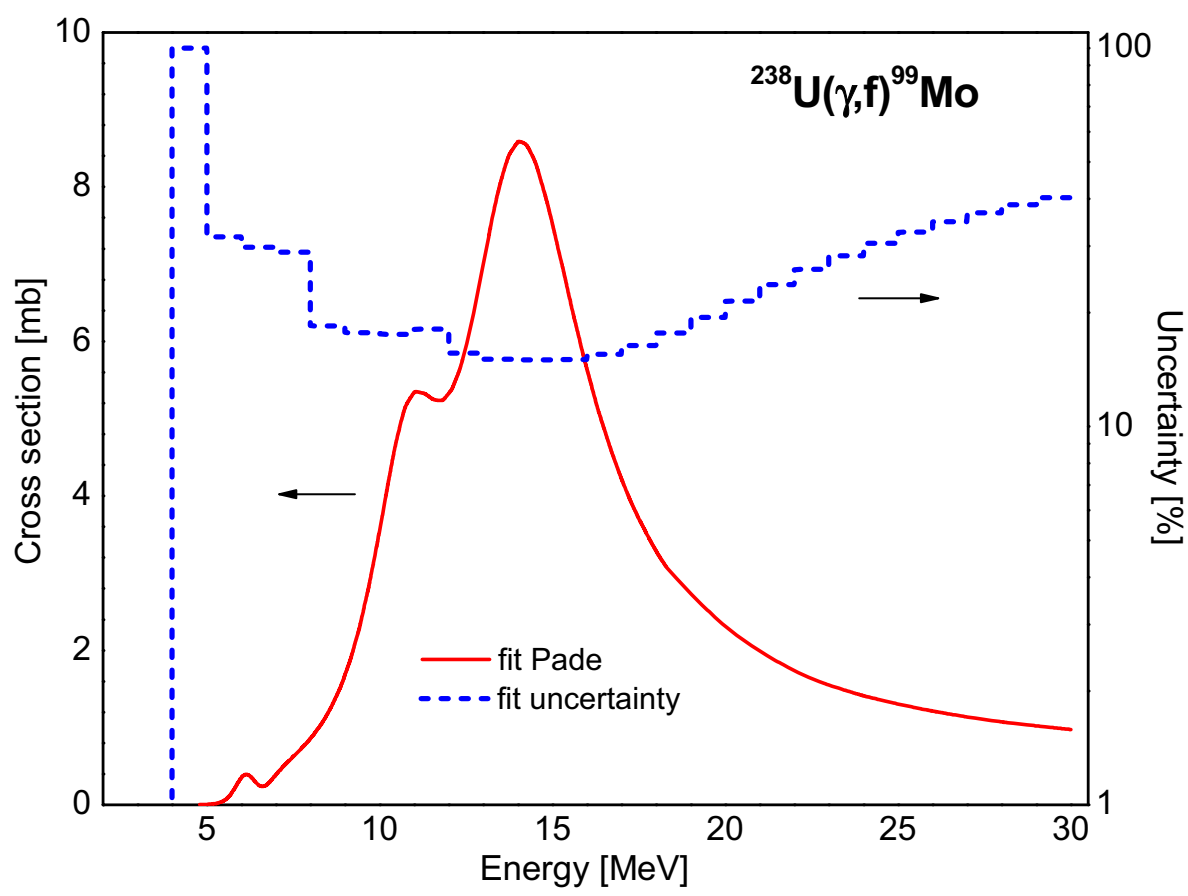

$\left.N=283, \chi^{2}=3.36\right)$ together with the estimated uncertainties as percentages, including $4 \%$ systematic uncertainty (right-hand scale).

Data for the neutron-induced reaction on ${ }^{238} \mathrm{U}$ are most frequently used to estimate the cumulative photofission yield of ${ }^{99}$ Mo. Such data are available in all of the national and international data libraries, but their accuracy is not high. The following cumulative yields are given for a neutron energy range between 1.0 and $2.0 \mathrm{MeV}$ :

$(6.17 \pm 0.86) \%$ in the ENDF/B-VII.1 library, $(5.65 \pm 0.73) \%$ in the NEA-OECD JEFF-3.2 library, and

$6.12 \%$, without any uncertainties in the Japanese JENDL-4.0 library.

All libraries exhibit some energy dependence of the cumulative yields, but these changes for neutron energies of $14 \mathrm{MeV}$ do not exceed the uncertainties of the yield at lower energies. Under such circumstances, we decided to adopt the ENDF/B-VII.1 value of the cumulative yield for the whole energy region of the ${ }^{238} \mathrm{U}\left(\gamma_{2} f\right)$ reaction. The corresponding cross section for the ${ }^{238} \mathrm{U}\left(\gamma_{f} f\right){ }^{99}$ Mo reaction as obtained on the basis of the Padé approximant of the total fission cross section is shown in Fig. 52 together with the estimated uncertainties, the main contributor of which is identified with the isotope yield uncertainties.

\section{Integral yields for production of ${ }^{99} \mathrm{Mo}$ by gamma-ray and neutron-induced reactions}

Both the photon and neutron sources that are used for medical radioisotope production generate continuous spectra. These spectra depend on various accelerator-target combinations, the energy of the charged-particle beam, position of the target, etc., such that the production yield depends on the specific experimental arrangements and local circumstances. On the basis of the evaluated cross sections, flux and mass independent production yields can be calculated as a function of the energy of the bombarding particles defined as:

Activity/(incident particle $\times$ unit mass)

Derived in the form of a function, this energy is identical in shape to the excitation function. By knowing the energy distribution of the incident particle and the range of energy applied, the integral yield can be readily deduced.

\section{Summary and conclusions}

Significant improvements and substantial extensions have been made to the IAEA-NDS recommended cross-section database for the production of specific gamma-emitting radionuclides. Evaluations of production cross sections and their uncertainties were performed on twenty-two reactions for direct, indirect and generator production of ${ }^{51} \mathrm{Cr}$, ${ }^{99} \mathrm{Mo} /{ }^{99 \mathrm{~m}} \mathrm{Tc}$ and ${ }^{99 \mathrm{~m}} \mathrm{Tc},{ }^{111} \mathrm{In},{ }^{123} \mathrm{Cs} /{ }^{123} \mathrm{Xe} /{ }^{123} \mathrm{I}$ (and ${ }^{121} \mathrm{I}$ 
impurity), and ${ }^{201} \mathrm{~Pb} /{ }^{201} \mathrm{Tl}$ (and ${ }^{200} \mathrm{~Pb}$ and ${ }^{202 \mathrm{~m}} \mathrm{~Pb}$ impurities).

Additional production routes for ${ }^{51} \mathrm{Cr},{ }^{99 \mathrm{~m}} \mathrm{Tc}$ and ${ }^{123} \mathrm{I}$ were explored, and some earlier evaluated nuclear reactions to produce ${ }^{111} \mathrm{In}$ and ${ }^{201} \mathrm{Tl}$ were also re-defined. A Padé fitting method was applied to the selected datasets, and uncertainties in all of the recommended cross-section data were deduced following the evaluation methodology described and fully adopted in Ref. [9]. Known experimental data were compared with the theoretical predictions to be found in the TENDL-2015 and 2017 libraries, and significant disagreements in the magnitude and shape of the resulting excitation functions existed in some cases (especially when considering isomeric states or deuteron-induced reactions). No major differences were found in the predictions of these two versions of the TENDL libraries, therefore, improved modelling is required. All of the recommended cross-section data have been used with reasonable confidence to determine integral yields for radionuclide production. Thus, the resulting datasets adopted in the present evaluation are seen as being acceptable for all practical purposes with good confidence. However, in a few cases, the data are more uncertain because of an existing lack of well-measured data.

Selection of the optimal reaction depends on many factors such as available beam particles and their achievable energy range, targetry and possible recovery problems with enriched target materials, production yield, impurities, and necessary chemical separation processes. The recommended cross sections are directly related to production yields and the acceptable levels of radioactive impurities. More specifically, improved radionuclidic purity is an important issue for practical applications in nuclear medicine. Under such circumstances, excitation functions for radionuclidic impurities are required to aid in defining optimum target compositions and the full energy range of the beam within the target in order to avoid or at least minimise their production. Recommendations concerning radioisotopic contaminants have only been made in the present evaluation for the production of ${ }^{123} \mathrm{I}$ with ${ }^{124} \mathrm{Xe}$ targets, and ${ }^{201} \mathrm{Tl}$ with ${ }^{203} \mathrm{Tl}$ targets. Other radionuclidic impurities need to be studied in what remains an important evolutionary programme of work.

Both the recommended excitation functions and production yields are available on the web page of the IAEA NDS at www-nds.iaea.org/medical/gamma_emitters.html and also at the IAEA medical portal www-nds.iaea.org/ medportal/. These evaluated experimental data are important for existing and potential nuclear medicine applications, for improvement and validation of the various nuclear reaction models, and may also have useful roles in other fields of non-energy related nuclear studies (e.g., activation analysis and thin layer activation).
Acknowledgements The contents and preparation of this paper involved the support and hard work of a large number of individuals and institutions. Our sincere thanks are extended to all colleagues who have contributed to this IAEA coordinated research project over the previous five years.

The IAEA is grateful to all participant laboratories for their assistance in the work, and their support of individual staff to attend CRP meetings and undertake related activities. We also acknowledge the valuable contributions made by I. Spahn (Forschungszentrum Jülich) during his attendance at specific project meetings. Work described in this paper would not have been possible without IAEA Member State contributions. Studies at ANL were supported by the U.S. Department of Energy, Office of Science, Office of Nuclear Physics, under Contract No. DE-AC-06CH11357.

Open Access This article is distributed under the terms of the Creative Commons Attribution 4.0 International License (http://creative commons.org/licenses/by/4.0/), which permits unrestricted use, distribution, and reproduction in any medium, provided you give appropriate credit to the original author(s) and the source, provide a link to the Creative Commons license, and indicate if changes were made.

\section{References}

1. Qaim SM (1982) Nuclear data relevant to cyclotron produced short-lived medical radioisotopes. Radiochim Acta 30:147-162; Qaim SM, Stöcklin G (1983) Production of some medically important short-lived neutron-deficient radioisotopes of halogens. Radiochim Acta 34:25-40; Qaim SM (1986) Recent developments in the production of ${ }^{18} \mathrm{~F},{ }^{75,76,77} \mathrm{Br}$ and ${ }^{123} \mathrm{I}$. Int $\mathrm{J}$ Rad Appl Instrum A Appl Radiat Isot 37:803-810; Qaim SM (1987) Cyclotron production of generator radionuclides. Radiochim Acta 41:111-118

2. Obložinský P (1995) First research coordination meeting on development of reference charged particle cross-section database for medical radioisotope production. IAEA report INDC(NDS)-349, IAEA, Vienna, Austria. www-nds.iaea.org/ publications/indc/indc-nds-0349.pdf

3. Gul K, Hermanne A, Mustafa MG, Nortier FM, Obložinský P, Qaim SM, Scholten B, Shubin Y, Takács S, Tárkányi FT, Zhuang Y (2001) Charged particle cross-section database for medical radioisotope production: diagnostic radioisotopes and monitor reactions. IAEA technical report IAEA-TECDOC-1211, May 2001, IAEA, Vienna, Austria. www-nds.iaea.org/publica tions/tecdocs/iaea-tecdoc-1211.pdf

4. IAEA charged particle cross section database for medical radioisotope production, updated 2003-2004. www-nds.iaea. org/medical/. See also the IAEA medical portal at www-nds. iaea.org/medportal/

5. Takács S, Tárkányi F, Hermanne A, Paviotti de Corcuera R (2003) Validation and upgrading of the recommended cross section data of charged particle reactions used for production of PET radioisotopes. Nucl Instrum Methods Phys Res B 211:169-189

6. Takács S, Tárkányi F, Hermanne A (2005) Validation and upgrading of the recommended cross-section data of charged particle reactions: gamma emitter radioisotopes. Nucl Instrum Methods Phys Res B 240:790-802

7. Běták E, Caldeira AD. Capote R, Carlson BV, Choi HD, Guimarães FB, Ignatyuk AV, Kim SK, Király B, Kovalev SF, Menapace E, Nichols AL, Nortier M, Pompeia P, Qaim SM, Scholten B, Shubin YN, Sublet J-C, Tárkányi F (2011) Nuclear data for the production of therapeutic radionuclides. In: Qaim 
SM, Tárkányi F, Capote R (eds) IAEA Technical Reports Series no. 473. International Atomic Energy Agency, Vienna. wwwnds.iaea.org/publications/tecdocs/sti-doc-010-0473/

8. Nichols AL, Capote R (2013) Summary report of first research coordination meeting on nuclear data for charged-particle monitor reactions and medical isotope production, 3-7 December 2012, IAEA Headquarters, IAEA report INDC(NDS)-0630, February 2013, IAEA, Vienna, Austria. www-nds.iaea.org/pub lications/indc/indc-nds-0630.pdf; Nichols AL, Capote R, Nortier FM (2015) Summary report of second research coordination meeting on nuclear data for charged-particle monitor reactions and medical isotope production, 8-12 December 2014, IAEA Headquarters, IAEA report INDC(NDS)-0675, April 2015, IAEA, Vienna, Austria. www-nds.iaea.org/publications/indc/ indc-nds-0675.pdf; Nichols AL, Nortier FM, Capote R (2017) Summary report of third research coordination meeting on nuclear data for charged-particle monitor reactions and medical isotope production, 30 May-3 June 2016, IAEA Headquarters, IAEA report INDC(NDS)-0717, January 2017, IAEA, Vienna, Austria. www-nds.iaea.org/publications/indc/indc-nds-0717.pdf; Nichols AL, Capote R (2014) Nuclear data for medical applications-recent developments and future requirements. In: Herman M, Hoblit SD, Johnson TD, McCutchan EA, Sonzogni AA (eds) International conference on nuclear data for science and technology, 4-8 March 2013, New York, USA. Published in Proceedings of the international conference on nuclear data for science and technology. Nucl Data Sheets 120:239-241

9. Hermanne A, Ignatyuk AV, Capote R, Carlson BV, Engle JW, Kellett MA, Kibedi T, Kim GN, Kondev FG, Hussain M, Lebeda O, Luca A, Nagai Y, Naik H, Nichols AL, Nortier FM, Suryanarayana SV, Takács S, Tárkányi FT, Verpelli M (2018) Reference cross sections for charged-particle monitor reactions. Nucl Data Sheets 148:338-382

10. Koning AJ, Rochman D, Kopecký J, Sublet J-C, Bauge E, Hilaire S, Romain P, Morillon B, Duarte H, van der Marck S, Pomp S, Sjostrand H, Forrest RA, Henriksson H, Cabellos O, Goriely S, Leppanen J, Leeb H, Plompen A, Mills RW (2017) TENDL-2015: TALYS-based evaluated nuclear data library. tendl.web.psi.ch/tendl_2015/tendl2015.html. TENDL-2017: TALYS-based evaluated nuclear data library. tendl.web.psi.ch/ tendl_2017/tendl2017.html

11. Capote R, Smith DL, Trkov A (2010) Nuclear data evaluation methodology including estimates of covariances. EPJ Web Conf 8:04001

12. Padé HE (1892) Sur la représentation approchée d' une fonction par des fractions rationnelles. Suppl Ann Sci L'Ecole Norm Sup Ser 9:3-93

13. Graves-Morris PR (ed) (1973) Padé approximants and their applications. Academic Press, New York

14. Baker Jr GA (1975) Essentials of Padé approximants. Academic Press, New York

15. Vinogradov VN, Gai EV, Rabotnov NS (1987) Analytical approximation of data in nuclear and neutron physics. Energoatomizdat, Moscow

16. Gai EV (2007) Some algorithms for the nuclear data evaluation and construction of the uncertainty covariance matrices. Probl Atom Sci Technol Ser Nucl Constants 1-2:56-65

17. Badikov SA, Gai EV (2003) Some sources of the underestimation of evaluated cross-section uncertainties. IAEA report INDC(NDS)-438, pp 117-129, IAEA, Vienna, Austria. wwwnds.iaea.org/publications/indc/indc-nds-0438.pdf

18. Gai EV, Ignatyuk AV (2008) Uncertainties and covariances of the fission cross sections and the fission neutron multiplicities for actinides. Nucl Data Sheets 109:2890-2893

19. NuDat, NNDC, Brookhaven National Laboratory, USA. Decay data retrieval code. www.nndc.bnl.gov/nudat2/
20. Johnson CH, Galonsky A, Ulrich JP (1958) Proton strength functions from $(p, n)$. Phys Rev 109:1243-1254 (EXFOR: T0122)

21. Albert RD (1959) $(p, n)$ cross section and proton optical-model parameters in the $4-5.5 \mathrm{MeV}$ energy region. Phys Rev 115:925-927 (EXFOR: T0130)

22. Tanaka S, Furukawa M (1959) Excitation functions for $(p, n)$ reactions with titanium, vanadium, chromium, iron and nickel up to $E_{\mathrm{p}}=14 \mathrm{MeV}$. J Phys Soc Jpn 14:1269-1275 (EXFOR: B0043)

23. Shore BW, Wall NS, Irvine JW (1961) Interactions of 7.5 MeV protons with copper and vanadium. Phys Rev 123:276-283 (EXFOR: T0125)

24. Albouy G, Gusakow M, Poffé N, Sergolle H, Valentin L (1962) Réaction $(p, n)$ a moyenne énergie. J Phys Radium 23:1000-1002 (EXFOR: B0106)

25. Hansen LF, Albert RD (1962) Statistical theory predictions for 5- to $11-\mathrm{MeV}(p, n)$ and $(p, p)$ nuclear reactions in ${ }^{51} \mathrm{~V},{ }^{59} \mathrm{Co}$, ${ }^{63} \mathrm{Cu},{ }^{65} \mathrm{Cu}$ and ${ }^{103} \mathrm{Rh}$. Phys Rev 128:291-299 (EXFOR: B0066)

26. Taketani H, Alford WP (1962) $(p, n)$ cross sections on $\mathrm{Ti}^{47}, \mathrm{~V}^{51}$, $\mathrm{Cr}^{52}, \mathrm{Co}^{59}$, and $\mathrm{Cu}^{63}$ from 4 to $6.5 \mathrm{MeV}$. Phys Rev 125:291-294 (EXFOR: B0051)

27. Wing J, Huizenga JR (1962) $(p, n)$ cross sections of $\mathrm{V}^{51}, \mathrm{Cr}^{52}$, $\mathrm{Cu}^{63}, \mathrm{Cu}^{65}, \mathrm{Ag}^{107}, \mathrm{Ag}^{109}, \mathrm{Cd}^{111}, \mathrm{Cd}^{114}$ and $\mathrm{La}^{139}$ from 5 to 10.5 MeV. Phys Rev 128:280-290 (EXFOR: T0124)

28. Hontzeas S, Yaffe L (1963) Interaction of vanadium with protons of energies up to $84 \mathrm{MeV}$. Can J Chem 41:2194-2209 (EXFOR: C2008)

29. Humes RM, Dell Jr GF, Ploughe WD, Hausman HJ (1963) $(p, n)$ cross sections at $6.75 \mathrm{MeV}$. Phys Rev 130:1522-1524 (EXFOR: B0061)

30. Johnson CH, Trail CC, Galonsky A (1964) Thresholds for $(p, n)$ reactions on 26 intermediate-weight nuclei. Phys Rev 136:B1719-B1729 (EXFOR: T0126)

31. Dell GF, Ploughe WD, Hausman HJ (1965) Total reaction cross sections in the mass range 45 to 65 . Nucl Phys 64:513-523 (EXFOR: B0064)

32. Harris KK, Grench HA, Johnson RG, Vaughn FJ (1965) The $\mathrm{V}^{51}(p, n) \mathrm{Cr}^{51}$ reaction as a neutron source of known intensity. Nucl Instrum Methods 33:257-260 (EXFOR: T0030)

33. Chodil G, Jopson RC, Mark H, Swift CD, Thomas RG, Yates MK (1967) $(p, n)$ and $(p, 2 n)$ cross sections on nine elements. Nucl Phys A 93:648-672 (EXFOR: C0693)

34. Gadioli E, Grassi Strini AM, Bianco GL, Strini G, Tagliaferri G (1974) Excitation functions of ${ }^{51} \mathrm{~V},{ }^{56} \mathrm{Fe},{ }^{65} \mathrm{Cu}(p, n)$ reactions between 10 and $45 \mathrm{MeV}$. Nuovo Cimento A 22:547-558 (EXFOR: B0027)

35. Barrandon JN, Debrun JL, Kohn A, Spear RH (1975) Étude du dosage de $\mathrm{Ti}, \mathrm{V}, \mathrm{Cr}, \mathrm{Fe}, \mathrm{Ni}, \mathrm{Cu}$ et $\mathrm{Zn}$ par activation avec des protons d'énergie limitée á $20 \mathrm{MeV}$. Nucl Instrum Methods 127:269-278 (EXFOR: O0086)

36. Mehta MK, Kailas S, Sekharan KK (1977) Total $(p, n)$ reaction cross-section study on V-51 over incident energy-range 1.56-5.53 MeV. Pramana 9:419-434 (EXFOR: D6059)

37. Michel R, Brinkmann G, Weigel H, Herr W (1979) Measurement and hybrid-model analysis of proton-induced reactions with V, Fe and Co. Nucl Phys A 322:40-60 (EXFOR: A0146)

38. Michel R, Brinkmann G (1980) On the depth-dependent production of radionuclides $(44 \leq \mathrm{A} \leq 59)$ by solar protons in extraterrestrial matter. J Radioanal Chem 59:467-510 (EXFOR: A0145)

39. Zyskind JL, Barnes CA, Davidson JM, Fowler WA, Marrs RE, Shapiro MH (1980) Competition effects in proton-induced reactions on V-51. Nucl Phys A 343:295-314 (EXFOR: C0627) 
40. Stück T (1983) Proton induced reactions on Ti, V, Mn, Fe, Co and Ni. Measurement and hybrid model analysis of integral excitation functions and their application in model calculation for the production of cosmogenic nuclides. Faculty of Mathematics and Natural Science, University of Cologne, Cologne, FRG, pp 1-165, thesis (EXFOR: A0100)

41. Kailas S, Gupta SK, Kerekatte SS, Fernandes CV (1985) V-51 $(p, n)$ Cr-51 reaction from $E_{\mathrm{p}} 1.9$ to $4.5 \mathrm{MeV}$. Pramana 24:629-635 (EXFOR: A0332)

42. Michel R, Peiffer F, Stück R (1985) Measurement and hybrid model analysis of integral excitation-functions for proton-induced reactions on vanadium, manganese and cobalt up to $200 \mathrm{MeV}$. Nucl Phys A 441:617-639 (EXFOR: A0100)

43. Bastos MAV, Debritto JLQ, Vinagre UM, Dasilva AG (1990) A production method for Cr-51 at IEN's cyclotron. Radiochim Acta 50:189-191 (EXFOR: D0699)

44. Jung P (1992) Cross sections for the production of helium and long-living radioactive isotopes by protons and deuterons. In: Qaim SM (ed) Proceedings of the international conference on nuclear data for science and technology, 13-17 May 1991, Jülich, Germany. Springer, Berlin, pp 352-354

45. Levkovskij VN (1991) The cross-sections of activation of nuclides of middle-range mass $(A=40-100)$ by protons and $\alpha$ particles of middle range energies $(E=10-50 \mathrm{MeV})$. INTERVESTI, Moscow (EXFOR: A0510)

46. Wenrong Z, Hanlin L, Weixiang Y (1994) Excitation function of V-51(p,n)Cr-51 up to $22 \mathrm{MeV}$. Chin J Nucl Phys 16:67 (EXFOR: S0042)

47. Musthafa MM, Sharma MK, Singh BP, Prasad R (2005) Measurement and analysis of cross sections for $(p, n)$ reactions in V-51 and In-113. Appl Radiat Isot 62:419-428 (EXFOR: 01237)

48. Solieman AHM, Al-Abyad M, Ditrói F, Saleh ZA (2016) Experimental and theoretical study for the production of ${ }^{51} \mathrm{Cr}$ using p, d, ${ }^{3} \mathrm{He}$ and ${ }^{4} \mathrm{He}$ projectiles on V, Ti and $\mathrm{Cr}$ targets. Nucl Instrum Methods Phys Res B 366:19-27 (EXFOR: D4339)

49. Ditrói F, Tárkányi F, Takács S, Hermanne A (2016) Activation cross-sections of proton induced reactions on vanadium in the 37-65 MeV energy range. Nucl Instrum Methods Phys Res B 381:16-28 (EXFOR: D4356)

50. Weinreich R, Probst HJ, Qaim SM (1980) Production of chromium-48 for applications in life sciences. Appl Radiat Isot 31:223-232 (EXFOR: A0169)

51. Jung P (1987) Helium production and long-term activation by protons and deuterons in metals for fusion reactor application. J Nucl Mater 144:43-50

52. Wenrong Z, Hanlin L, Weixiang Y (1992) Cross section measurement for V-51(d,2n)Cr-51 reaction. Chin J Nucl Phys 14:309 (EXFOR: S0039)

53. Sonzogni AA, Romo ASMA, Mosca HO, Nassiff SJ (1993) Alpha and deuteron induced reactions on vanadium. J Radioanal Nucl Chem 170:143-156 (EXFOR: A0555)

54. Tárkányi F, Ditrói F, Takács S, Hermanne A, Baba M, Ignatyuk AV (2011) Investigation of activation cross-sections of deuteron induced reactions on vanadium up to $40 \mathrm{MeV}$. Nucl Instrum Methods Phys Res B 269:1792-1800 (EXFOR: D4246)

55. Michel R, Bodemann R, Busemann H, Daunke R, Gloris M, Lange H-J, Klug B, Krins A, Leya I, Lupke M, Neumann S, Reinhardt H, Schnatz-Buttgen M, Herpers U, Schiekel Th, Sudbrock F, Holmqvist B, Conde H, Malmborg P, Suter M, Dittrich-Hannen B, Kubik P-W, Synal H-A (1997) Cross sections for the production of residual nuclides by low- and medium-energy protons from the target elements $\mathrm{C}, \mathrm{N}, \mathrm{O}, \mathrm{Mg}, \mathrm{Al}$, $\mathrm{Si}, \mathrm{Ca}, \mathrm{Ti}, \mathrm{V}, \mathrm{Mn}, \mathrm{Fe} \mathrm{Co}, \mathrm{Ni}, \mathrm{Cu}, \mathrm{Sr}, \mathrm{Y}, \mathrm{Zr}, \mathrm{Nb}, \mathrm{Ba}$ and $\mathrm{Au}$. Nucl Instrum Methods Phys Res B 129:153-193 (EXFOR: O0276)
56. Al-Abyad M, Spahn I, Qaim SM (2010) Experimental studies and nuclear model calculations on proton induced reactions on manganese up to $45 \mathrm{MeV}$ with reference to production of $\mathrm{Fe}-55$, Mn-54 and Cr-51. Appl Radiat Isot 68:2393-2397 (EXFOR: D0632)

57. Ditrói F, Tárkányi F, Takács S, Hermanne A, Yamazaki H, Baba M, Mohammadi A (2013) Activation cross-sections of longer lived products of proton induced nuclear reactions on manganese up to $70 \mathrm{MeV}$. Nucl Instrum Methods Phys Res B 308:34-39 (EXFOR: D4286)

58. Ditrói F, Tárkányi F, Takács S, Hermanne A, Yamazaki H, Baba M, Mohammadi A, Ignatyuk AV (2011) Activation cross-sections of deuteron induced reactions on manganese up to $40 \mathrm{MeV}$. Nucl Instrum Methods Phys Res B 269:1878-1883 (EXFOR: D4247)

59. Rayudu GVS (1964) Formation cross sections of various radionuclides from $\mathrm{Ni}, \mathrm{Fe}, \mathrm{Si}, \mathrm{Mg}, \mathrm{O}$ and $\mathrm{C}$ for protons of energies between 130 and $400 \mathrm{MeV}$. Can J Chem 42:1149-1154 (EXFOR: 0073)

60. Williams IR, Fulmer CB (1967) Excitation functions for radioactive isotopes produced by protons below $60 \mathrm{MeV}$ on $\mathrm{Al}$, $\mathrm{Fe}$, and $\mathrm{Cu}$. Phys Rev 162:1055-1061 (EXFOR: B0073)

61. Brodzinski RL, Rancitelli LA, Cooper JA, Wogman NA (1971) High-energy proton spallation of iron. Phys Rev C 4:1257-1265 (EXFOR: C0272)

62. Walton JR, Yaniv A, Heymann D, Edgerley D, Rowe MW (1973) $\mathrm{He}$ and $\mathrm{Ne}$ cross sections in natural $\mathrm{Mg}$, Si targets and radionuclide cross sections in natural $\mathrm{Si}, \mathrm{Ca}, \mathrm{Ti}$ and $\mathrm{Fe}$ targets bombarded with 14 to $45 \mathrm{MeV}$ protons. J Geophys Res 78:6428-6442 (EXFOR: O0350)

63. Schoen NC, Orlov G, McDonald RJ (1979) Excitation functions for radioactive isotopes produced by proton bombardment of $\mathrm{Fe}$ $\mathrm{Co}$, and $\mathrm{W}$ in the energy range from 10 to $60 \mathrm{MeV}$. Phys Rev C 20:88-92 (EXFOR: T0276)

64. Barchuk IF, Bulkin VS, Kuzmenkova VA, Kurilo PM, Lobach YN, Ogorodnik AF, Procopenko VS, Sklyarenko VD, Tokarevsky VV (1987) Excitation functions of the reactions induced by interactions of protons over an energy range up to $67 \mathrm{MeV}$ with silicon and iron nuclei. At Energiya 63:30 (EXFOR: A0339)

65. Fassbender F, Shubin YuN, Qaim SM (1999) Formation of activation products in interactions of medium energy protons with $\mathrm{Na}, \mathrm{Si}, \mathrm{P}, \mathrm{S}, \mathrm{Cl}, \mathrm{Ca}$ and Fe. Radiochim Acta 84:59-67 (EXFOR: O0728)

66. Ditrói F, Tárkányi F, Csikái J, Uddin MS, Hagiwara M, Baba M (2004) Investigation of activation cross sections of the proton induced nuclear reactions on natural iron at medium energies. In: International conference on nuclear data for science and technology, Santa Fe, NM, USA, vol 769, pp 1011-1014

67. Sisterson JM, Vincent J (2006) Cross section measurements for proton-induced reactions in $\mathrm{Fe}$ and $\mathrm{Ni}$ producing relatively short-lived radionuclides at $E_{\mathrm{p}}=140-500 \mathrm{MeV}$. Nucl Instrum Methods Phys Res B251:1-8 (EXFOR: C1447)

68. Al-Abyad M, Comsan MNH, Qaim SM (2009) Excitation functions of proton-induced reactions on ${ }^{\text {nat }} \mathrm{Fe}$ and enriched ${ }^{57} \mathrm{Fe}$ with particular reference to the production of ${ }^{57} \mathrm{Co}$. Appl Radiat Isot 67:122-128 (EXFOR: D0500)

69. Kim K, Khandaker MU, Naik H, Kim G (2014) Excitation functions of proton induced reactions on ${ }^{\text {nat }} \mathrm{Fe}$ in the energy region up to $45 \mathrm{MeV}$. Nucl Instrum Methods Phys Res B 322:63-69 (EXFOR: D7007)

70. Graves SA, Ellison PA, Barnhart TE, Valdovinos HF, Birnbaum ER, Nortier FM, Nickles RJ, Engle JW (2016) Nuclear excitation functions of proton-induced reactions $\left(E_{\mathrm{p}}=35-90 \mathrm{MeV}\right)$ from $\mathrm{Fe}, \mathrm{Cu}$ and $\mathrm{Al}$. Nucl Instrum Methods Phys Res B 386:44-53 (EXFOR: C22430) 
71. Iguchi A, Amano H, Tanaka S (1960) $(\alpha, n)$ cross sections for ${ }^{48} \mathrm{Ti}$ and ${ }^{51}$ V. J At Energy Soc Jpn 2:682-684 (EXFOR: E1930)

72. Vonach H, Haight RC, Winkler G (1983) $(\alpha, n)$ and total $\alpha$ reaction cross sections for ${ }^{48} \mathrm{Ti}$ and ${ }^{51} \mathrm{~V}$. Phys Rev $\mathrm{C}$ 28:2278-2285 (EXFOR: C0318)

73. Chang CN, Kent JJ, Morgan JF, Blatt SL (1973) Total cross section measurements by X-ray detection of electron-capture of residual activity. Nucl Instrum Methods 109:327-331 (EXFOR: C0951)

74. Michel R, Brinkmann G, Stück R (1983) Integral excitation functions of $\alpha$-induced reactions on titanium, iron and nickel. Radiochim Acta 32:173-189 (EXFOR: A0148)

75. Morton AJ, Tims SG, Scott AF (1992) The ${ }^{48} \mathrm{Ti}(\alpha, n)^{51} \mathrm{Cr}$ and ${ }^{48} \mathrm{Ti}(\alpha, p){ }^{51} \mathrm{~V}$ cross sections. Nucl Phys A $128: 167-182$ (EXFOR: D0061)

76. Tárkányi F, Szelecsényi F, Kopecký P (1992) Cross section data for proton, ${ }^{3} \mathrm{He}$ and $\alpha$-particle induced reactions on ${ }^{\text {nat }} \mathrm{Ni},{ }^{\text {nat }} \mathrm{Cu}$ and ${ }^{\text {nat }} \mathrm{Ti}$ for monitoring beam performance. In: Qaim SM (ed) Proceedings of the international conference on nuclear data for science and technology, 13-17 May 1991, Jülich, Germany. Springer, Berlin, pp 529-532

77. Peng X, He F, Long X (1998) Excitation functions for the reactions induced by alpha-particle impact of natural titanium. Nucl Instrum Methods Phys Res B 140:9-12 (EXFOR: O1074)

78. Hermanne A, Sonck M, Takács S, Szelecsényi F, Tárkányi $F$ (1999) Excitation functions of alpha particle induced reactions on ${ }^{\text {nat }} \mathrm{Ti}$ with reference to monitoring and TLA. Nucl Instrum Methods Phys Res B152:187-201; grouped into seven series of data in the original publication-compiler has reproduced them on the appropriate figure as two different datasets (labelled ' $a$ ' and 'b') (EXFOR: D4089)

79. Baglin CM, Norman ER, Larimer RM, Rech GA (2004) Measurement of ${ }^{107} \mathrm{Ag}(\alpha, \gamma){ }^{111}$ In cross sections., In: Proceedings of the international conference on nuclear data for science and technology, Santa Fe, NM, USA, vol 769, 2, pp 1370-1373 (EXFOR: C1474)

80. Takács S, Tárkányi F, Hermanne A (2006) Production of In radioisotopes for medical use by alpha bombardment of natural silver target. In: 15th Pacific basin nuclear conference, Sydney, Australia, October 2006; data received as a private communication

81. Király B, Takács S, Tárkányi F, Hermanne A (2007) Cross section measurements on $\mathrm{Er}, \mathrm{Nb}$ and $\mathrm{Yb}$, private communication (2007)

82. Takács S, Tárkányi F, Hermanne A (2007) Cross section measurements of nuclear reactions on $\mathrm{Cu}$ and $\mathrm{Ti}$ target by alpha bombardment for monitoring use-data received as private communication

83. Uddin MS, Scholten B (2016) Excitation functions of alpha particle induced reactions on ${ }^{\text {nat }} \mathrm{Ti}$ up to $40 \mathrm{MeV}$. Nucl Instrum Methods Phys Res B380:15-19 (EXFOR: O2304)

84. Lagunas-Solar MC, Kiefer PM, Carvacho OF, Lagunas CA, Cha YP (1991) Cyclotron production of NCA ${ }^{99 \mathrm{~m}} \mathrm{Tc}$ and ${ }^{99} \mathrm{Mo}$ : an alternative non-reactor supply source of instant ${ }^{99 \mathrm{~m}} \mathrm{Tc}$ and ${ }^{99} \mathrm{Mo} \rightarrow{ }^{99 \mathrm{~m}} \mathrm{Tc}$ generators. Appl Radiat Isot 42:643-657 (EXFOR: C0068)

85. Scholten B, Lambrecht RM, Cogneau M, Vera Ruiz H, Qaim SM (1999) Excitation functions for the cyclotron production of ${ }^{99 \mathrm{~m}} \mathrm{Tc}$ and ${ }^{99} \mathrm{Mo}$. Appl Radiat Isot 51:69-80 (EXFOR: O0737)

86. Takács S, Szûcs Z, Tárkányi F, Hermanne A, Sonck M (2003) Evaluation of proton-induced reactions on ${ }^{100} \mathrm{Mo}$ : new cross sections for the production of ${ }^{99 \mathrm{~m}} \mathrm{Tc}$ and ${ }^{99}$ Mo. J Radioanal Nucl Chem 257:195-201 (EXFOR: D4115)

87. Uddin MS, Hagiwara M, Tárkányi F, Ditrói F, Baba M (2004) Experimental studies on the proton-induced activation reactions of molybdenum in the energy range $22-67 \mathrm{MeV}$. Appl Radiat Isot 60:911-920 (EXFOR: E1894)

88. Khandaker MU, Uddin MS, Kim KS, Lee YS, Kim GN (2007) Measurement of cross-sections for the $(p, x n)$ reactions in natural molybdenum. Nucl Instrum Methods Phys Res B 262:171-181 (EXFOR: D0446)

89. Lebeda O, Pruszyński M (2010) New measurement of excitation functions for $(p, x)$ reactions on natMo with special regard to the formation of ${ }^{95 \mathrm{~m}} \mathrm{Tc},{ }^{96 \mathrm{~m}+\mathrm{g}} \mathrm{Tc},{ }^{99 \mathrm{~m}} \mathrm{Tc}$ and ${ }^{99} \mathrm{Mo}$. Appl Radiat Isot 68:2355-2365 (EXFOR: D0615)

90. Alharbi AA, Azzam A, McCleskey M, Roeder B, Spiridon A, Simmons E, Goldberg VZ, Banu A, Trache L, Tribble RE (2011) Medical radioisotopes production: A comprehensive cross-section study for the production of Mo and Tc radioisotopes via proton induced nuclear reactions on ${ }^{\text {nat }} \mathrm{Mo}$. In: Singh N (ed) Medicine diagnostics radioisotopes-applications in biomedical science. InTech, Croatia, pp 3-26 (EXFOR: C2157). ISBN 978-953-307-748-2

91. Chodash P, Angell CT, Benitez J, Norman EB, Pedretti M, Shugart H, Swanberg E, Yee R (2011) Measurement of excitation functions for the ${ }^{\text {nat }} \mathrm{Mo}(d, x){ }^{99} \mathrm{Mo}$ and ${ }^{\text {nat }} \mathrm{Mo}(p, x){ }^{99} \mathrm{Mo}$ reactions. Appl Radiat Isot 69:1447-1452 (EXFOR: C1871)

92. Gagnon K, Bénard F, Kovacs M, Ruth TJ, Schafferd P, Wilson JS, McQuarrie SA (2011) Cyclotron production of 99mTc: experimental measurement of the ${ }^{100} \mathrm{Mo}(p, x){ }^{99} \mathrm{Mo},{ }^{99 \mathrm{~m}} \mathrm{Tc}$ and ${ }^{99 \mathrm{~g}} \mathrm{Tc}$ excitation functions from 8 to $18 \mathrm{MeV}$. Nucl Med Biol 38:907-916 (EXFOR: C2156)

93. Tárkányi F, Ditrói F, Hermanne A, Takács S, Ignatyuk AV (2012) Investigation of activation cross-sections of proton induced nuclear reactions on ${ }^{\text {nat }}$ Mo up to $40 \mathrm{MeV}$ : new data and evaluation. Nucl Instrum Methods Phys Res B 280:45-73 (EXFOR: D4264)

94. Manenti S, Holzwarth U, Loriggiola M, Gini L, Esposito J, Groppi F, Simonelli F (2014) The excitation functions of ${ }^{100} \mathrm{Mo}(p, x){ }^{99} \mathrm{Mo}$ and ${ }^{100} \mathrm{Mo}(p, 2 n){ }^{99 \mathrm{~m}} \mathrm{Tc}$. Appl Radiat Isot 94:344-348 (EXFOR: O2263)

95. Takács S, Hermanne A, Ditrói F, Tárkányi F, Aikawa M (2015) Re-examination of cross sections of the ${ }^{100} \mathrm{Mo}(p, 2 n)^{99 \mathrm{~m}} \mathrm{Tc}$ reaction. Nucl Instrum Methods Phys Res B 347:26-38 (EXFOR: D4322)

96. Červenák J, Lebeda O (2016) Experimental cross-sections for proton-induced nuclear reactions on ${ }^{\text {nat }}$ Mo. Nucl Instrum Methods Phys Res B 380:32-49 (EXFOR: D0805)

97. Sonck M, Takács S, Szelecsényi F, Hermanne A, Tárkányi F (1999) Excitation function of deuteron induced nuclear reactions on ${ }^{\text {nat }} \mathrm{Mo}$ and ${ }^{100} \mathrm{Mo}(90 \%)$ up to $50 \mathrm{MeV}$ : an alternative route for the production of ${ }^{99}$ Mo. In: Duggan JL, Morgan IL (eds) Proceedings of the 15th international conference on application of accelerators in research and industry, Denton, Texas, USA, November 1998. AIP conference proceedings, vol 475, pp 987-990, AIP New York, Woodbury, USA (EXFOR: D4098)

98. Lebeda O, Fikrle M (2010) New measurement of excitation functions for $(d, x)$ reactions on nat-Mo with special regard to the formation of ${ }^{95 \mathrm{~m}} \mathrm{Tc},{ }^{96 \mathrm{~m}+\mathrm{g}} \mathrm{Tc},{ }^{99 \mathrm{~m}} \mathrm{Tc}$ and ${ }^{99} \mathrm{Mo}$. Appl Radiat Isot 68:2425-2432 (EXFOR: D0631)

99. Tárkányi F, Hermanne A, Takács S, Sonck M, Szûcs Z, Király B, Ignatyuk AV (2011) Investigation of alternative production routes of ${ }^{99 m} \mathrm{Tc}$ : deuteron induced reactions on ${ }^{100} \mathrm{Mo}$. Appl Radiat Isot 69:18-25 (EXFOR: D4235)

100. Tárkányi F, Ditrói F, Takács S, Király B, Hermanne A, Sonck M, Baba M, Ignatyuk AV (2012) Investigation of activation cross-sections of deuteron induced nuclear reactions on natural Mo up to $50 \mathrm{MeV}$. Nucl Instrum Methods Phys Res B 274:1-25 (EXFOR: D4260) 
101. Lagunas-Solar MC, Zeng NX, Mirshad I, Grey-Morgan T (1996) An update on the direct production of ${ }^{99 \mathrm{~m}} \mathrm{Tc}$ with proton beams and enriched ${ }^{100}$ Mo targets. Trans Am Nucl Soc 74:137 (EXFOR: C0963)

102. Khandaker MU, Moinul Haque Meaze AKM, Kim K, Son D, Kim GN (2006) Measurements of the proton-induced reaction cross-sections of ${ }^{\text {nat }}$ Mo by using the MC50 cyclotron at the Korea Institute of Radiological and Medical Sciences. J Korean Phys Soc 48:821-826

103. Sonck M, Takács S, Szelecsényi F, Hermanne A, Tárkányi F (1997) Excitation functions of deuteron induced nuclear reactions on ${ }^{\text {nat }}$ Mo up to $21 \mathrm{MeV}$ : an alternative route for the production of ${ }^{94 \mathrm{~m},{ }^{99 \mathrm{~m}} \mathrm{Tc} \text { and }}{ }^{99} \mathrm{Mo}$. In: Reffo G, Ventura A, Grandi $\mathrm{C}$ (eds) Proceedings of the international conference on nuclear data for science and technology, 19-24 May 1997, Trieste, Italy, Part 2, pp 1637-1639, Editrice Compositori, Italy (EXFOR: D4100)

104. Otozai K, Kume S, Mito A, Okamura H, Tsujino R, Kanchiku Y, Katoh T, Gotoh H (1966) Excitation functions for the reactions induced by protons on $\mathrm{Cd}$ up to $37 \mathrm{MeV}$. Nucl Phys 80:335-348 (EXFOR: P0019)

105. Nieckarz Jr WJ, Caretto Jr AA (1969) Production of ${ }^{111}$ In and ${ }^{114 \mathrm{~m}}$ In from the separated isotopes of cadmium using 70 - to 400-MeV protons. Phys Rev 178:1887-1893 (EXFOR: C0345)

106. Skakun EA, Kljucharev AP, Rakivnenko YN, Romanij IA (1975) Excitation functions of $(p, n)$ - and $(p, 2 n)$-reactions on cadmium isotopes. Izv Akademii Nauk SSSR Ser Fiz 39:24-30 (EXFOR: A0001)

107. Nortier FM, Mills SJ, Steyn GF (1990) Excitation functions and production rates of relevance to the production of ${ }^{111} \mathrm{In}$ by proton bombardment of ${ }^{\text {nat }} \mathrm{Cd}$ and ${ }^{\text {nat }}$ In up to $100 \mathrm{MeV}$. Appl Radiat Isot 41:1201-1208 (EXFOR: A0500)

108. Tárkányi F, Szelecsényi F, Kopecký P, Molnár T, Andó L, Mikecz P, Tóth G, Rydl A (1994) Cross sections of proton induced nuclear reactions on enriched ${ }^{111} \mathrm{Cd}$ and ${ }^{112} \mathrm{Cd}$ for the production of ${ }^{111}$ In for use in nuclear medicine. Appl Radiat Isot 45:239-249 (EXFOR: D4027)

109. Tárkányi F, Király B, Ditrói F, Takács S, Csikái G, Hermanne A, Uddin MS, Hagiwara M, Baba M, Ido T, Shubin YN, Kovalev SF (2006) Activation cross-sections on cadmium: proton induced nuclear reactions up to $80 \mathrm{MeV}$. Nucl Instrum Methods Phys Res B 245:379-394

110. Khandaker MU, Kim K, Lee MW, Kim KS, Kim GN, Cho YS, Lee YO (2008) Production cross-sections for the residual radionuclides from the ${ }^{\text {nat }} \mathrm{Cd}(p, x)$ nuclear processes. Nucl Instrum Methods Phys Res B 266:4877-4887 (EXFOR: D0516)

111. Al-Saleh FS (2008) Cross sections of proton induced nuclear reactions on natural cadmium leading to the formation of radionuclides of indium. Radiochim Acta 96:461-465 (EXFOR: D0467)

112. Hermanne A, Adam-Rebeles R, Van den Winkel P, Tárkányi F, Takács S (2014) Production of ${ }^{111}$ In and ${ }^{114 \mathrm{~m}}$ In by proton induced reactions: an update on excitation functions, chemical separation-purification and recovery of target material. Radiochim Acta 102:1111-1126 (EXFOR: D4320)

113. Kurenkov NV, Malinin AB, Sebyakin AA, Venikov NI (1989) Excitation functions of proton-induced nuclear reactions on ${ }^{124}$ Xe: production of ${ }^{123}$ I. J Radioanal Nucl Chem 135:39-50 (EXFOR: A0436)

114. Tárkányi F, Qaim SM, Stocklin G, Sajjad M, Lambrecht RM, Schweickert H (1991) Excitation functions of $(p, 2 n)$ and $(p, p n)$ reactions and differential and integral yields of ${ }^{123} \mathrm{I}$ in proton induced nuclear reactions on highly enriched ${ }^{124} \mathrm{Xe}$. Appl Radiat Isot 42:221-228 (EXFOR: D4029)

115. Hermanne A, Tárkányi F, Takács S, Adam-Rebeles R, Ignatyuk A, Spellerberg S, Schweikert R (2011) Limitation of the long- lived ${ }^{121} \mathrm{Te}$ contaminant in production of ${ }^{123} \mathrm{I}$ through the ${ }^{124} \mathrm{Xe}(p, x)$ route. Appl Radiat Isot 69:358-368 (EXFOR: D4238)

116. Sakai M, Ikegama H, Yamazaki T, Saito K (1965) Nuclear structure of $\mathrm{Hg}^{200}$. Nucl Phys 65:177-202; see also data file in Physics Data number 15-5 (1982) 013

117. Lebowitz G, Greene MW, Fairchild R, Bradley-Moore PR, Atkins HL, Ansari AN, Richards P, Belgrave E (1975) Thallium-201 for medical use. J Nucl Med 16:151-155 (EXFOR: C1028)

118. Lagunas-Solar MC, Jungerman JA, Peek NF, Theus RM (1978) Thallium-201 yields and excitation functions for the lead activities produced by irradiation of natural thallium with 15-60 MeV protons. Int J Appl Radiat Isot 29:159-165 (EXFOR: T0148)

119. Blue JW, Liu DC, Smathers JB (1978) Thallium 201 production with the idle beam from neutron therapy. Med Phys 5:532-535 (EXFOR: C1027)

120. Qaim SM, Weinreich R, Ollig H (1979) Production of ${ }^{201} \mathrm{Tl}$ and ${ }^{203} \mathrm{~Pb}$ via proton induced nuclear reactions on natural thallium. Int J Appl Radiat Isot 30:85-95 (EXFOR: A0185)

121. Bonardi M, Birattari C, Salomone A (1983) ${ }^{201} \mathrm{Tl}$ production for medical use by $(p, x n)$ nuclear reactions on $\mathrm{Tl}$ and $\mathrm{Hg}$ natural and enriched targets. In: Bockhoff $\mathrm{KH}$ (ed) Proceedings of the international conference on nuclear data for science and technology, May 1983, Antwerp, Belgium, pp 916-918. Additional information in Girardi F, Goetz L, Sabbioni E, Marafante E, Merlini M, Acerbi E, Birattari C, Castiglioni M, Resmini F (1975) Preparation of ${ }^{203} \mathrm{~Pb}$ compounds for studies on pathways and effects of lead pollution. Int J Appl Radiat Isot 26:267-277

122. Hermanne A, Walravens N, Cichelli O (1992) Optimisation of isotope production by cross section determination. In: Qaim SM (ed) Proceedings of the international conference on nuclear data for science and technology, 13-17 May 1991, Jülich, Germany, Springer-Verlag, Berlin, Germany, pp 616-618 [also private communication from authors (EXFOR: A0494)]

123. Al-Saleh FS, Al-Harbi AA, Azzam A (2007) Yield and excitation function measurements of some nuclear reactions on natural thallium induced by protons leading to the production of medical radioisotopes ${ }^{201} \mathrm{Tl}$ and ${ }^{203} \mathrm{~Pb}$. Radiochim Acta 9:127-132 (EXFOR: 01509)

124. Tárkányi F, Ditrói F, Hermanne A, Takács S, Adam-Rebeles R, Walravens N, Cichelli O, Ignatyuk AV (2013) Investigation of activation cross-sections of proton induced nuclear reactions on ${ }^{\text {nat }} \mathrm{Tl}$ up to $42 \mathrm{MeV}$ : review, new data and evaluation. Appl Radiat Isot 74:109-122 (EXFOR: D4277)

125. Beil H, Bergere R, Carlos P, Lepretre A, De Miniac A, Veyssiere A (1974) A study of the photoneutron contribution to the giant dipole resonance in doubly even Mo isotopes. Nucl Phys A 227:427-449 (EXFOR: L0032)

126. Ejiri H, Shima T, Miyamoto S, Horikawa K, Kitagawa Y, Asano Y, Date S, Ohashi Y (2011) Resonant photonuclear reactions for isotope transmutation. J Phys Soc Jpn 80:094202 (EXFOR: K2373)

127. Utsunomiya H, Goriely S, Kondo T, Iwamoto C, Akimune H, Yamagata T, Toyokawa H, Harada H, Kitatani F, Lui Y-W, Larsen AC, Guttormsen M, Koehler PE, Hilaire S, Peru S, Martini M, Koning AJ (2013) Photoneutron cross sections for Mo isotopes: a step toward a unified understanding of $(\gamma, n)$ and $(n, \gamma)$ reactions. Phys Rev C 88:015805 (EXFOR: K2433)

128. Chadwick MB, Herman M, Obložinský P, Dunn ME, Danon Y, Kahler AC, Smith DL, Pritychenko B, Arbanas G, Arcilla R, Brewer R, Brown DA, Capote R, Carlson AD, Cho YS et al (2011) ENDF/B-VII.1 nuclear data for science and technology: cross sections, covariances, fission product yields and decay data. Nucl Data Sheets 112:2887-2996 
129. Fabry A, Jacquemin R (1969) Integral determination of $2200 \mathrm{~m} /$ sec activation cross sections. Euratom progress report EANDC No. 115, p 195 (EXFOR: 20186)

130. Gleason $G$ (1977) Thermal neutron $(n, \gamma)$ cross sections and resonance integrals: Part 2, private communication (EXFOR: 10662)

131. Kurosawa M, Shimizu K (1979) Estimation for production of Molybdenum-99 using $(n, \gamma)$ reaction. J At Energy Soc Jpn 21:505-509 (EXFOR: 21584)

132. Wyrick JM, Poenitz WP (1982) Neutron-capture-activation cross sections of 94-, 96-Zr and 98-, 100-Mo at thermal and $30 \mathrm{keV}$ energy. Conf Rep Argonne Natl Lab Rep Ser 4(83):196 (EXFOR: 12831)

133. Nguyen VD, Pham DK, Kim TT, Bui VL, Rahman MS, Kim KS, Kim G, Oh Y, Lee H-S, Cho M-H, Ko IS, Namkung W (2009) Thermal neutron cross-section and resonance integral of the ${ }^{98} \operatorname{Mo}(n, \gamma){ }^{99}$ Mo reaction. Nucl Instrum Methods Phys Res B 267:462-468 (EXFOR: 31656)

134. El Abd A (2010) Measurements of the thermal neutron crosssections and resonance integrals for ${ }^{186} \mathrm{~W}(n, \gamma){ }^{187} \mathrm{~W}$ and ${ }^{98} \operatorname{Mo}(n, \gamma){ }^{99}$ Mo reactions. J Radioanal Nucl Chem 284:321-326 (EXFOR: 31693)

135. Farina Arbocco F, Vermaercke P, Smits K, Sneyers L, Strijckmans K (2013) Experimental determination of $k_{0}, Q_{0},<E_{r}>$ factors and neutron cross-sections for 41 isotopes of interest in neutron activation analysis. J Radioanal Nucl Chem 296:931-938 (EXFOR: 23266)

136. Macklin RL, Lazar NH, Lyon WS (1957) Neutron activation cross sections with Sb-Be neutrons. Phys Rev 107:504-508 (EXFOR: 11399)

137. Booth R, Ball WP, MacGregor MH (1958) Neutron activation cross sections at $25 \mathrm{keV}$. Phys Rev 112:226-229 (EXFOR: 11429)

138. Vervier JF (1958/1959) Section efficace de capture radiative pour des neutrons d'une source Sb-Be. Nucl Phys 9:569-576 (EXFOR: 20205)

139. Hasan SS, Chaubey AK, Sehgal ML (1968) Study of the average level spacing from neutron-capture cross-section. Nuovo Cimento B 58:402-406 (EXFOR: 30077)

140. Chaturvedi SN, Prasad R (1970) Measurement of the $(n, \gamma)$ cross section by activation technique in the $\mathrm{keV}$ region. In: Nuclear and solid state physics symposium, Madurai, vol 2, p 615 (EXFOR: 30493 \#1)

141. Sriramachandra Murty M, Siddappa K, Rama Rao J (1973) Capture cross sections of intermediate neutrons. J Phys Soc Jpn 35:8-11 (EXFOR: 31712)

142. Rimawi K, Chrien RE (1977) $24 \mathrm{keV}$ neutron capture studies in Mo isotopes. Phys Rev C 15:1271-1281 (EXFOR: 10660 \#1)

143. Anand RP, Jhingan ML, Bhattacharya D, Kondaiah E (1979) $25 \mathrm{keV}$-neutron capture cross-sections. Nuovo Cimento A 50:247-257 (EXFOR: 30390)

144. Lyon WS, Macklin RL (1959) Neutron activation at $195 \mathrm{keV}$. Phys Rev 114:1619-1620 (EXFOR: 11399; EXFOR: 11407)

145. Weston LW, Seth KK, Bilpuch EG, Newson HW (1960) Neutron capture cross sections in the keV region. Part II. Spin-orbit coupling and the optical model. Ann Phys 10:477-489 (EXFOR: 11818)

146. Kapchigashev SV, Popov YuP (1964) Capture cross sections in construction materials for neutrons with energies up to $50 \mathrm{keV}$. Sov At Energy 15:808 (EXFOR: 40663)

147. Peto G, Milligy Z, Hunyadi I (1967) Radiative capture crosssections for $3 \mathrm{MeV}$ neutrons. J Nucl Energy 21:797-801 (EXFOR: 30031)

148. Stupegia DC, Schmidt M, Keedy CR, Madson AA (1968) Neutron capture between $5 \mathrm{keV}$ and $3 \mathrm{MeV}$. J Nucl Energy 22:267-281 (EXFOR: 11624)
149. Dovbenko AG, Kolesov VE, Koroleva VP, Tolstikov VA (1969) Cross section of Mn-55, Ga-69, Ga-71 and Mo-98 for radiative capture of fast neutrons. Sov At Energy 26:82 (EXFOR: 40001)

150. Musgrove ARL, Allen BJ, Boldeman JW, Macklin RL (1976) Average neutron resonance parameters and radiative capture cross sections for the isotopes of molybdenum. Nucl Phys A 270:108-140; see also Int. Conf. Nuclear Physics and Nuclear Data, Harwell, UK (1978) 449

151. Trofimov JN, Nemilov JA (1984) Mo-98 radiation capture crosssection for neutron energy range $0.3-2 \mathrm{MeV}$. Vop At Nauki Tekhn Ser Yadernye Konstanty 1984(3/57):15 (EXFOR: 40855)

152. Chunhao W, Yijun X, Xianguan L, Fuqing H, Jingfu Y, Zhihua Y, Xiufeng P, Mantian L, Xiaobing L, Hanlin L (1992) Mea-

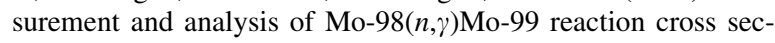
tion. In: Qaim SM (ed) Proceedings of the international conference on nuclear data for science and technology, 13-17 May 1991, Jülich, Germany, Springer-Verlag, Berlin, Germany, pp 370-372

153. Blinov MV, Chuvaev SV, Filatenkov AA, Jakovlev VA, Rimski-Korsakov AA (1996) Measurement of cross sections of some reactions of importance in fusion reactor technology. IAEA report INDC(NDS)-342, pp 53-64, IAEA, Vienna, Austria. www-nds.iaea.org/publications/indc/indc-nds-0342.pdf (EXFOR: 41406)

154. Bhike M, Saxena A, Roy BJ, Choudhury RK, Kailas S, Ganesan $\mathrm{S}$ (2009) Measurement of ${ }^{67} \mathrm{Zn}(n, p){ }^{67} \mathrm{Cu},{ }^{92} \mathrm{Mo}(n, p){ }^{92 \mathrm{~m}} \mathrm{Nb}$, and ${ }^{98} \mathrm{Mo}(n, \gamma){ }^{99} \mathrm{Mo}$ reaction cross sections at incident neutron energies of $E_{\mathrm{n}}=1.6$ and $3.7 \mathrm{MeV}$. Nucl Sci Eng 163:175-182 (EXFOR: 14251); Bhike M, Roy BJ, Saxena A, Choudhury RK, Kailas S, Ganesan S (2012) Measurement of ${ }^{232} \mathrm{Th}(n, \gamma)^{233} \mathrm{Th}$, ${ }^{98} \mathrm{Mo}(n, \gamma){ }^{99} \mathrm{Mo}, \quad{ }^{186} \mathrm{~W}(n, \gamma){ }^{187} \mathrm{~W}, \quad{ }^{115} \mathrm{In}(n, \gamma){ }^{116 \mathrm{~m} 1} \mathrm{In}, \quad$ and ${ }^{92} \mathrm{Mo}(n, p){ }^{92 \mathrm{~m}} \mathrm{Nb}$ cross sections in the energy range of 1.6 to 3.7 MeV. Nucl Sci Eng 170:44-53 (EXFOR: 33038)

155. Uddin MS, Afroze N, Hossain SM, Zakaria AKM, Islam MA (2015) Measurement of cross section of the ${ }^{98} \operatorname{Mo}(n, \gamma){ }^{99} \mathrm{Mo}$ reaction using monochromatic thermal neutrons. Radiochim Acta 103:85-90 (EXFOR: 31757)

156. International collaboration of Data Bank member countries coordinated by the JEFF Scientific Co-ordination Group, The JEFF-3.2 Nuclear Data Library, NEA OECD, Paris. www.oecdnea.org/dbforms/data/eva/evatapes/jeff_32/. Accessed 5 March 2014

157. Shibata K, Iwamoto O, Nakagawa T, Iwamoto N, Ichihara A, Kunieda S, Chiba S, Furutaka K, Otuka N, Ohsawa T, Murata T, Matsunobu H, Zukeran A, Kamada S, Katakura J (2011) JENDL-40: a new library for nuclear science and engineering. J Nucl Sci Technol 48:1-30

158. Blokhin AI, Gai EV, Ignatyuk AV, Koba II, Manokhin VN, Pronyaev VG (2016) New version of the neutron data library BROND-3.1. Vop At Nauki Tekhn Ser Nucl React Constants 2(2):62-93. https://vant.ippe.ru/en/brond-3-1

159. Mughabghab SF (2006) Atlas of neutron resonances: resonance parameters and thermal cross sections $Z=1-100$. Elsevier, Amsterdam (EXFOR: V1001)

160. Paul EB, Clarke RL (1953) Cross section measurements of reactions induced by neutrons of $14.5 \mathrm{MeV}$ energy. Can J Phys 31:267-277 (EXFOR: 11274)

161. Strohal P, Cindro N, Eman B (1962) Reaction mechanism and shell effects from the interaction of $14.6 \mathrm{MeV}$ neutrons with nuclei. Nucl Phys 30:49-67 (EXFOR: 30008)

162. Khurana CS, Hans HS (1961) Cross-sections for $(n, 2 n)$ reactions at $14.8 \mathrm{MeV}$. Nucl Phys 28:560-569 (EXFOR: 31247)

163. Cuzzocrea P, Perillo E, Notarrigo S (1967) Activation cross sections of Mo isotopes for $14.1 \mathrm{MeV}$ neutrons. Nucl Phys A 103:616-624 (EXFOR: 21141) 
164. Csikai J, Peto G (1967) Influence of direct inelastic scattering on $(n, 2 n)$ cross sections. Acta Phys Hung 23:87-94; Csikai J (1968) Magreakciok kiserleti vizsgalata $14 \mathrm{MeV}$ koruli neutronokkal. Magyar Fizikai Folyoirat 16:123 (EXFOR: 30119)

165. Lu WD, Ranakumar N, Fink RW (1970) Activation cross sections for $(n, 2 n)$ reactions at $14.4 \mathrm{MeV}$ in the region $Z=40-60$. Precision measurements and systematics. Phys Rev C 1:350-357 (EXFOR: 10497)

166. Qaim SM (1972) Activation cross sections, isomeric cross-section ratios and systematics of $(n, 2 n)$ reactions at $14-15 \mathrm{MeV}$. Nucl Phys A 185:614-624; see also Chemical Nuclear Data Conference, Canterbury, UK (1971) 121

167. Maslov GN, Nasyrov F, Pashkin NF (1974) Experimental crosssections for nuclear reactions involving neutrons with energies of about $14 \mathrm{MeV}$. IAEA report INDC(CCP)-42, pp 10-12, IAEA, Vienna, Austria. www-nds.iaea.org/publications/indc/ indc-ccp-0042.pdf; see also Vop At Nauki Tekhn Ser Jadernye Konstanty, Issue 9 (1972) 50 (EXFOR: 40136)

168. Araminowicz J, Dresler J (1973) Investigation of the $(n, 2 n)$ reaction with $14.6 \mathrm{MeV}$ neutrons. Inst Badan Jadr Nucl Res, Swierk + Warsaw Report No. 1464, p 14 (EXFOR: 30264)

169. Fujino Y, Hyakutake M, Kumabe I (1977) Activation cross sections on zirconium and molybdenum isotopes induced by 14.6 MeV neutrons. Japan progress report to NEANDC No. 51, p 60 (EXFOR: 20850)

170. Amemiya S, Ishibashi K, Katoh T (1982) Neutron activation cross section of molybdenum isotopes at $14.8 \mathrm{MeV}$. J Nucl Sci Technol 19:781-788 (EXFOR: 21840)

171. Atsumi H, Miyade $H$, Yoshida M, Ishii $T$, Yamamoto $H$, Kawade K, Katoh T, Takahashi A, Iida T (1984) Measurement of neutron activation cross-sections of fusion reactor materials at 14.6 MeV. Japan progress report to NEANDC No. 106/U, p 55 (EXFOR: 21935)

172. Rahman MM, Qaim SM (1985) Excitation functions of some neutron threshold reactions on isotopes of molybdenum. Nucl Phys A 435:43-53 (EXFOR: 21990)

173. Thiep TD, Do NV, An TT, Son NN (2003) Nuclear reactions with $14 \mathrm{MeV}$ neutrons and bremsstrahlungs in giant dipole resonance (GDR) region using small accelerators. Nucl Phys A 722:568-572

174. Marcinkowski A, Stankiewicz K, Garuska U, Herman M (1986) Cross sections of fast neutron induced reactions on molybdenum isotopes. Z Phys A323:91-96. Proceedings of the international conference on nuclear data for basic and applied science, Santa Fe, NM, USA (1985) 601 (EXFOR: 30809)

175. Molla NI, Rahman MM, Khatun S, Fazlul Hoque AKM, Miah R, Khan AA (1986) Activation cross sections for some isotopes of $\mathrm{Mg}, \mathrm{Ti}, \mathrm{V}, \mathrm{Ni}, \mathrm{Zr}$ and $\mathrm{Mo}$ at $14 \mathrm{MeV}$ neutrons. Bangladesh/ IAEA report INDC(BAN)-003, IAEA, Vienna, Austria. wwwnds.iaea.org/publications/indc/indc-ban-0003.pdf (EXFOR: 30825)

176. Muyao Z, Yongfa Z, Chuanshan W, Lu Z, Yitai C, Shuxin Z, Shenjun Z, Kuanzhong X, Shenmuo Z, Xueshi C, Yiping Z, Qinguan Y (1987) Shell effect from the cross section of the $(n, 2 n)$ reaction produced by $14.6 \mathrm{MeV}$ neutron. Chin $\mathrm{J}$ Nucl Phys 9:3 (EXFOR: 30755)

177. Ikeda Y, Konno C, Oishi K, Nakamura T, Miyade H, Kawade K, Yamamoto H, Katoh T (1988) Activation cross section measurements for fusion reactor structural materials at neutron energy from 13.3 to $15.0 \mathrm{MeV}$ using FNS facility. Japan Atomic Energy Research Institute report JAERI-1312 (EXFOR: 22089)

178. Xiangzhong K, Yongchang W, Junqian Y, Xuezhi W, Jingkang Y, Jing W (1991) The cross section measurements for the Mo100(n,2n)Mo-99, Mo-96(n,p)Nb-96 and Mo-92(n, $) \mathrm{Zr}-$ $89 \mathrm{~m}+\mathrm{g}$ reactions. High Energy Phys Nucl Phys Chin 15:549 (EXFOR: 32579 \#1)
179. Osman KT, Habbani FI (1996) Measurement and study of $(n, p)$ reaction cross sections for $\mathrm{Cr}, \mathrm{Ti}, \mathrm{Ni}, \mathrm{Co}, \mathrm{Zr}$ and $\mathrm{Mo}$ isotopes using $14.7 \mathrm{MeV}$ neutrons. Sudan/IAEA report INDC(SUD)-001, IAEA, Vienna, Austria. www-nds.iaea.org/ publications/indc/indc-sud-0001.pdf (EXFOR: 31464)

180. Reimer P, Avrigeanu V, Chuvaev SV, Filatenkov AA, Glodariu T, Koning AJ, Plompen AJM, Qaim SM, Smith DL, Weigmann $\mathrm{H}$ (2005) Reaction mechanisms of fast neutrons on stable Mo isotopes below $21 \mathrm{MeV}$. Phys Rev C 71:044617 (EXFOR: 22889)

181. Semkova V, Nolte R (2014) Measurement of neutron activation cross sections on Mo isotopes in the energy range from $7 \mathrm{MeV}$ to $15 \mathrm{MeV}$. In: EPJ web of conferences, vol 66, p 03077

182. Filatenkov AA (1999) Neutron activation cross sections measured at KRI in neutron energy region 13.4-14.9 MeV, Khlopin Radium Institute report KRI-252 (EXFOR: 41298). IAEA report INDC(CCP)-0460 Rev (2016) IAEA, Vienna, Austria. www-nds.iaea.org/publications/indc/indc-ccp-0460-rev.pdf (EXFOR: 41614)

183. Huizenga JR, Clarke KM, Gindler JE, Vandenbosch R (1962) Photofission cross sections of several nuclei with mono-energetic gamma rays. Nucl Phys 34:439-456 (EXFOR: M0505); Manfredini A, Muchnik M, Fiore L, Ramorino C, De Carvalho HG, Lang J, Müller R (1965) ${ }^{238}$ U fission induced by low-energy monochromatic gamma rays: cross sections between 5 and 8 MeV. Nucl Phys 74:377-384 (EXFOR: M0535)

184. Manfredini A, Muchnik M, Fiore L, Ramorino C, De Carvalho HG, Bösch R, Wölfli W (1966) Results on the cross section of ${ }^{238} \mathrm{U}$ fission induced by low energy mono-energetic gamma rays. Nuovo Cimento B 44:218-221 (EXFOR: L0093)

185. Khan AM, Knowles JW (1972) Photofission of ${ }^{232} \mathrm{Th},{ }^{238} \mathrm{U}$ and ${ }^{235} \mathrm{U}$ near threshold using a variable energy beam of $\gamma$ rays. Nucl Phys A 179:333-352 (EXFOR: M0504)

186. Mafra OY, Kuniyoshi S, Goldemberg J (1972) Intermediate structure in the photoneutron and photofission cross sections in ${ }^{238} \mathrm{U}$ and ${ }^{232}$ Th. Nucl Phys A 186:110-126 (EXFOR: M0433)

187. Bergere R, Beil H, Carlos B, Veyssiere A, Lepretre A (1972) Study of the giant resonance of fissile nuclei. In: Conference on nuclear structure studies, Sendai, Japan (1972), p 273 (EXFOR: L0082)

188. Anderl RA, Hall JE, Morrison RC, Struss RG, Yester MV, Zaffarano DJ (1972) Compton scattered neutron capture gamma rays for photofission studies. Nucl Instrum Methods 102:101-108 (EXFOR: L0092); Anderl RA, Yester MV, Morrison RC (1973) Photofission cross sections of ${ }^{238} U$ and ${ }^{235} \mathrm{U}$ from $5.0 \mathrm{MeV}$ to $8.0 \mathrm{MeV}$. Nucl Phys A 212:221-240 (EXFOR: M0431)

189. Veyssiere A, Beil H, Bergere R, Carlos P, Lepretre A (1973) A study of the photo-fission and photo-neutron processes in the giant dipole resonance of ${ }^{232} \mathrm{Th},{ }^{238} \mathrm{U}$ and ${ }^{237} \mathrm{~Np}$. Nucl Phys A 199:45-64 (EXFOR: L0031)

190. Dickey PA, Axel P (1975) ${ }^{238} \mathrm{U}$ and ${ }^{232}$ Th photofission and photoneutron emission near threshold. Phys Rev Lett 35:501-504 (EXFOR: L0081)

191. Caldwell JT, Dowdy EJ, Alvarez RA, Berman BL, Meyer P (1980) Experimental determination of photo-fission neutron multiplicities for ${ }^{235} \mathrm{U},{ }^{236} \mathrm{U},{ }^{238} \mathrm{U}$, and ${ }^{232} \mathrm{Th}$ using monoenergetic photons. Nucl Sci Eng 73:153-163 (EXFOR: L0185)

192. Ries H, Mank G, Drexler J, Heil R, Huber K, Kneissl U, Ratzek R, Stroher H, Weber T, Wilke W (1984) Absolute photofission cross sections for ${ }^{235,238} \mathrm{U}$ in the energy range $11.5-30 \mathrm{MeV}$. Phys Rev C 29:2346-2348 (EXFOR: M0503)

193. Lepretre A, Bergere R, Bourgeois P, Carlos P, Fagot J, Fallou JL, Garganne P, Veyssiere A, Ries H, Goble R, Kneissl U, Mank G, Stroher H, Wilke W, Ryckbosch D, Jury J (1987) Absolute photofission cross sections for ${ }^{232} \mathrm{Th}$ and ${ }^{235,238} \mathrm{U}$ measured with 
monochromatic tagged photons $\left(20 \mathrm{MeV}<E_{\gamma}<110 \mathrm{MeV}\right)$. Nucl Phys A 472:533-557 (EXFOR: M0491)

194. Csige L, Filipescu DM, Glodariu T, Gulyas J, Gunther MM, Habs D, Karwowski HJ, Krasznahorkay A, Rich GC, Sin M, Stroe L, Tesileanu O, Thirolf PG (2013) Exploring the multihumped fission barrier of ${ }^{238} \mathrm{U}$ via sub-barrier photofission. Phys Rev C 87:044321 (EXFOR: L0179)

195. Dzhilavyan LZ, Nedorezov VG (2013) Photofission of ${ }^{238} U$ in the giant-resonance region. Phys At Nucl 76:1444-1451 (EXFOR: M0870)
196. Varlamov VV, Peskov NN (2007) Evaluation of $(\gamma, x n),(\gamma, s n)$, $(\gamma, n),(\gamma, 2 n)$, and $(\gamma, f)$ reactions cross sections for actinide nuclei ${ }^{232} \mathrm{Th},{ }^{238} \mathrm{U},{ }^{237} \mathrm{~Np}$, and ${ }^{239} \mathrm{Pu}$ : consistency between data obtained using quasi-monoenergetic annihilation and bremsstrahlung photons, Moscow State University, Institute of Nuclear Physics report No. 2007, 8/829 (EXFOR: M0722) 